\title{
Colour maps of acid-base titrations with colour indicators: how to choose the appropriate indicator and how to estimate the systematic titration errors
}

\author{
Heike Kahlert $^{1} \cdot$ Gabriele Meyer $^{1} \cdot$ Anja Albrecht $^{1}$
}

Received: 5 April 2016/Accepted: 22 April 2016/Published online: 29 April 2016

(C) Springer International Publishing Switzerland 2016

\begin{abstract}
To recognise the end point of acid-base titrations, colour indicators are still frequently used. Colour indicators can cause systematic errors, and the theoretical evaluation of these errors is given in many textbooks. Random errors caused by the transition range of an indicator can also be estimated with the help of $\mathrm{pH}-\log c_{\mathrm{i}}$ diagrams. However, very often, undergraduate students have problems to correctly interpret the colours of the different species of an indicator (its acidic and alkaline forms) and colour changes during titration. Frequent questions are of the type: "Is it still blue, or is it already red?" The aim of the present text is to show how carefully a suitable colour indicator has to be chosen, and what colour changes happen at the inflection point of a titration. Typical acid-base titrations like the alkalimetry of hydrochloric acid, sulphuric acid, oxalic acid, and the acidimetry of borax at two concentration levels using eleven common colour indicators are compared with potentiometric end point determination. Photographs were taken of solutions containing the indicators during the course of titration, i.e., at different $\mathrm{pH}$ values. These photographs were used to prepare a colour map for each indicator. Such colour maps are very helpful to find the most suitable indicator for a certain reaction, and also to estimate the maximum accuracy.
\end{abstract}

Keywords Acid-base titrations · Colour indicators · Titration error

Electronic supplementary material The online version of this article (doi:10.1007/s40828-016-0026-4) contains supplementary material, which is available to authorized users.

Heike Kahlert

hkahlert@uni-greifswald.de

1 Institute of Biochemistry, University of Greifswald, Felix-Hausdorff-Str. 4, 17487 Greifswald, Germany

\section{Introduction}

The development of volumetric methods paralleled the development of chemical industries due to the demand for rapid, reliable and accurate analyses. Despite the fact that instrumental analytical methods are nowadays dominating in analytical laboratories, titrimetry still plays an important role. Instrumental methods are useful for determinations in the range of minor and trace levels, where classical analytical methods perform either poor or not at all. The latter give results of high precision and accuracy at high concentration levels (let us say between $10^{-3}$ and $1 \mathrm{~mol} \mathrm{~L}^{-1}$ ), whereas instrumental methods possess an inferior performance at high concentrations. The main advantage of the classical methods like titrimetry, gravimetry and coulometry is that they are so-called "primary methods" (absolute methods) needing no calibration. This is just one reason why the classical titrations are still part of the undergraduate curriculum for chemistry students. Another is the high didactic value in teaching solution equilibria. And there are numerous significant standardised methods using classical titrations, e.g. the Total Acid Number (TAN) in fat and oil derivatives (EN 14104). In national and the International Pharmacopoeia one can find a collection of recommended procedures for the analysis of active pharmaceutical ingredients based on classical titrations.

According to the IUPAC definition [1], " ..... titration is the process of determining the quantity of a substance A by adding measured increments of substance $B$, with which it reacts...." When a species A (the analyte) is titrated with the reagent $\mathrm{B}$ (the standardised solution or titrant) the reaction stoichiometry may be (1) $\mathrm{A}+\mathrm{B} \rightarrow \mathrm{C}$, or (2) $\mathrm{A}+2 \mathrm{~B} \rightarrow \mathrm{C}$, or (3) $\mathrm{A}+3 \mathrm{~B} \rightarrow \mathrm{C}$, or whatever else. In each of these cases, the equivalence point is defined for the condition that to $n$ mol A were given (1) $n$ mol $\mathrm{B}$, (2) 
$2 n$ mol B, or (3) $3 n$ mol B, i.e., the exact amount of B given in the reaction equations. In other words, the objective of an acid-base titration is the determination of the volume of the titrant solution $B$ which contains this exact number of moles. ${ }^{1}$ The analytical concentration of the substance A can be calculated by simple stoichiometric equations [2-5]. Of course, these reactions are (almost always; in case of proton transfer reactions really always) equilibrium reactions, so that they should be better given as (1) $\mathrm{A}+\mathrm{B} \rightleftarrows \mathrm{C}$, (2) $\mathrm{A}+2 \mathrm{~B} \rightleftarrows \mathrm{C}$, and (3) $\mathrm{A}+3 \mathrm{~B} \rightleftarrows \mathrm{C}$. The reason why they are frequently written with only one reaction arrow from left to right is that the equilibrium is usually strongly favouring the products. To display the advancement of a titration, the $\mathrm{pH}$ of the titration solution can be plotted versus the added volume of the titrant. However, using the volume it is difficult to compare several titrations while each sample would need a differently scaled volume axis. To overcome this problem, the degree of titration $\tau$ is often used. The degree of titration can be defined as the current added amount of titrant divided by the amount of titrant which is necessary to reach the equivalence point [6]. It is unity at the equivalence point. In practice, it is necessary to find a proper method to determine this equivalence point, e.g., with instrumental methods (potentiometric, conductometric, spectrophotometric) as well as with colour indicators. In all cases a pronounced change of a certain property of the solution can be observed, more or less closely to the equivalence point. The point at which this change is registered is also called the end point of a titration. In that sense, the equivalence point can be considered as the true value, and the end point is an estimate of this true value with an uncertainty including systematic and random sources of error.

The principles of titrimetric methods have been developed at the beginning of the 18th century, and interesting historical annotations are given in the literature [7-11]. Already in the middle of the 18th century, indicator papers soaked with litmus have been used for a precise indication of the completion of the reaction between potash and an acid. Along with the development of dyestuff industry, synthetic indicators have been developed in the middle of the 19th century, and the application of indicators in volumetric analysis has been increased as apparatus and methods became more accurate, and as more new indicator substances were synthesised about 1870. Already at that early stage, attempts have been made to mix indicators to achieve better visual end points. Also at that time it has been recognised that certain titrations were not successful

\footnotetext{
1 Instead of measuring the volume of the titrant, one may measure its mass. That is called a gravimetric titration. Here we consider only the more common volumetric titrations.
}

when using the colour change of known indicators as end point of the reaction.

Wilhelm Ostwald has published a theory of the colour change of indicators based on the principle of ionic equilibria at the end of the 19th century. He attributed the colour change to a transition between molecules and ions. Hantzsch and others have shown that the colour change is due to a structural change. Following the definition given by Kolthoff [12], an acid-base indicator is itself a moderately strong or weak acid or base of which the ionic form possesses a colour and constitution different from the colour and structure of the neutral form. In aqueous solution, the following equilibrium is established for the acidbase pair $\mathrm{HI} / \mathrm{I}^{-}$:

$\mathrm{HI}+\mathrm{H}_{2} \mathrm{O} \rightleftarrows \mathrm{I}^{-}+\mathrm{H}_{3} \mathrm{O}^{+}$

(HI: indicator acid, $\mathrm{I}^{-}$: indicator base). Of course, other acid-base pairs also exist, e.g. $\mathrm{H}_{2} \mathrm{I} / \mathrm{HI}^{-}, \mathrm{HI}^{-} / \mathrm{I}^{2-}, \mathrm{HI}^{+} / \mathrm{I}$, etc. The chemical equilibrium (1) is characterised by the acidity constant $K_{\mathrm{a}}$, which is here called $K_{\mathrm{I}}$ (I for indicator):

$K_{\mathrm{I}}=\frac{a_{\mathrm{I}^{-}}^{\mathrm{c}} a_{\mathrm{H}_{3} \mathrm{O}^{+}}^{\mathrm{c}}}{a_{\mathrm{HI}}^{\mathrm{c}}}$

and $\mathrm{p} K_{\mathrm{I}}=-\log K_{\mathrm{I}}$. During titration the equilibrium (1) is established according to the $\mathrm{pH}$ of the solution, i.e., for $\mathrm{pH}$ smaller than $\mathrm{p} K_{\mathrm{I}}$, the acidic form of the indicator dominates, and for $\mathrm{pH}$ larger than $\mathrm{p} K_{\mathrm{I}}$, the indicator base dominates. At $\mathrm{pH}=\mathrm{p} K_{\mathrm{I}}$ the ratio $a_{\mathrm{HI}}^{\mathrm{c}} / a_{\mathrm{I}^{-}}^{\mathrm{c}}$ is unity, and around this $\mathrm{pH}$, a continuous colour change takes place from the colour of the acidic form to the colour of the indicator base. Indicators can be monochromic (one species is colourless, one species absorbs light in the visible range; one-colour indicator) or bichromic (both species absorb light at different wavelengths in the visible range; two-colour indicator). In case of two-colour indicators, a mixed colour is obtained in the range $\frac{1}{10} \leq \frac{a_{\mathrm{HI}}^{\mathrm{c}}}{a_{\mathrm{I}^{-}}^{\mathrm{c}}} \leq \frac{10}{1}$, assuming that our eyes sense the admixture of a colour when that species is present at the $10 \%$ level (with respect to the overall indicator concentration). According to the Henderson-Hasselbalch equation (buffer equation: $\mathrm{pH}=\mathrm{p} K_{\mathrm{I}}-\log \frac{a_{\mathrm{HI}}^{\mathrm{c}}}{a_{\mathrm{I}^{-}}^{\mathrm{c}}}$ [6] this is equal to the $\mathrm{pH}$ range $\Delta(\mathrm{pH})=\mathrm{p} K_{\mathrm{I}} \pm 1$, and this range is called the transition interval [1]. Of course, it is a rough estimation under the assumption that both colours are perceived with the same sensitivity by the human eye. The transition interval is also affected by the ionic strength of the solution when the activity coefficients of both, the acidic and the alkaline species of the indicator, are influenced in a different manner, e.g. if one species is charged the other one is neutral. This leads to the so-called salt error.

In case of one-colour indicators the coloured form can be detected if it presents only $10 \%$ of the overall indicator 
concentration, i.e., the $\mathrm{pH}$ at which the coloured form will be detected depends on the overall concentration of the indicator.

To intensify the overall colour change, mixed indicators containing a supplementary dye can be used, e.g. a mixture of Methyl red and Methylene blue. In this case, acidic solutions $\left(\mathrm{pH}<\mathrm{p} K_{\mathrm{I}}\right)$ are violet (combination of brilliant fuchsia and blue), basic solutions $\left(\mathrm{pH}>\mathrm{p} K_{\mathrm{I}}\right)$ have a green colour (combination of yellow and blue), and at $\mathrm{pH}=\mathrm{p} K_{\mathrm{I}}$ (with $\mathrm{p} K_{\mathrm{I}}$ being the acidity constant of Methyl red), the solution appear of greyish colour (combination of yellow, fuchsia, and blue). Note that Methylene blue is not a $\mathrm{pH}$ indicator and acts in these mixtures only as a constant colour component. However, Methylene blue is a redox indicator and can be reduced to a colourless form, which has to be avoided in the acid-base titrations mentioned above.

Today, more than 200 colour indicators are known; and the complete $\mathrm{pH}$ range in aqueous solutions from strong acidic to strong alkaline conditions is covered, i.e., for almost all acid-base titrations in aqueous solutions a proper indicator is available [13]. Of course, acid base titrations are not limited to water as the solvent, but numerous titrations can be performed in non-aqueous solutions, but these methods will not be considered in this text. The question is how to find the most appropriate indicator for an individual titration, so that the systematic and random errors are at a minimum, i.e., the overall titration error is at a minimum. A systematic error results when the $\mathrm{pH}$ of the transition point of the indicator deviates from the $\mathrm{pH}$ of the equivalence point of the titration. (Of course there are various other possibilities for the occurrence of systematic errors, e.g., wrongly calibrated pipettes and burets, but these sources of systematic errors will not be considered here.) Another source of systematic error is the so-called "indicator error", i.e., consumption of the titrant by the indicator. In order to minimise this error, the concentration of the indicator should be chosen as small as possible, i.e., in the concentration range of $10^{-7}$ to $10^{-6} \mathrm{~mol} \mathrm{~L}^{-1}$. At this concentration level the systematic indicator error is negligible. When the $\mathrm{pH}$ of the transition point of an indicator (or the $\mathrm{pH}$ of the end point, cf. definitions) does not exactly match the $\mathrm{pH}$ of the equivalence point, $\mathrm{pH}_{\text {eqp }}$, the titration is either stopped to early (insufficient amount of added titrant, i.e., negative systematic error) or too late (excessive addition of titrant, i.e., positive systematic error). The first consideration has to be at what $\mathrm{pH}$ the equivalence point occurs. Only in case of titrations of very strong acids with very strong bases, and vice versa, the equivalence point equals the neutrality point of water, i.e., $\mathrm{pH}=7$ at $25{ }^{\circ} \mathrm{C}$. In case of titrations of acids with $\mathrm{p} K_{\mathrm{a}}$ values between 0 and 14 with a very strong base, the equivalence point is more alkaline because of the protolysis reaction of the generated

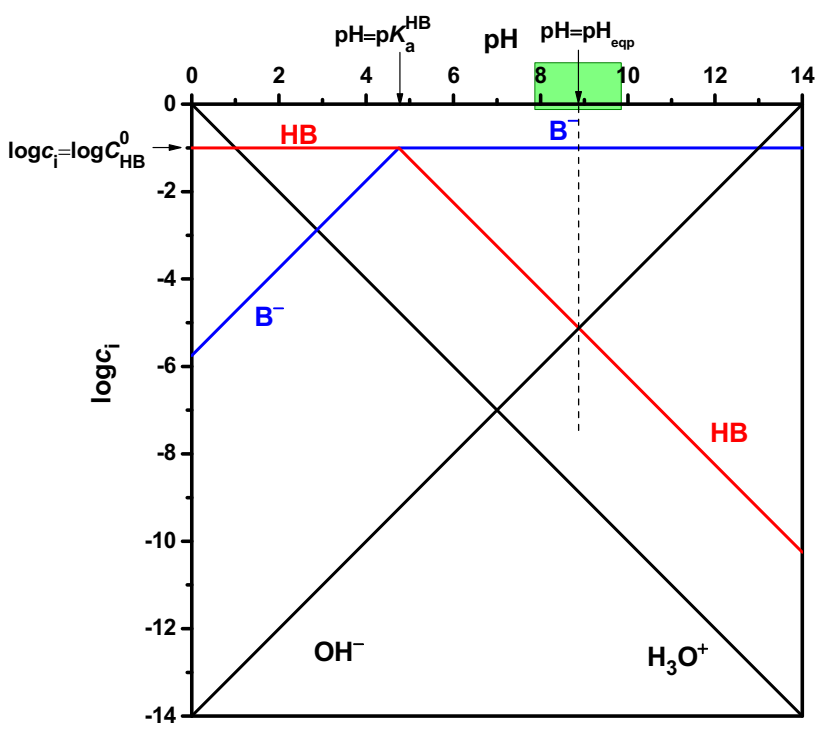

Fig. 1 The $\mathrm{pH}-\log c_{\mathrm{i}}$ diagram with the $\mathrm{H}_{3} \mathrm{O}^{+}$-line, the $\mathrm{OH}^{-}$-line and the asymptotes of $\mathrm{HB}$ and $\mathrm{B}^{-}$for acetic acid with $C_{\mathrm{HB}}^{\circ}=0.1$ mol L ${ }^{-1}$ and $\mathrm{p} K_{\mathrm{a}}=4.75$. Green mark optimal indicator transition interval for the titration of acetic acid at that concentration with a strong base; in case of a two-colour indicator $\mathrm{p} K_{\mathrm{I}}=\mathrm{pH}_{\text {eqp }}$ provides optimal condition

corresponding base. In case of titrations of bases with $\mathrm{p} K_{\mathrm{b}}$ values between 0 and 14 with a very strong acid the equivalence point is more acidic because of the protolysis reaction of the generated corresponding acid. To estimate the $\mathrm{pH}$ value at the equivalence point of an acid-base titration, $\mathrm{pH}-\log c_{\mathrm{i}}$ diagrams, also called Hägg diagrams or Sillén diagrams, are very useful $[6,14-16]$. With the help of such diagrams, a first choice of a proper indicator can be made (see Fig. 1).

Additionally, one can roughly estimate the concentration range in which a titration with an accepted titration error can be performed. In many textbooks one finds, that titrations in the range of $1-0.1 \mathrm{mmol}$ (i.e., a concentration range of about $0.01-0.001 \mathrm{~mol} \mathrm{~L}^{-1}$ for a titration volume of about $100 \mathrm{~mL}$ ) of the analyte are possible [17, 18]. Such general formulation is questionable, as we will see later. Let us consider an experiment as described in the textbooks: $1 \mathrm{mmol}$ of a strong acid (e.g., hydrochloric acid) is present in $100 \mathrm{~mL}$ aqueous solution, so that its concentration is $0.01 \mathrm{~mol} \mathrm{~L} \mathrm{~L}^{-1}$. The $\mathrm{pH}-\log c_{\mathrm{i}}$ diagram is shown in Fig. 2, line a; is the base (here $\mathrm{Cl}^{-}$) line. If we accept a titration error of $\pm 0.1 \%$, we have to find an indicator with a transition interval between $\mathrm{pH}=5$ (point $\mathrm{A}$ : nearly $0.1 \%$ of the initial concentration of acid $\left(\mathrm{H}_{3} \mathrm{O}^{+}\right.$ions $)$is still present in the solution) and $\mathrm{pH}=9$ (point $\mathrm{B}$ : an excess of $0.1 \%$ of $\mathrm{OH}^{-}$ions has been added to the solution). If the concentration is one decade smaller (Fig. 2, line b), the indicator must have a transition interval between $\mathrm{pH}=6$ (point C: nearly $0.1 \%$ of the acid is still present in the 


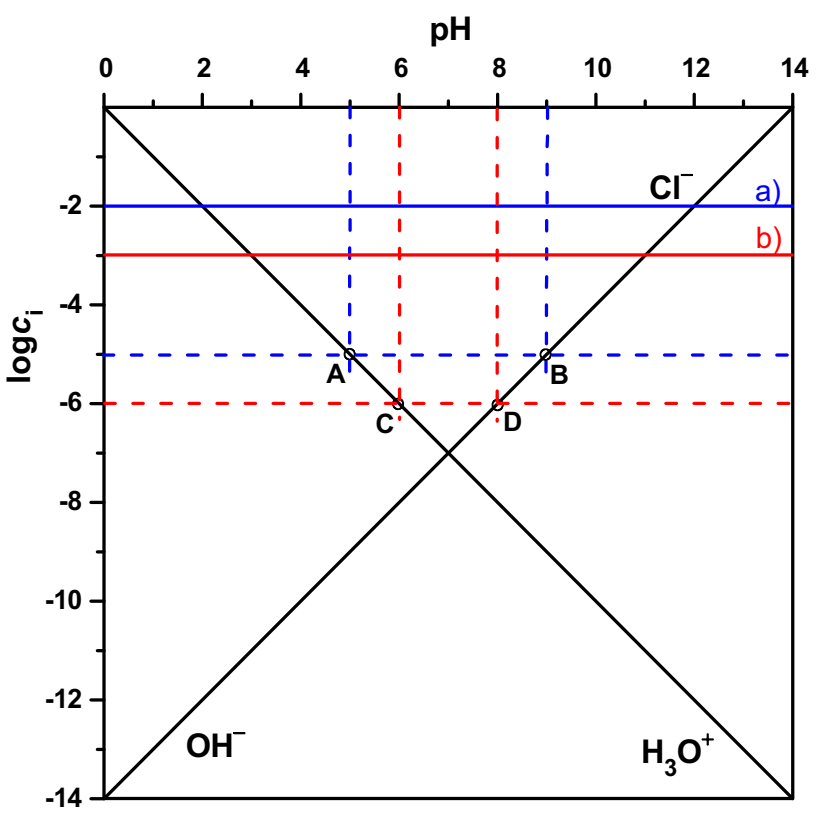

Fig. $2 \mathrm{pH}-\log c_{\mathrm{i}}$ diagram of $\mathrm{HCl}(\mathrm{HCl}$ is used here to designate hydrochloric acid. Of course, in an aqueous solution of hydrochloric acid, practically no $\mathrm{HCl}$ molecules are present, but only $\mathrm{H}_{3} \mathrm{O}^{+}$and $\mathrm{Cl}^{-}$ ions) in a concentration of a $0.01 \mathrm{~mol} \mathrm{~L}^{-1}$, and $\mathbf{b} 1 \times 10^{-3} \mathrm{~mol} \mathrm{~L}^{-1}$

solution) and $\mathrm{pH}=8$ (an excess of $0.1 \%$ of $\mathrm{OH}^{-}$ions has been added to the solution) to guarantee the same systematic error of less than $\pm 0.1 \%$, i.e., the number of applicable indicators is drastically diminished.

In case of the titrations of weak acids with a strong base, the concentration and the strength of the acid have an influence on the possible accuracy (cf. Fig 3a, b).

When the acid has a $\mathrm{p} K_{\mathrm{a}}=5$ and the overall concentration is $0.01 \mathrm{~mol} \mathrm{~L}^{-1}$ (curve a) in (Fig. 3a), the transition interval of the indicator has to be between $\mathrm{pH}=8$ (point $\mathrm{A}$ : nearly $0.1 \%$ of the acid is still present in the solution) and $\mathrm{pH}=9$ (an excess of $0.1 \%$ of $\mathrm{OH}^{-}$ions has been added to the solution), to have a systematic error of $\pm 0.1 \%$. Due to the fact that most indicators show a transition range of about two $\mathrm{pH}$ units, titration errors for such titrations are larger than $\pm 0.1 \%$. A titration error of less than $\pm 0.1 \%$ can be achieved with an indicator with a transition range between $\mathrm{pH}=8$ (cf. point $\mathrm{C}$ ) and $\mathrm{pH}=10$ (cf. point $\mathrm{D}$ ) if the concentration is one decade higher (cf. curve b) in Fig. 3a, whereas in case of smaller concentrations a major error is expected. Acids with $\mathrm{p} K_{\mathrm{a}}$ values higher than 5 can only be titrated at higher concentrations, e.g., an acid with $\mathrm{p} K_{\mathrm{a}}=6$ and an overall concentration of $0.1 \mathrm{~mol} \mathrm{~L}^{-1}$ needs an indicator with a transition range between 9 and 10 (cf. Fig. 3b, points $\mathrm{C}$ and $\mathrm{B}$, points $\mathrm{A}$ and $\mathrm{B}$ are valid for an acid HA with $\mathrm{p} K_{\mathrm{a}}=5$ and an overall concentration of $0.1 \mathrm{~mol} \mathrm{~L}^{-1}$ ). Thymolphthalein has a transition interval $9.3 \leq \mathrm{pH} \leq 10.5$; the maximum possible accuracy is around $0.5 \%$. If we consider the overall random error of the titration, the slope
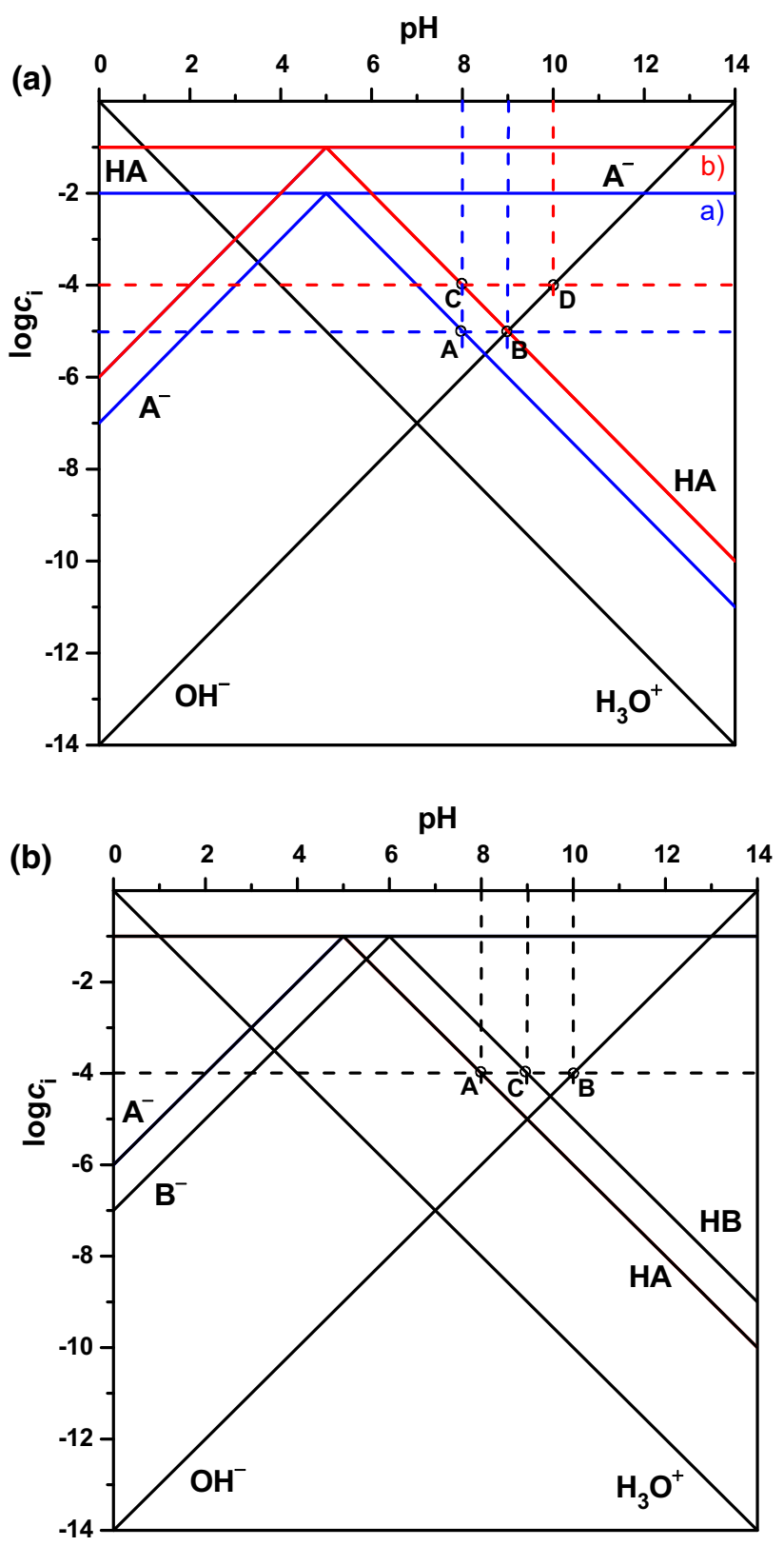

Fig. 3 a $\mathrm{pH}-\log c_{\mathrm{i}}$ diagram of an acid $\mathrm{HA}$ with $\mathrm{p} K_{\mathrm{a}}=5$ in a concentration of a $0.01 \mathrm{~mol} \mathrm{~L}^{-1}$, and b $0.1 \mathrm{~mol} \mathrm{~L}-1$. b $\mathrm{pH}-\log c_{\mathrm{i}}$ diagram of an acid HA with $\mathrm{p} K_{\mathrm{a}}=5$ in a concentration of $0.1 \mathrm{~mol} \mathrm{~L}^{-1}$, and of an acid $\mathrm{HB}$ with $\mathrm{p} K_{\mathrm{a}}=6$ in a concentration of $0.1 \mathrm{~mol} \mathrm{~L}^{-1}$

of the titration curve and the dimension of the transition interval of the indicator are decisive. The smaller the slope of the titration curve the larger is the contribution to the overall random error, as it has been shown in [6]. Another effect is related to the colour contrast of the indicator species. The smaller the contrast between the colours of the indicator species (e.g., the contrast between orange and yellow) the more difficult it is to decide whether the transition point is reached or not. In most common textbooks, 
rules can be found for choosing suitable indicators [17, 18]. However, these rules are of general character and fail in many cases; e.g. Methyl orange is often said to be applicable for the titration of a strong acid like hydrochloric acid with a strong base in the concentration range from 0.01 to $0.001 \mathrm{~mol} \mathrm{~L}^{-1}$. The transition interval of Methyl orange is $3.0 \leq \mathrm{pH} \leq 4.4$, the colour changes from red to yellow, and within the transition interval the mixed colour is orange. Besides the low contrast between orange and yellow and hence the difficulties to decide whether the end point has been reached or not, the theoretical titration error calculated with the $\mathrm{pH}-\log c_{\mathrm{i}}$ diagram is even at the upper end of the transition interval $(\mathrm{pH}=4.4)-0.4 \%$ in case of high concentration and $-4 \%$ in case of low concentration of the acid. Frequently, the transition intervals of indicators are given, and the colour changes are either only described in words or with schemes not showing the real colours at different $\mathrm{pH}$ values. Because of the ambiguity of verbal descriptions, in this manuscript colour maps of typical classical acid-base titrations are given. These maps were generated by taking photographs of solutions with a defined ionic strength at different $\mathrm{pH}$ values and containing the colour indicators. These pictures were used to draw a colour map for each indicator. The excellent all-in-one freeware for $\mathrm{pH}$ and acid-base equilibrium calculations and for simulation and analysis of Potentiometric Titration Curves CurTiPot allows to calculate titration curves for many acids and bases in any concentration [19]. Superimposing colour maps and simulated titration curves can help to find out individually the most suitable indicator for a certain reaction, and to estimate a titration error (maximum accuracy).

\section{Definitions}

The definitions of the following terms are in agreement with the IUPAC recommendations [1].

Sample solution containing the substance to be determined quantitatively.

Titrant standardised solution containing the active agent with which a titration is made.

Equivalence point the point in a titration at which the amount of titrant added is chemically equivalent to the amount of sample to be titrated.

End point the point in a titration at which the colour of the solution shows a pronounced change

Transition point of an indicator is the point, at which $\mathrm{pH}=\mathrm{p} K_{\mathrm{I}}$, and $a_{\mathrm{HI}}^{\mathrm{c}} / a_{\mathrm{I}^{-}}^{\mathrm{c}}$ is unity.

Titration error difference in the amount of titrant added until end point is detected and the amount of substance being titrated, represented by the expression: (end point value - equivalence point value).
Degree of titration $\tau$ ratio between the current added amount of titrant divided by the amount of titrant which is necessary to reach the equivalence point. It is unity at the equivalence point.

\section{Experimental}

In Table 1, the acid-base indicators are given, which are included in this paper. Their transition intervals, and the preparation of indicator solutions are included [12, 13]. All compounds were of analytical grade. To prepare the indicator Tashiro, Methylene blue from Riedel de Haën was used. The concentrations of the indicators were chosen so that the influence of the protonation/deprotonation of the indicator is negligible, but colours were clearly detectable.

To prepare the sample solutions as well as the titrants, ampules containing $\mathrm{HCl}$ and $\mathrm{NaOH}\left(C^{\circ}=0.1 \mathrm{~mol} \mathrm{~L}^{-1}\right.$, Merck) and $\mathrm{H}_{2} \mathrm{SO}_{4}$ and oxalic acid $\left(C^{\mathrm{o}}=0.05 \mathrm{~mol} \mathrm{~L}^{-1}\right.$, Merck) were used. Solid borax (disodium tetraborate decahydrate), $\mathrm{Na}_{2} \mathrm{~B}_{4} \mathrm{O}_{7} \cdot 10 \mathrm{H}_{2} \mathrm{O}$ (Merck), was used to prepare a stock solution with a concentration of $0.05 \mathrm{~mol} \mathrm{~L}^{-1}$. Titrations were performed by using standard glass burettes with a reading precision of $0.025 \mathrm{~mL}$ (half of a scale division). A certain amount of the sample was transferred with a standard glass pipette $( \pm 0.05 \mathrm{~mL})$ into a conical flask, and it was filled up with water to about $100 \mathrm{~mL}$. Then the indicator was added (resulting concentrations in the sample solutions are given in Table 1), and the titration was performed. Each experiment was repeated 10 times.

Sample solutions for potentiometric titrations were prepared in the same manner in a beaker. The titrant was added either with the standard glass burette in case of high concentrations of the sample, or with a transfer pipette (10-100 $\pm 0.6 \mu \mathrm{L}, \mathrm{VWR}$, Germany) in case of small concentrations. Titrations were followed by using a glass electrode (InLab ${ }^{\circledR}$, Mettler Toledo, Swiss) in conjunction with a pH metre 761 Calimatic (Knick, Germany). The glass electrode was calibrated before each measurement. For each sample and concentration, 11 experiments were performed (one with each indicator).

To construct the colour maps, the titration curves were recorded by measuring the $\mathrm{pH}$ of the solutions with a glass electrode, and the coloured solutions where photographed in spectrophotometric cuvettes. For this, Britton-Robinson buffer solutions were prepared according to [21] with a variation of the $\mathrm{pH}$ in $0.4 \mathrm{pH}$ increments. For each indicator, these buffer solutions were prepared and the indicator was added in the concentrations given in Table 1 . The $\mathrm{pH}$ of each buffer solution was measured in the absence and presence of the indicator, and no detectable differences could be noted. Individual pictures were taken and the colour maps were created using the freeware PhotoScape. 
Table 1 Transition intervals and protocols for preparing stock solutions of acid-base indicators used in this study

\begin{tabular}{|c|c|c|c|c|c|c|}
\hline \multirow[t]{2}{*}{ Indicator } & \multicolumn{2}{|c|}{$\begin{array}{l}\text { Transition } \\
\text { interval }\end{array}$} & \multirow[t]{2}{*}{$\mathrm{p} K_{\mathrm{I}}[20]$} & \multirow[t]{2}{*}{ Preparation } & \multirow[t]{2}{*}{$\begin{array}{l}\text { Concentration in sample } \\
\text { solution in } \mathrm{mol} \mathrm{L}^{-1}\end{array}$} & \multirow[t]{2}{*}{ Purchased from } \\
\hline & $\mathrm{pH}_{\min }$ & $\mathrm{pH}_{\max }$ & & & & \\
\hline Bromophenol blue & 3.0 & 4.6 & 3.85 & $\begin{array}{l}250 \mathrm{mg}, 14.9 \mathrm{~mL} \mathrm{NaOH}(0.01 \mathrm{M}) \\
235.1 \mathrm{~mL} \text { water }\end{array}$ & $3 \times 10^{-6}$ & Feinchemie Sebnitz \\
\hline Congo red & 3.0 & 5.0 & 4.0 & $100 \mathrm{mg}, 100 \mathrm{~mL}$ water & $3 \times 10^{-6}$ & Feinchemie Sebnitz \\
\hline Methyl orange & 3.0 & 4.4 & 3.46 & $100 \mathrm{mg}, 100 \mathrm{~mL}$ water & $5 \times 10^{-6}$ & Feinchemie Sebnitz \\
\hline Bromocresol green & 3.8 & 5.4 & 4.66 & $\begin{array}{l}100 \mathrm{mg}, 14.3 \mathrm{~mL} \mathrm{NaOH}(0.01 \mathrm{M}), \\
235.7 \mathrm{~mL} \text { water }\end{array}$ & $2 \times 10^{-6}$ & Feinchemie Sebnitz \\
\hline Methyl red & 4.4 & 6.2 & 5.0 & $20 \mathrm{mg}, 100 \mathrm{~mL}$ ethanol-water $60 \% \mathrm{v} / \mathrm{v}$ & $7 \times 10^{-7}$ & Fluka \\
\hline Tashiro & 4.4 & 6.2 & 5.0 & $\begin{array}{l}125 \mathrm{mg} \text { Methyl red, } 85 \mathrm{mg} \text { Methylene } \\
\text { blue, } 100 \mathrm{~mL} \text { methanol }\end{array}$ & $7 \times 10^{-6}$ & \\
\hline Neutral red & 6.8 & 8.0 & 7.38 & $10 \mathrm{mg}, 100 \mathrm{~mL}$ ethanol-water $50 \% \mathrm{v} / \mathrm{v}$ & $5 \times 10^{-7}$ & Merck \\
\hline Cresol red & 7.0 & 8.8 & 8.3 & $\begin{array}{l}100 \mathrm{mg}, 26.2 \mathrm{~mL} \mathrm{NaOH}(0.01 \mathrm{M}), \\
223.8 \mathrm{~mL} \text { water }\end{array}$ & $4 \times 10^{-6}$ & Feinchemie Sebnitz \\
\hline Thymol blue & & & & $\begin{array}{l}100 \mathrm{mg}, 21.5 \mathrm{~mL} \mathrm{NaOH}(0.01 \mathrm{M}) \\
228.5 \mathrm{~mL} \text { water }\end{array}$ & $6 \times 10^{-6}$ & Feinchemie Sebnitz \\
\hline 1st transition & 1.2 & 2.8 & & & & \\
\hline 2nd transition & 8.0 & 9.6 & 8.9 & & & \\
\hline Phenolphthalein & 8.0 & 10.0 & 9.4 & $50 \mathrm{mg}, 100 \mathrm{~mL}$ ethanol-water $70 \% \mathrm{v} / \mathrm{v}$ & $2 \times 10^{-6}$ & Schering AG Berlin \\
\hline Thymolphthalein & 9.3 & 10.5 & 9.7 & $100 \mathrm{mg}, 100 \mathrm{~mL}$ ethanol-water $80 \% \mathrm{v} / \mathrm{v}$ & $2 \times 10^{-6}$ & Feinchemie Sebnitz \\
\hline
\end{tabular}

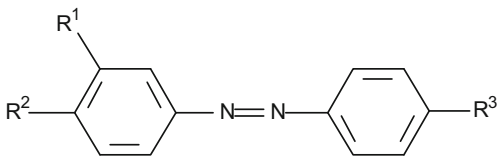

Scheme 1 General formula of Azo dyes (only one resonance structure is shown)

\section{Azo dyes}

Most acid base indicators which contain an azo group are derivatives of azobenzene (two phenyl rings linked by a $\mathrm{N}=\mathrm{N}$ double bond, Scheme 1) with $R^{3}$ being an amino group. Additionally, the introduction of polar substituents, such as carboxyl or sulfonic acid groups increases the solubility of the compounds. Azo dyes are indicator bases. During protonation a cation is formed, and the positive charge is delocalized, i.e., resonance between the aromatic ring and a quinoide structure (Scheme 2). The colour change is from yellow to red (or red violet).

Azo dyes are especially valuable because of their small salt error.

\section{Methyl orange}

Methyl orange is an orange powder. The sodium salt is moderately soluble in water. The aqueous stock solution should contain $0.1 \%$ of the indicator. The transition interval is from 3.0 to 4.4 (Scheme 3).
Figure $4 \mathrm{a}$ and $\mathrm{b}$ depict the titration curves for $1 \mathrm{mmol}$ $\mathrm{HCl} \quad\left(C^{\mathrm{o}} \approx 0.01 \mathrm{molL}^{-1}\right)$ and $0.1 \mathrm{mmol} \mathrm{HCl}$ $\left(C^{\mathrm{o}} \approx 0.001 \mathrm{~mol} \mathrm{~L}^{-1}\right)$ with $0.1 \mathrm{M} \mathrm{NaOH}$ and Methyl orange as indicator. Similar curves can be observed in case of $0.5 \mathrm{mmol} \mathrm{H}_{2} \mathrm{SO}_{4}\left(C^{\mathrm{o}} \approx 5 \times 10^{-3} \mathrm{~mol} \mathrm{~L}^{-1}\right)$ and $0.05 \mathrm{mmol} \mathrm{H}_{2} \mathrm{SO}_{4}\left(C^{\mathrm{o}} \approx 5 \times 10^{-4} \mathrm{~mol} \mathrm{~L}^{-1}\right)$. The colours of the starting solutions ( $v=0$ and $\tau=0$ in Fig. 4) differ in case of high and low concentrations, because the titrations start at different $\mathrm{pH}$ values. In case of high concentrations, the starting colour is of vivid red pink $(\mathrm{pH}=2.1$ ), changing to red orange during progressive titration. At $\tau \approx 0.91$ ( $\tau$ : degree of titration) the solution is already orange in colour $(\mathrm{pH}=3.1)$. A distinct transition takes place between $\tau \approx 0.985$ and $\tau=(0.994 \pm 0.002)$ from orange to bright yellow $(\mathrm{pH} \approx 3.8-4.2$, titration error at first bright yellow $-0.6 \%$ ). In case of small concentrations the colour of the starting solutions is already orange $(\mathrm{pH}=3.0)$. The transition from orange to bright yellow takes place between $\tau \approx 0.8$ and $\tau=(0.96 \pm 0.01)(\mathrm{pH} \approx 3.7-4.4$, titration error $-4 \%)$.

In case of high concentrations of oxalic acid $\left(C^{\mathrm{o}} \approx 5 \times 10^{-3} \mathrm{~mol} \mathrm{~L}^{-1}, \mathrm{pH}=2.4\right)$, the sample solution with Methyl orange is of vivid red pink, too (Fig. 5a). But the colour changes quickly to red orange during progressive titration. Already at $\tau \approx 0.5(\mathrm{pH}=3.8)$ the solution is yellow orange in colour. The transition takes place between $\tau \approx 0.62$ and $\tau=(0.90 \pm 0.03)$ from yellow orange to bright yellow $(\mathrm{pH} \approx 4.7$, titration error $-10 \%)$. 


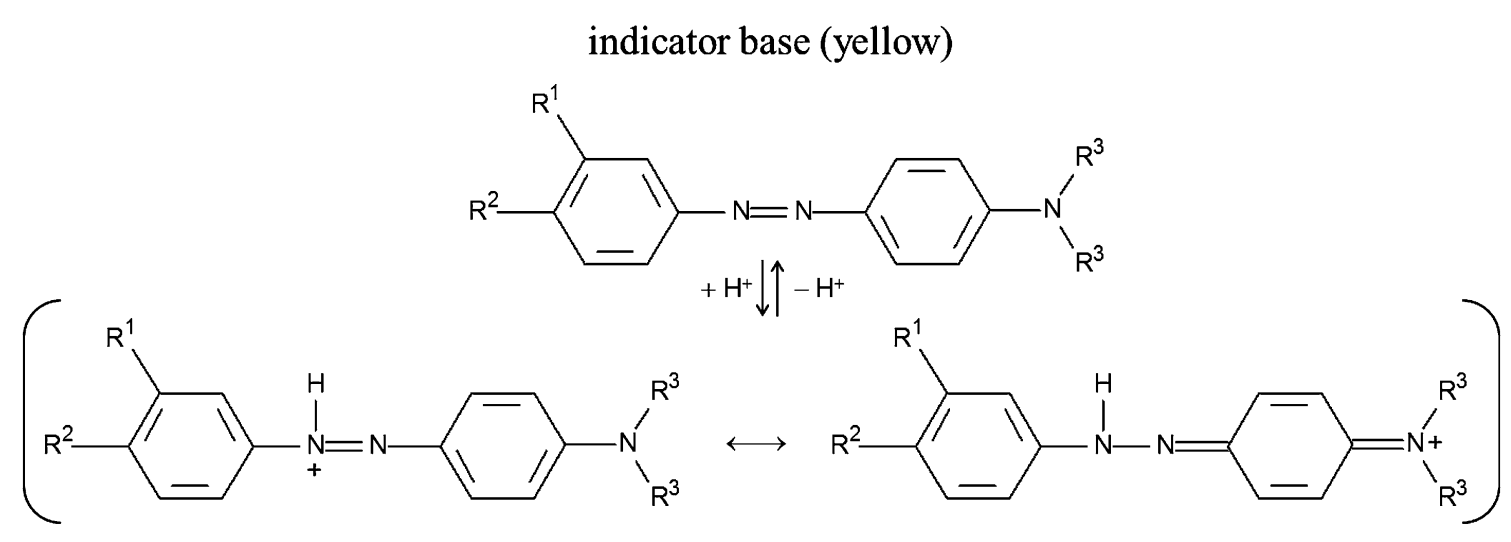

\section{indicator acid (red)}

Scheme 2 Schematic description of the structural changes of Azo dyes during protonation/deprotonation (only one resonance structure is given for the indicator base and two for the indicator acid)

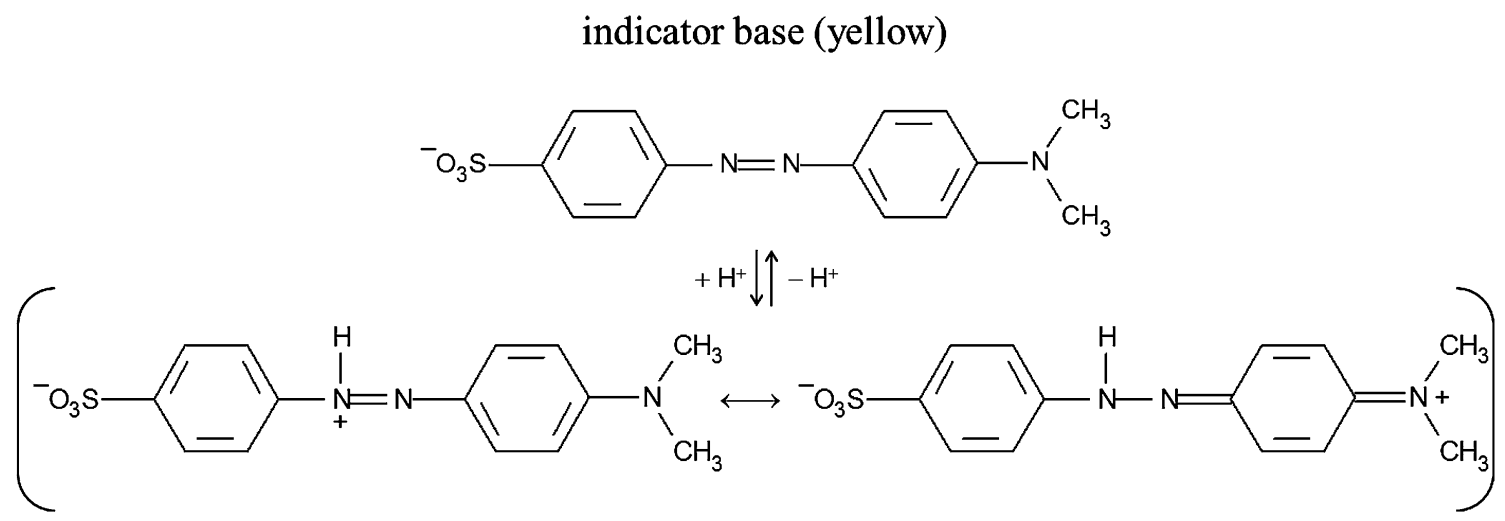

\section{indicator acid (red)}

Scheme 3 Structure of Methyl orange (only one resonance structure is given for the indicator base and two for the indicator acid)
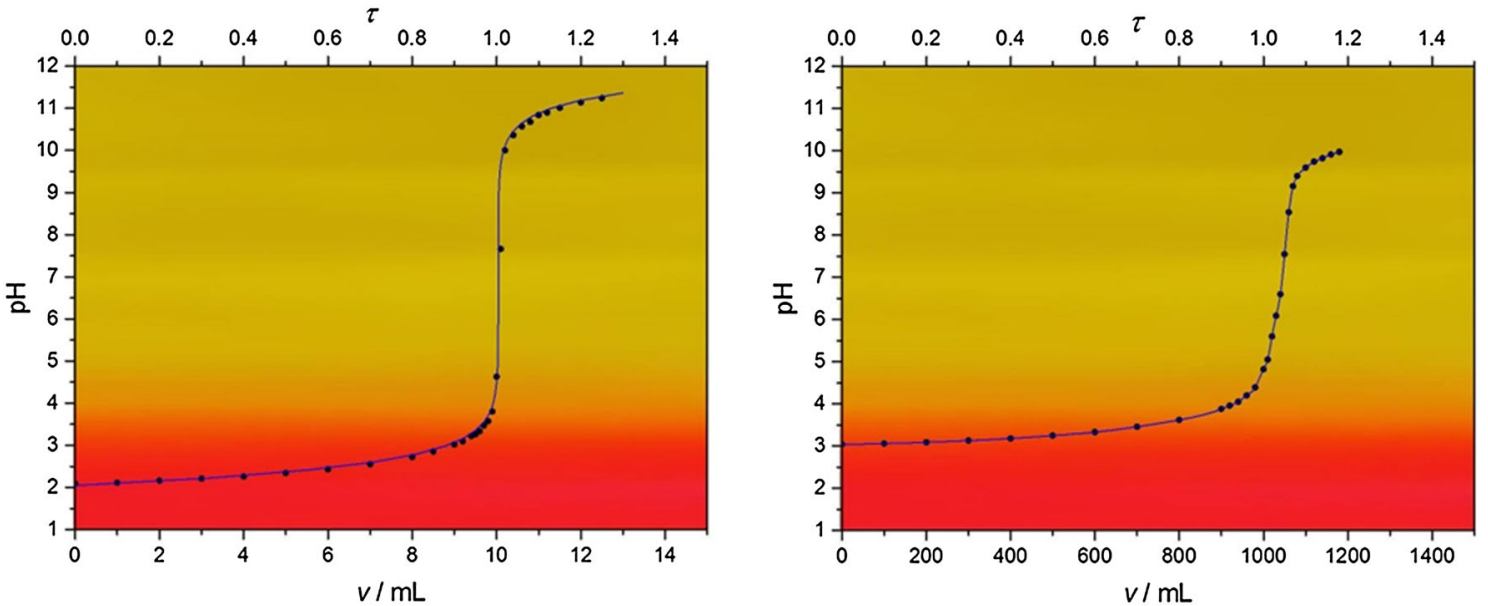

Fig. 4 Titration of a $1 \mathrm{mmol} \mathrm{HCl}\left(C^{\mathrm{o}} \approx 0.01 \mathrm{~mol} \mathrm{~L}^{-1}\right)$, and $\mathbf{b} 0.1 \mathrm{mmol} \mathrm{HCl}\left(C^{\mathrm{o}} \approx 0.001 \mathrm{~mol} \mathrm{~L}^{-1}\right)$ with $0.1 \mathrm{M} \mathrm{NaOH}$ and Methyl orange as indicator. Similar curves are observable for $\mathrm{H}_{2} \mathrm{SO}_{4}$. Dots experimental points, straight lines fits of experimental results with CurTiPot 

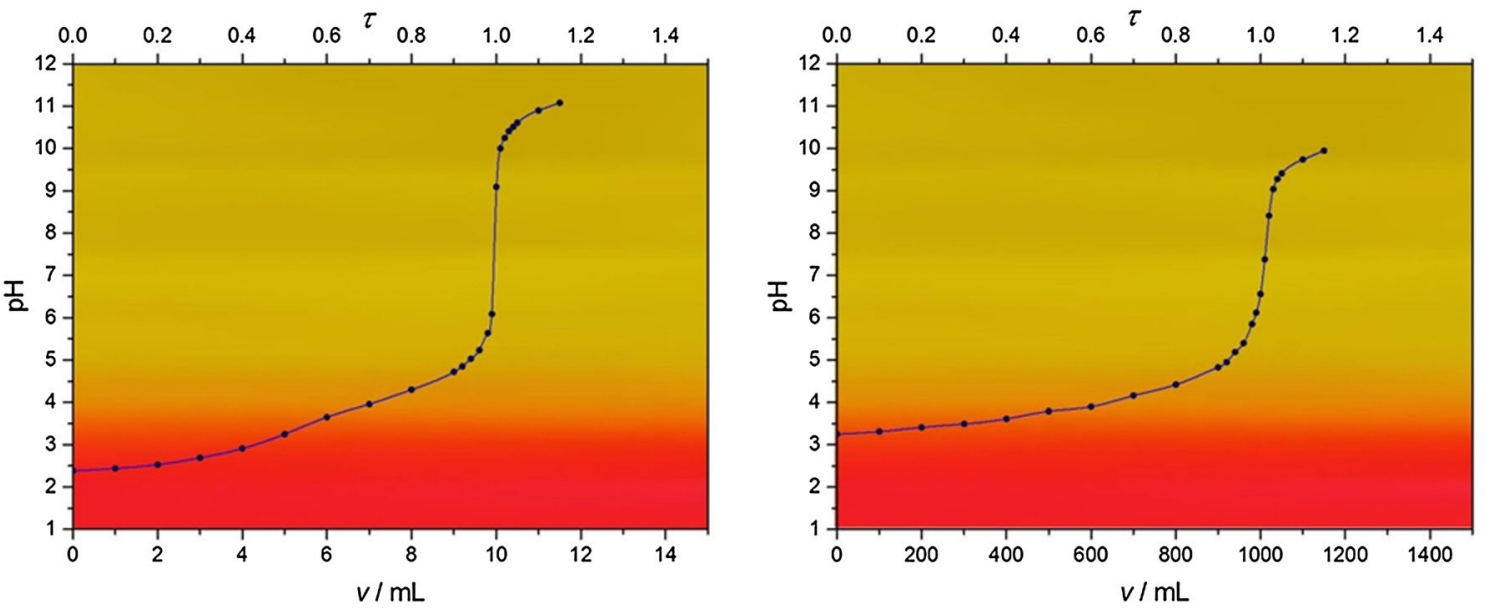

Fig. 5 Titration of a $0.5 \mathrm{mmol}$ oxalic acid $\left(C^{\mathrm{o}} \approx 5 \times 10^{-3} \mathrm{~mol} \mathrm{~L}^{-1}\right)$, and b $0.05 \mathrm{mmol}$ oxalic acid $\left(C^{\mathrm{o}} \approx 5 \times 10^{-4} \mathrm{~mol} \mathrm{~L}^{-1}\right)$ with $0.1 \mathrm{M}$ $\mathrm{NaOH}$ and Methyl orange as indicator. Dots experimental points, straight lines fits of experimental results with CurTiPot
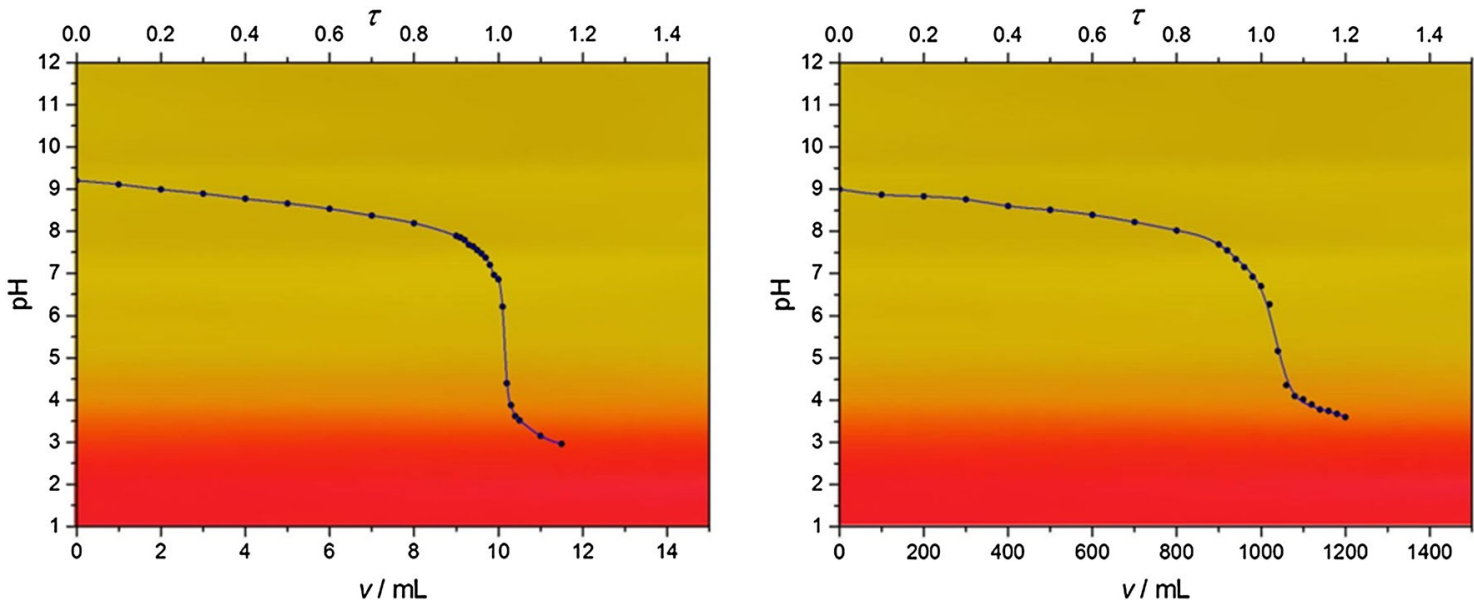

Fig. 6 Titration of a $0.5 \mathrm{mmol}$ borax $\left(C^{\mathrm{o}} \approx 5 \times 10^{-3} \mathrm{~mol} \mathrm{~L}^{-1}\right)$, and b $0.05 \mathrm{mmol}$ borax $\left(C^{\mathrm{o}} \approx 5 \times 10^{-4} \mathrm{~mol} \mathrm{~L}{ }^{-1}\right)$ with $0.1 \mathrm{M} \mathrm{HCl}$ and Methyl orange as indicator. Dots experimental points, straight lines fits of experimental results with CurTiPot

In case of low concentrations $\left(C^{\mathrm{o}} \approx 5 \times 10^{-4} \mathrm{~mol} \mathrm{~L}^{-1}\right.$, $\mathrm{pH}=3.3$ ) the colour of the starting solution is already yellow orange (Fig. 5b). The transition from yellow orange to bright yellow is smeared out, and bright yellow is reached at $\tau=0.83 \pm 0.04(\mathrm{pH} \geq 4.5$, titration error $-17 \%)$.

Solutions of both concentrations of borax $\left(C^{\mathrm{o}} \approx 5 \times 10^{-3} \mathrm{~mol} \mathrm{~L}^{-1}\right.$ and $\left.C^{\mathrm{o}} \approx 5 \times 10^{-4} \mathrm{~mol} \mathrm{~L}^{-1}\right)$ are brilliant yellow before the addition of hydrochloric acid $(\mathrm{pH}=9.2$ and $\mathrm{pH}=9.0$ for high and low concentrations, respectively). In case of high concentrations, the transition from yellow to yellow orange (first orange undertone) is observable at $\tau=1.012 \pm 0.004$ $(\mathrm{pH}=4.3$, titration error $+1.2 \%)$, but the colour changes gradually to orange, red orange and at least vivid red pink when continuing the addition of hydrochloric acid (i.e., large excess, $\mathrm{pH}<3.0$, cf. Figure $6 \mathrm{a}$ ). In case of low concentrations, the transition from yellow to yellow orange is hardly visible at $\tau=1.17 \pm 0.06(\mathrm{pH}=4.3$, titration error $+17 \%$ ), a real transition to orange and red orange is only obtainable, if an excess of hydrochloric acid is added (cf. Fig. 6b).

\section{Methyl red}

Methyl red is a very common indicator for titrations of strong acids with strong bases. It is a dark red violet crystalline powder. In contrast to Methyl orange, it is sparingly soluble in water, and a stock solution should contain $0.02 \%$ of the indicator in a $60 \%$ ethanol water mixture. The transition interval is from $\mathrm{pH} 4.4$ to 6.2 (Scheme 4). In the literature [13], the colour transition is given from yellow (base) to red (acid), but as it is shown in Fig. 7, a better description for the colour of the acid is fuchsia. 


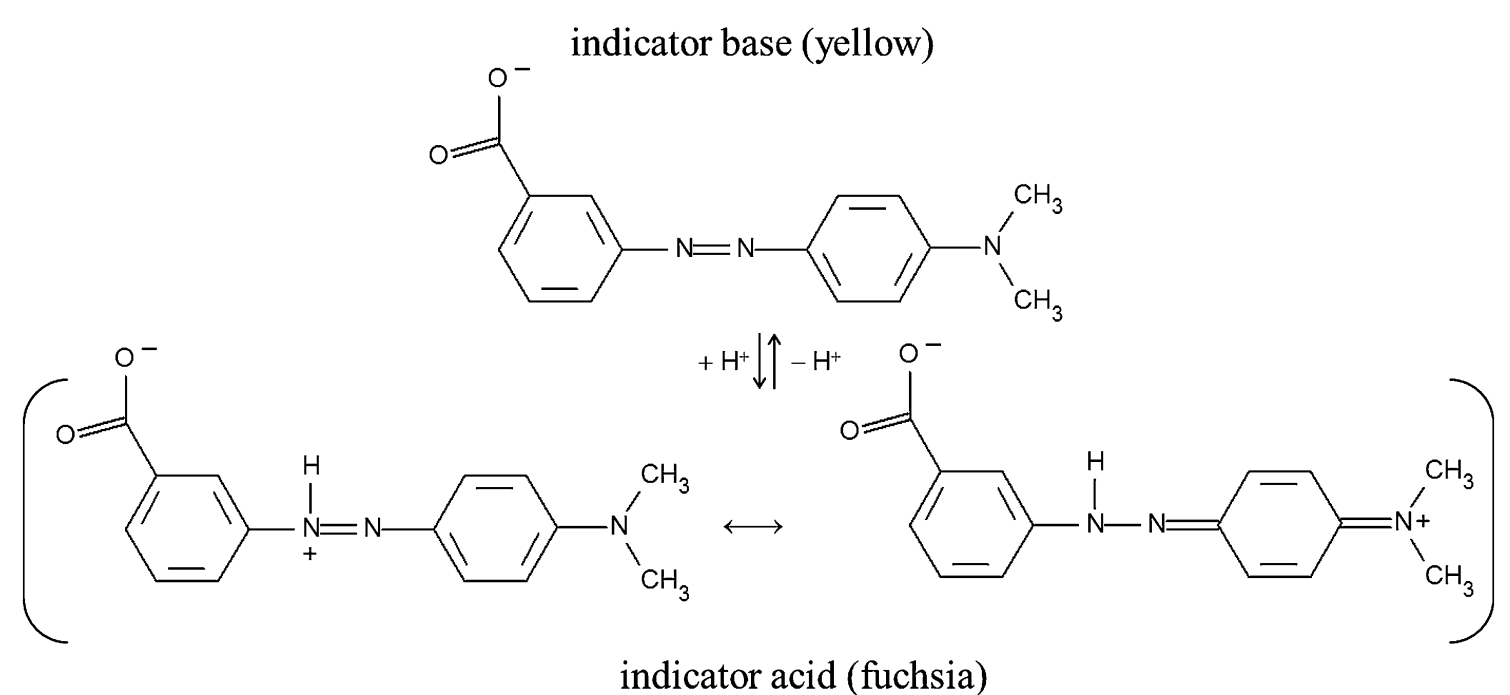

Scheme 4 Structure of Methyl red (only one resonance structure is given for the indicator base and two for the indicator acid)
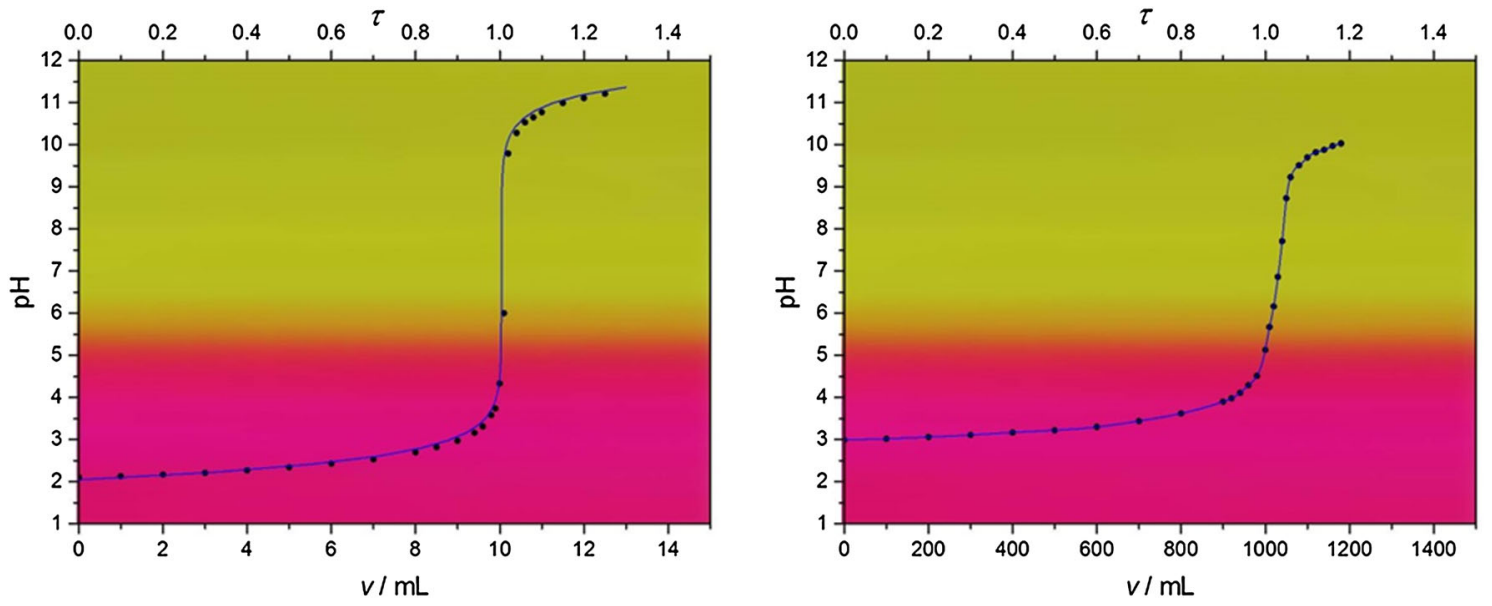

Fig. 7 Titration of a $1 \mathrm{mmol} \mathrm{HCl}\left(C^{\mathrm{o}} \approx 0.01 \mathrm{~mol} \mathrm{~L}^{-1}\right)$ and $0.1 \mathrm{mmol} \mathrm{HCl}\left(C^{\mathrm{o}} \approx 0.001 \mathrm{~mol} \mathrm{~L}{ }^{-1}\right)$ with $0.1 \mathrm{M} \mathrm{NaOH}$ and $\mathrm{Methyl}$ red as indicator. Similar curves are observable for $\mathrm{H}_{2} \mathrm{SO}_{4}$. Dots experimental points, straight lines fits of experimental results with CurTiPot

In case of high and low concentrations of strong acids, the sample solutions with Methyl red are of brilliant fuchsia colour $\left(\mathrm{pH}=2.1\right.$ and $\mathrm{pH}=3.0$ for $C^{\mathrm{o}} \approx 0.01$ mol L ${ }^{-1}$ and $C^{\mathrm{o}} \approx 0.001 \mathrm{~mol} \mathrm{~L}^{-1}$, respectively). This colour does not change markedly during ongoing titration (Fig. 7a, b). The transition from fuchsia to yellow is very sharp. Only very close to the transition point $(\tau>0.997$ and $\tau>0.98$ in case of high and low concentrations, respectively, $\mathrm{pH} \approx 4.5$ ), the fuchsia colour starts getting lighter. At $\tau \approx 1.000(\tau=0.999 \pm 0.002$, high concentration, and $\tau=1.00 \pm 0.02$, low concentration, $\mathrm{pH} \approx 6-7)$ the complete solution is yellow. In both cases the systematic error is negligible, as we will discuss later in detail. However, it must be mentioned here, that the yellow colour vanishes with time, and the colour of the solutions returns to fuchsia because carbon dioxide from ambient air dissolves, and this decreases the $\mathrm{pH}$ of the solution. The rate of the regeneration of the fuchsia colour depends strongly on the experimental and ambient conditions, e.g. the return of the colour is very fast when the solution is heavily shaken. Hence, it is not serious to give a certain time span in which the colour should stay, although, this is often done in textbooks. In praxis, this leads very often to the fact that undergraduate students read the end point too late.

In case of a weaker acid like oxalic acid, the transition is not as sharp as for strong acids (cf. Fig. 8a, b). We can see here, that both solutions are fuchsia before titration starts. The brilliant fuchsia turns pale at $\tau>0.90(\mathrm{pH}>4.7)$. At $\tau \approx 0.98(\mathrm{pH}=5.5)$ the pale fuchsia turns to red orange, and the transition to clear yellow is obtained at $\tau=0.990 \pm 0.003$ and $\tau=0.99 \pm 0.01(\mathrm{pH}=5.7)$ for 

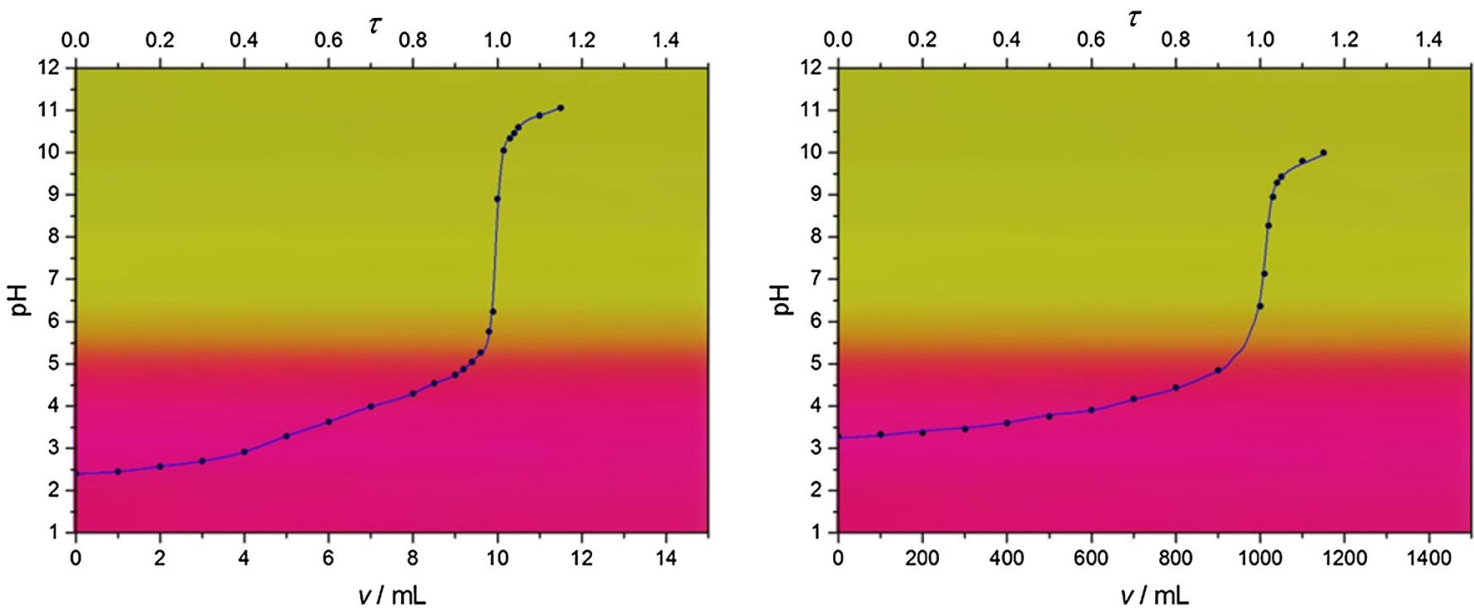

Fig. 8 Titration of a $0.5 \mathrm{mmol}$ oxalic acid $\left(C^{\mathrm{o}} \approx 5 \times 10^{-3} \mathrm{~mol} \mathrm{~L}^{-1}\right)$, and $\mathbf{b} 0.05 \mathrm{mmol}$ oxalic acid $\left(C^{\mathrm{o}} \approx 5 \times 10^{-4} \mathrm{~mol} \mathrm{~L}^{-1}\right)$ with $0.1 \mathrm{M}$ $\mathrm{NaOH}$ and Methyl red as indicator. Dots experimental points, straight lines fits of experimental results with CurTiPot
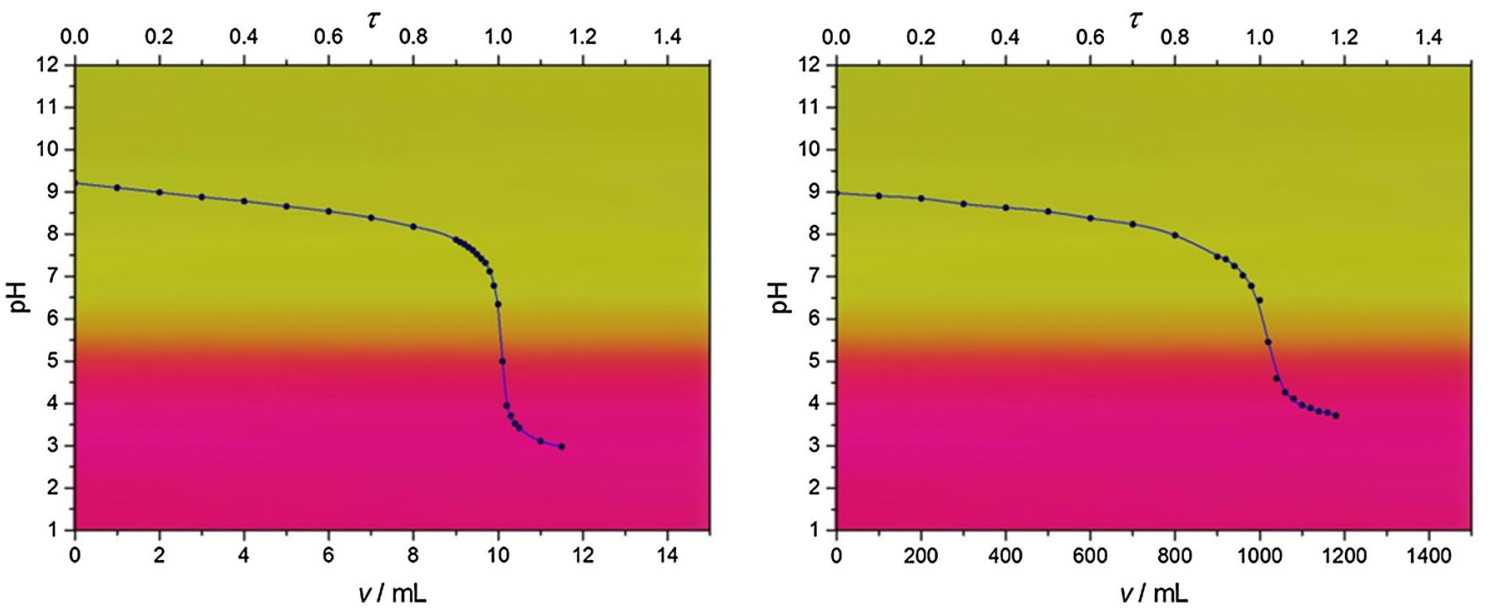

Fig. 9 Titration of a $0.5 \mathrm{mmol}$ borax $\left(C^{\mathrm{o}} \approx 5 \times 10^{-3} \mathrm{~mol} \mathrm{~L}^{-1}\right)$, and b $0.05 \mathrm{mmol}$ borax $\left(C^{\mathrm{o}} \approx 5 \times 10^{-4} \mathrm{~mol} \mathrm{~L} \mathrm{~L}^{-1}\right)$ with $0.1 \mathrm{M} \mathrm{HCl}$ and Methyl red as indicator. Dots experimental points, straight lines fits of experimental results with CurTiPot

high and low concentrations of oxalic acid, respectively (titration error $-1 \%$ ).

In case of borax a sharp transition is observable; here the colour changes from yellow to brilliant fuchsia (Fig. 9a, b). At $\tau \approx 0.99$ (high concentration) and $\tau \approx 0.98$ (low concentration) $(\mathrm{pH} \approx 6.0)$ the solutions start getting slightly orange (very weak orange undertone), and at $\tau=1.000 \pm 0.003$ and $\tau=1.00 \pm 0.01$ the transition to fuchsia for low and high concentrations is obtained, respectively $(\mathrm{pH}=5.2)$. In both cases, the titration error is negligible.

To give sharper endpoint colour changes, Methyl red can be mixed with a dye insensitive to $\mathrm{pH}$ changes like Methylene blue (Scheme 5). This mixture is called Tashiro. The transition interval is that of Methyl red, the colour changes from violet (mixture of blue and brilliant fuchsia) to green (mixture of yellow and blue). At the<smiles>CN(C)c1ccc2nc3ccc(=[N+](C)C)cc-3sc2c1</smiles>

$\mathrm{Cl}^{-}$

Scheme 5 Structure of Methylene blue (methylthioninium chloride, only one resonance structure is given)

transition point $\left(\mathrm{pH}=\mathrm{p} K_{\mathrm{I}}\right)$, the solution is grey, but it is recommendable to titrate to the first faint green colour in case of the volumetric determination of an acid.

As an example, in Fig. 10 the titration curve for $1 \mathrm{mmol}$ $\mathrm{HCl}\left(C^{0} \approx 0.01 \mathrm{~mol} \mathrm{~L}^{-1}\right)$ with $0.1 \mathrm{~mol} \mathrm{~L}^{-1} \mathrm{NaOH}$ is shown. 


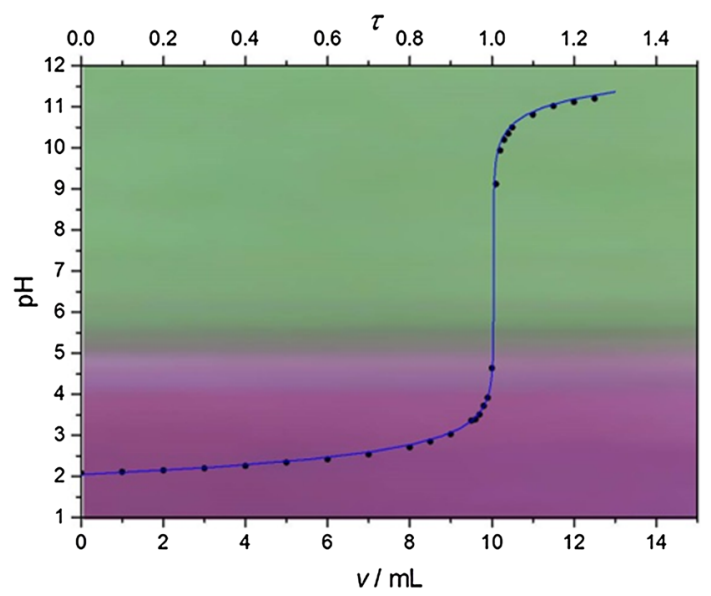

Fig. 10 Titration of $1 \mathrm{mmol} \mathrm{HCl}\left(C^{\mathrm{o}} \approx 0.01 \mathrm{~mol} \mathrm{~L}^{-1}\right)$ with $0.1 \mathrm{M}$ $\mathrm{NaOH}$ and Tashiro as indicator. Dots experimental points, straight line fit of experimental results with CurTiPot

\section{Congo red}

Congo red, as the disodium salt, is a red powder. It is soluble in water, and the aqueous stock solution should contain $0.1 \%$ of the indicator. The transition interval is from 3.0 to 5.0. This compound has a comparatively high salt error. It is a bisazo compound, resulting in a colour change different to that described above (cf. Scheme 6). In the literature [12], the colour transition is given from blue (acid) to red (base), but as shown in Fig. 11, it is better to describe the colour transition as blue violet to orange.

Sample solutions of high and low concentrations of hydrochloric acid and sulfuric acid with Congo red are pale blue violet $(\mathrm{pH}=2.1$ and $\mathrm{pH}=3.0$ for high and low concentrations, respectively, cf. Fig. 11a, b). In case of high concentrations the colour starts getting brighter already at $\tau \approx 0.93(\mathrm{pH} \approx 3.2)$. Between $\tau \approx 0.98$ and $\tau \approx 0.99(\mathrm{pH} \approx 3.7-4.0)$ the transition takes place from violet to red violet, and the solutions become orange above $\tau=0.993 \pm 0.002(\mathrm{pH}=4.2$, titration error $-0.7 \%)$. In case of low concentrations the transition from violet to red violet and at least to orange is observable between $\tau \approx 0.8$ and $\tau=(0.94 \pm 0.02) \quad(\mathrm{pH} \approx 3.7-4.3$, titration error $-6 \%)$.

In case of oxalic acid, both titrations start with a pale blue violet colour $(\mathrm{pH}=2.4$ and $\mathrm{pH}=3.3$ for high and low concentration, respectively) (Fig. 12a, b). In case of high concentrations, at $\tau \approx 0.7(\mathrm{pH} \approx 3.8-4.0)$ it starts getting brighter and the solution becomes more violet. Between $\tau \approx 0.80$ and $\tau \approx 0.85$ the transition from red violet to orange red is observable, a clear orange is obtained at $\tau=0.87 \pm 0.02(\mathrm{pH}=4.6$, titration error $-13 \%)$. In case of low concentration, the transition interval is smeared out over a larger range of the titration degree; the solution starts getting brighter already about $\tau \approx 0.5(\mathrm{pH} \approx 3.8)$, and a clear orange is obtained already at $\tau=0.77 \pm 0.04(\mathrm{pH}=4.5$, titration error $-23 \%)$.

Figure 13a and $\mathrm{b}$ show the titration curves for high and low concentrations of borax with $\mathrm{HCl}$ and Congo red as indicator. In both cases, the solutions are orange before adding the $\mathrm{HCl}$. In case of high concentration, the transition from orange via red violet to violet is rather sharp, it starts at $\tau \approx 1.01(\mathrm{pH}=4.5)$, and the transition to blue violet is obtained at $\tau=1.014 \pm 0.004(\mathrm{pH}=4.0$, titration error $+1.4 \%)$. In case of small concentration, the transition starts later at $\tau \approx 1.05(\mathrm{pH}=4.5)$, and the transition from red violet to blue violet is not as sharp as in

\section{indicator base (orange)}
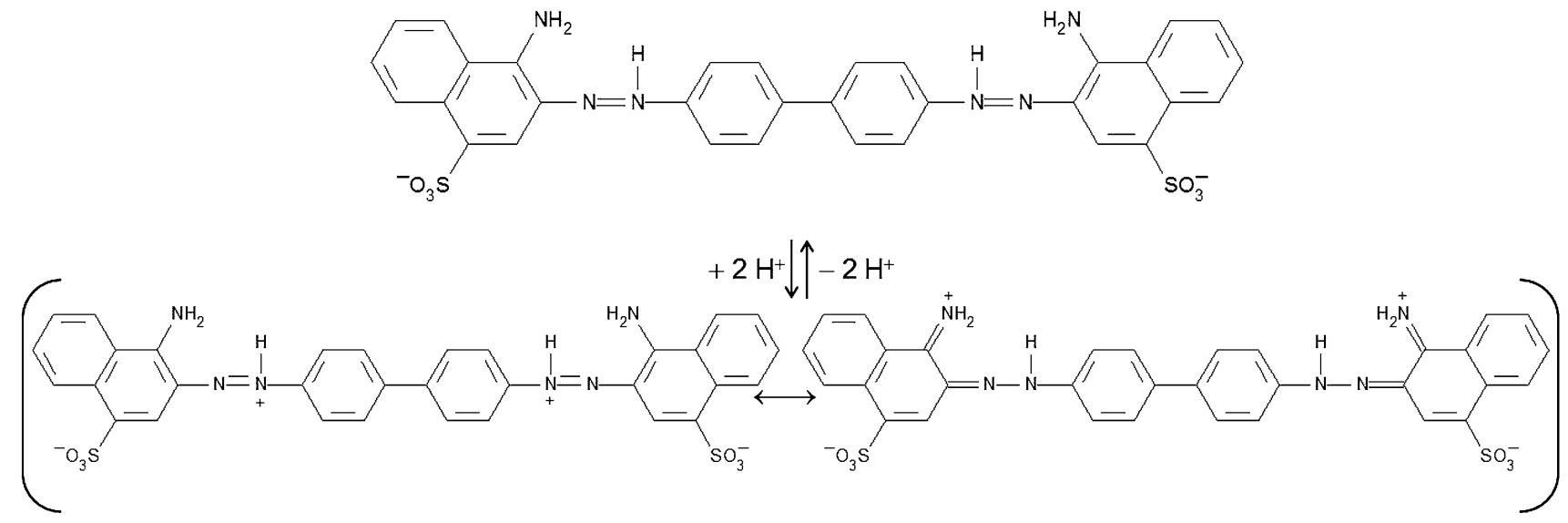

indicator acid (blue violet)

Scheme 6 Structure of Congo red (only one resonance structure is given for the base and two resonance structures are presented for the acid) 

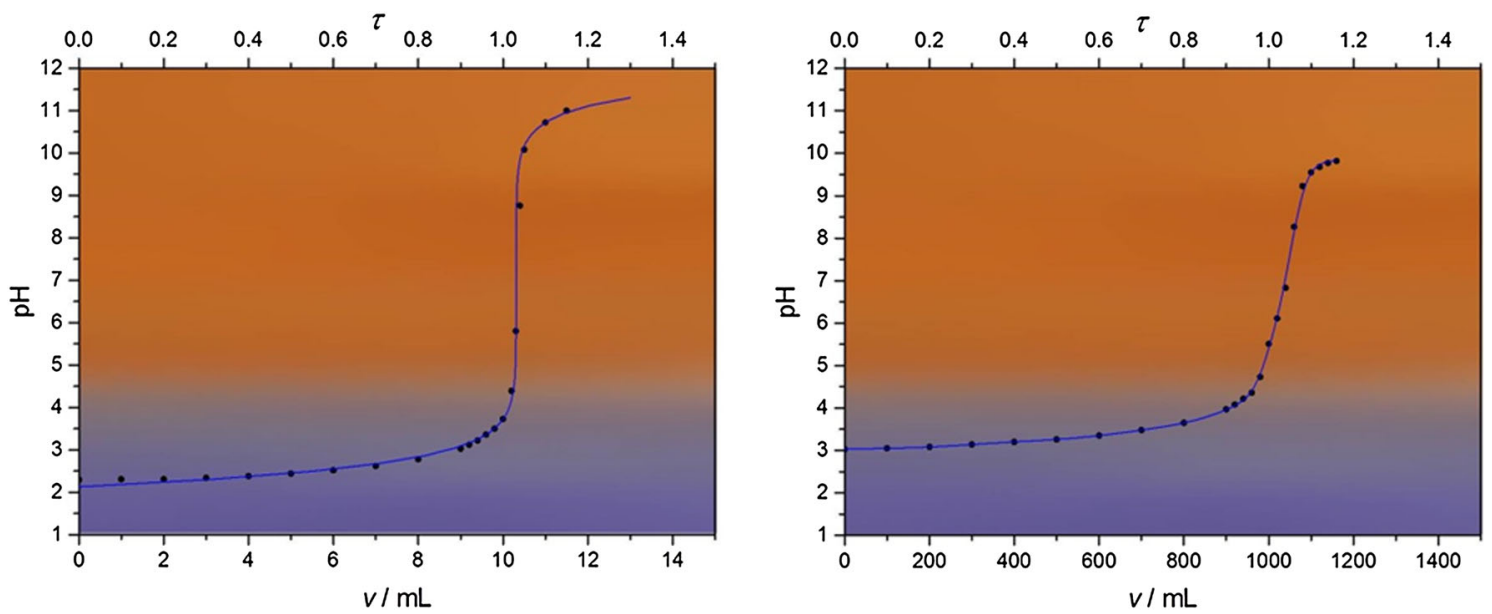

Fig. 11 Titration of a $0.5 \mathrm{mmol} \mathrm{H}_{2} \mathrm{SO}_{4}\left(C^{\mathrm{o}} \approx 5 \times 10^{-3} \mathrm{~mol} \mathrm{~L}^{-1}\right)$, and b $0.1 \mathrm{mmol} \mathrm{HCl}\left(C^{\mathrm{o}} \approx 0.001 \mathrm{~mol} \mathrm{~L}^{-1}\right)$ with $0.1 \mathrm{M} \mathrm{NaOH}$ and Congo red as indicator. Dots experimental points, straight lines fits of experimental results with CurTiPot
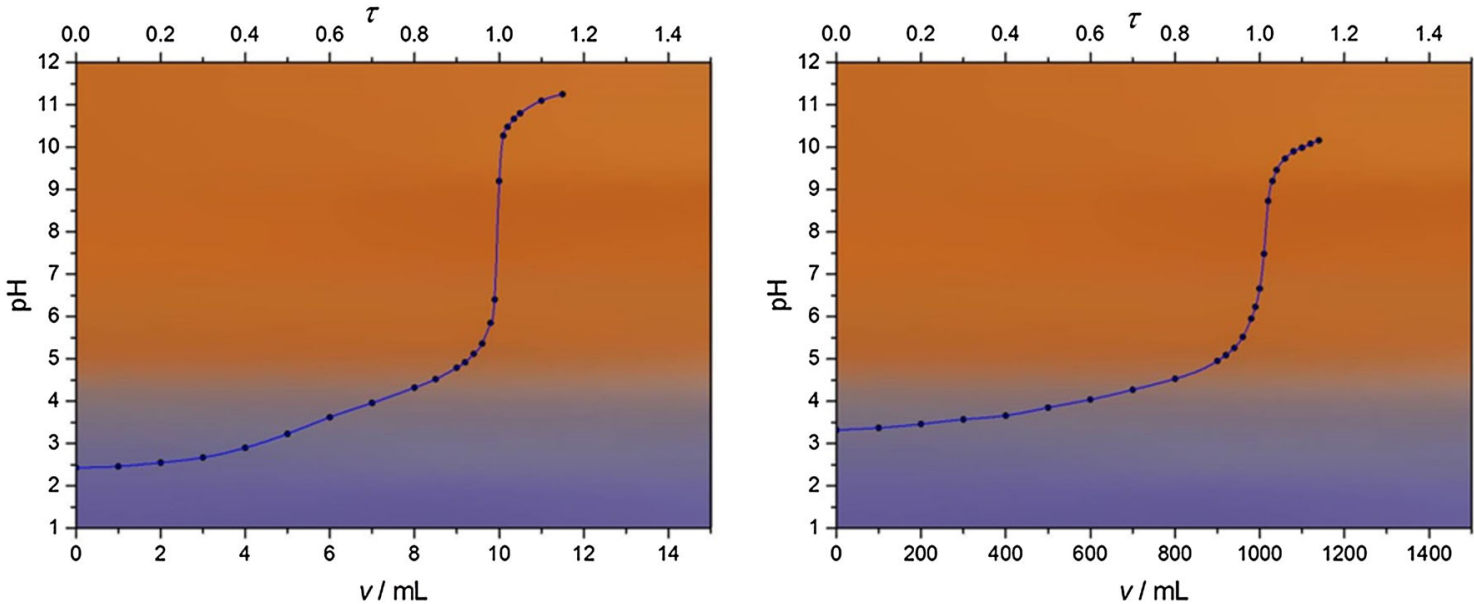

Fig. 12 Titration of a $0.5 \mathrm{mmol}$ oxalic acid $\left(C^{\mathrm{o}} \approx 5 \times 10^{-3} \mathrm{~mol} \mathrm{~L}{ }^{-1}\right)$, and b $0.05 \mathrm{mmol}$ oxalic acid $\left(C^{\mathrm{o}} \approx 5 \times 10^{-4} \mathrm{~mol} \mathrm{~L}{ }^{-1}\right)$ with $0.1 \mathrm{M}$ $\mathrm{NaOH}$ and Congo red as indicator. Dots experimental points, straight lines fits of experimental results with CurTiPot
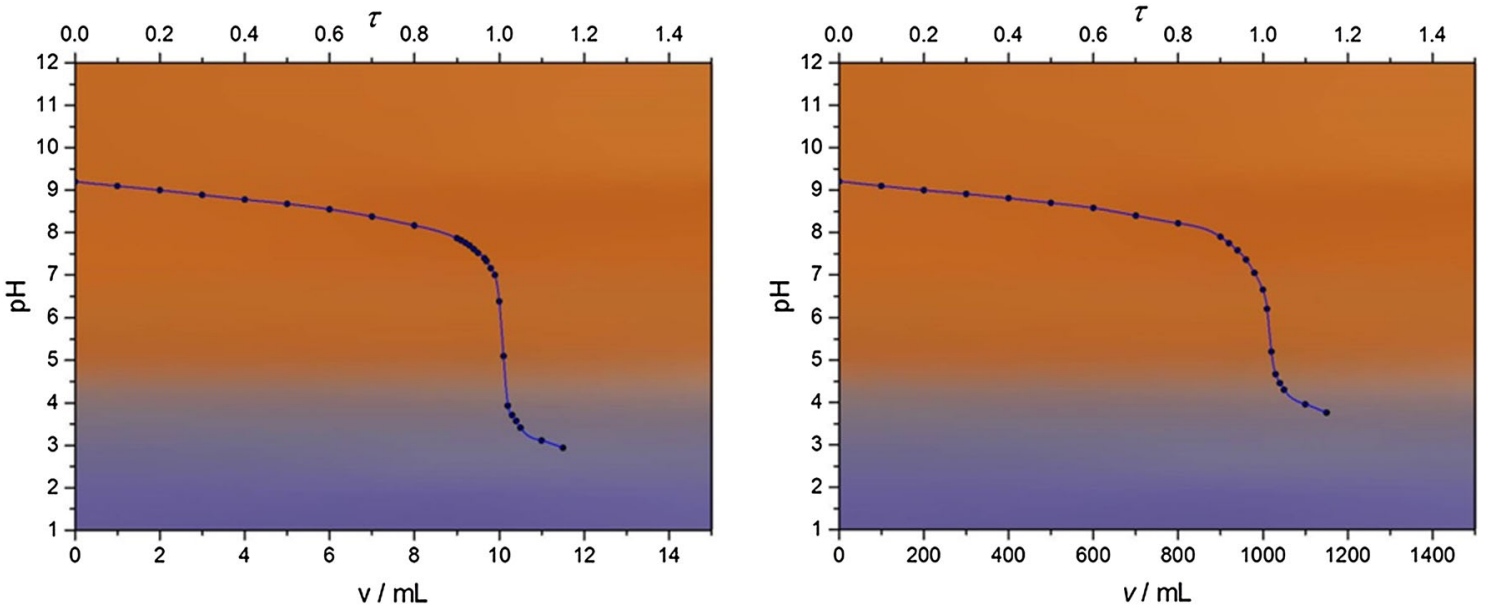

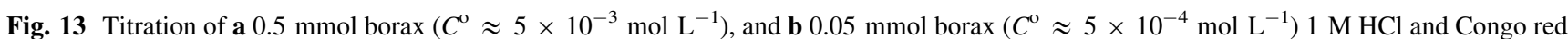
as indicator. Dots experimental points, straight lines fits of experimental results with CurTiPot 
<smiles>[R]c1cc(C2(c3cc([R])c(O)cc3[R])OC(=O)c3ccccc32)c([R])cc1O</smiles>

Scheme 7 General structure of Phthaleins

case of high concentrations. A clear blue violet is obtained at $\tau=1.15 \pm 0.02(\mathrm{pH}=4.0)$, i.e., the titration error is $+15 \%$.

\section{Phthaleins}

The Phthaleins (Scheme 7) are synthesised by heating phthalic anhydride with a derivative of phenol. All Phthaleins are rather insoluble in water but soluble in ethanol. In the acidic form most of the Phthaleins are colourless (lactone form), while in alkaline media a coloured quinoide structure is formed because of the opening of the lactone ring, i.e., most Phthaleins are monochromic indicators (Scheme 8).

In strongly alkaline solutions $(\mathrm{pH}>13)$ the coloured quinoide structure is transformed into the colourless trianion (Scheme 9).

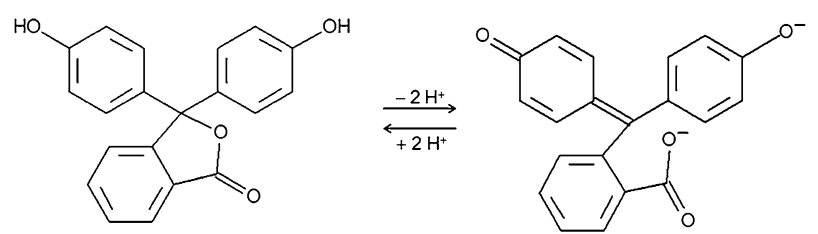

indicator acid (colourless)

indicator base (pink)

Scheme 10 Structure of Phenolphthalein (only one resonance structure is shown for each species)

\section{Phenolphthalein}

Phenolphthalein, one of the most popular indicators, can be considered as the basic compound of Phthaleins (Scheme 10). It is a white crystalline powder; stock solutions contain $0.05-0.1 \%$ of the indicator in an ethanol water mixture of 50-70\% ethanol. The transition interval of phenolphthalein is from 8.0 to 10 .

Solutions of high and low concentrations of strong acids as well as of weak acids appear colourless, when Phenolphthalein is added (see Figs. 14a, b, 15a, b). Under the conditions we consider here (concentration of Phenolphthalein is given in the experimental section, transition point at $\mathrm{pH} \approx 8.5$ ), for strong acids a sudden colour change to faint pink is obtained at $\tau=1.003 \pm 0.002$ and $\tau=1.02 \pm 0.02$ (high and low concentration, respectively). It is of outmost importance to
Scheme 8 Structural changes of Phthaleins during protonation/deprotonation (only one resonance structure is shown for the indicator acid and one resonance structure for the indicator base)<smiles>[R]c1cc(C2(c3cc([R])c(O)cc3[R])OC(=O)c3ccccc32)c([R])cc1O</smiles>

indicator acid (colourless)

Scheme 9 Structural changes of Phthaleins in strong alkaline solutions during protonation/ deprotonation $(\mathrm{pH}>13$, only one resonance structure is shown for each species)

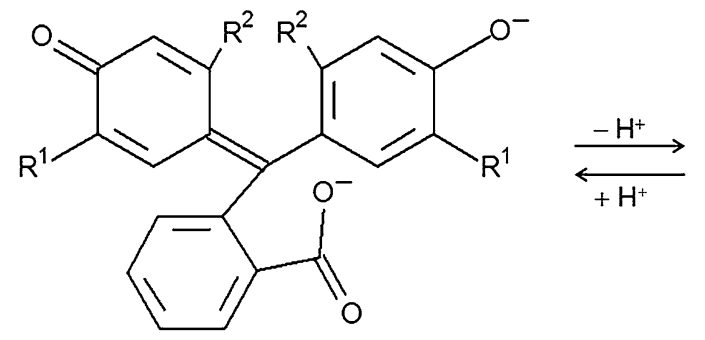

coloured quinone<smiles>[R]C1=CC(=C(c2cc([R])c([O-])cc2[R])c2ccccc2C(=O)[O-])C([R])=CC1=O</smiles>

indicator base (coloured)<smiles>[R]c1cc(C(O)(c2cc([R])c([O-])cc2[R])c2ccccc2C(=O)[O-])c([R])cc1[O-]</smiles>

colourless trianion 


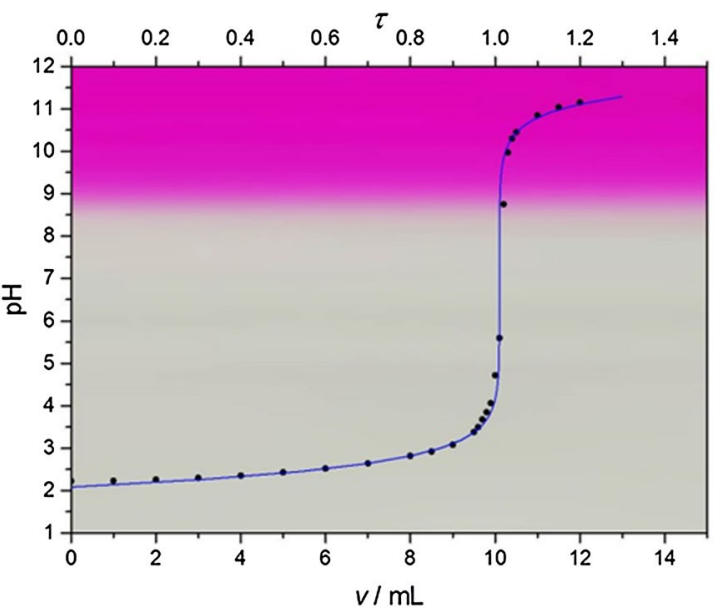

Fig. 14 Titration of a $0.5 \mathrm{mmol} \mathrm{H}_{2} \mathrm{SO}_{4}\left(C^{\mathrm{o}} \approx 5 \times 10^{-3} \mathrm{~mol} \mathrm{~L}^{-1}\right)$, and b $0.05 \mathrm{mmol} \mathrm{H}_{2} \mathrm{SO}_{4}\left(C^{\mathrm{o}} \approx 5 \times 10^{-4} \mathrm{~mol} \mathrm{~L}^{-1}\right)$ with $0.1 \mathrm{M}$ $\mathrm{NaOH}$ and Phenolphthalein as indicator. Similar curves are

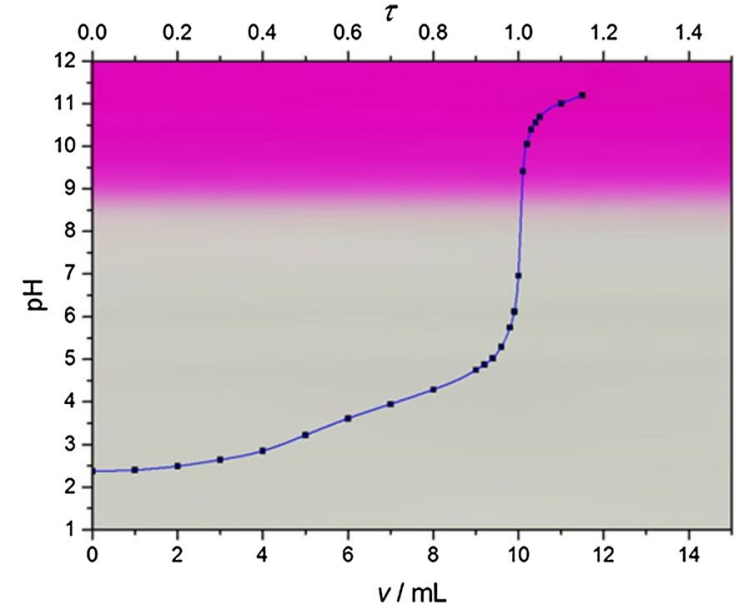

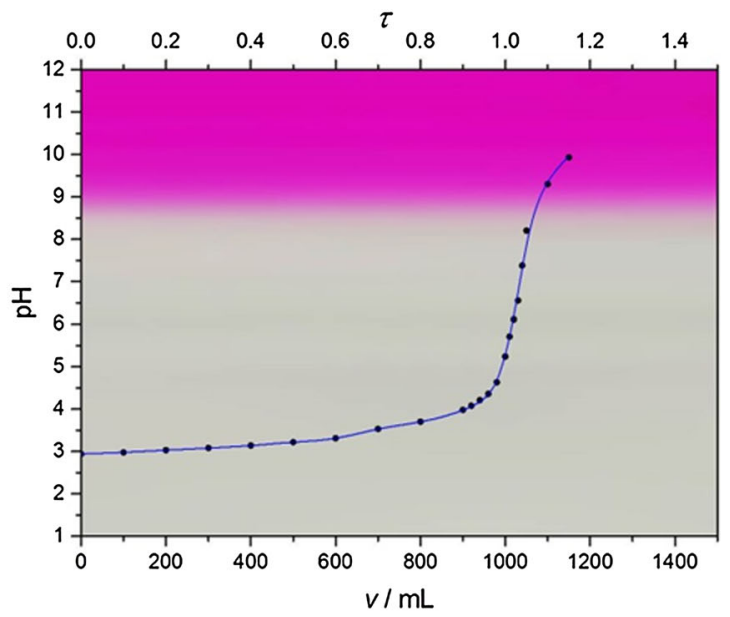

observable for $\mathrm{HCl}$. Dots experimental points, straight lines fits of experimental results with CurTiPot

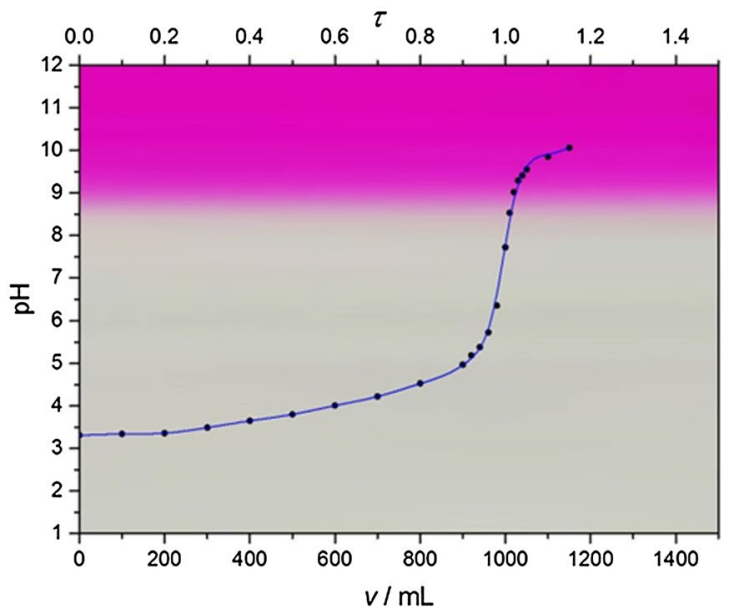

Fig. 15 Titration of a $0.5 \mathrm{mmol}$ oxalic acid $\left(C^{\mathrm{o}} \approx 5 \times 10^{-3} \mathrm{~mol} \mathrm{~L}^{-1}\right)$, and $\mathbf{b} 0.05 \mathrm{mmol}$ oxalic acid $\left(C^{\mathrm{o}} \approx 5 \times 10^{-4} \mathrm{~mol} \mathrm{~L} \mathrm{~L}^{-1}\right)$ with $0.1 \mathrm{M}$ $\mathrm{NaOH}$ and Phenolphthalein as indicator. Dots experimental points, straight lines fits of experimental results with CurTiPot

avoid all colour influences from outside, meaning that the background is covered with white paper. The faint colour fades with time until the solution appears colourless again due to the influence of ambient air (cf. Methyl red). If the solution appears dark pink, the endpoint is overshot. Phenolphthalein is a suitable indicator for the titration of weak acids with a strong base as it can be seen in case of oxalic acid (Fig. 15a, b). Here, the colour turns to faint pink at $\tau=1.000 \pm 0.003$ (high concentration) and $\tau=1.01 \pm 0.01$ (low concentration).

In contrast, Phenolphthalein is absolutely inappropriate as an indicator for the titration of weak bases with a strong acid, as it is depicted in Fig. 16a, b for borax. Although the sample solutions are pink, this colour fades quickly during ongoing titration, and the systematic deviation exceeds $-40 \% \quad(\tau=0.54 \pm 0.12$ for high concentration, $\tau=0.53 \pm 0.08$ for low concentrations).

\section{Thymolphthalein}

Thymolphthalein is a white crystalline powder; the structure is rather similar to Phenolphthalein with the exception that the two phenol groups are replaced by two thymol groups (Scheme 11). A stock solution contains $0.1 \%$ of the indicator in an $80 \%$ ethanol solution. Like phenolphthalein, it is a single-colour indicator. The transition range lies between $\mathrm{pH} 9.7$ and 10.5 .

Thymolphthalein turns from colourless to blue, but it has to be mentioned here, that it is only a fade blue, the transition is rather difficult to see and the influence of carbon dioxide from ambient air is rather pronounced due to the high $\mathrm{pH}$ values. In that range, the addition of about $5 \times 10^{-5}$. mol $\mathrm{L}^{-1}$ of $\mathrm{H}_{3} \mathrm{O}^{+}$ions leads to a change in $\mathrm{pH}$ of about 0.3 units. In case of strong acids (Fig. 17a, b), the first very faint 

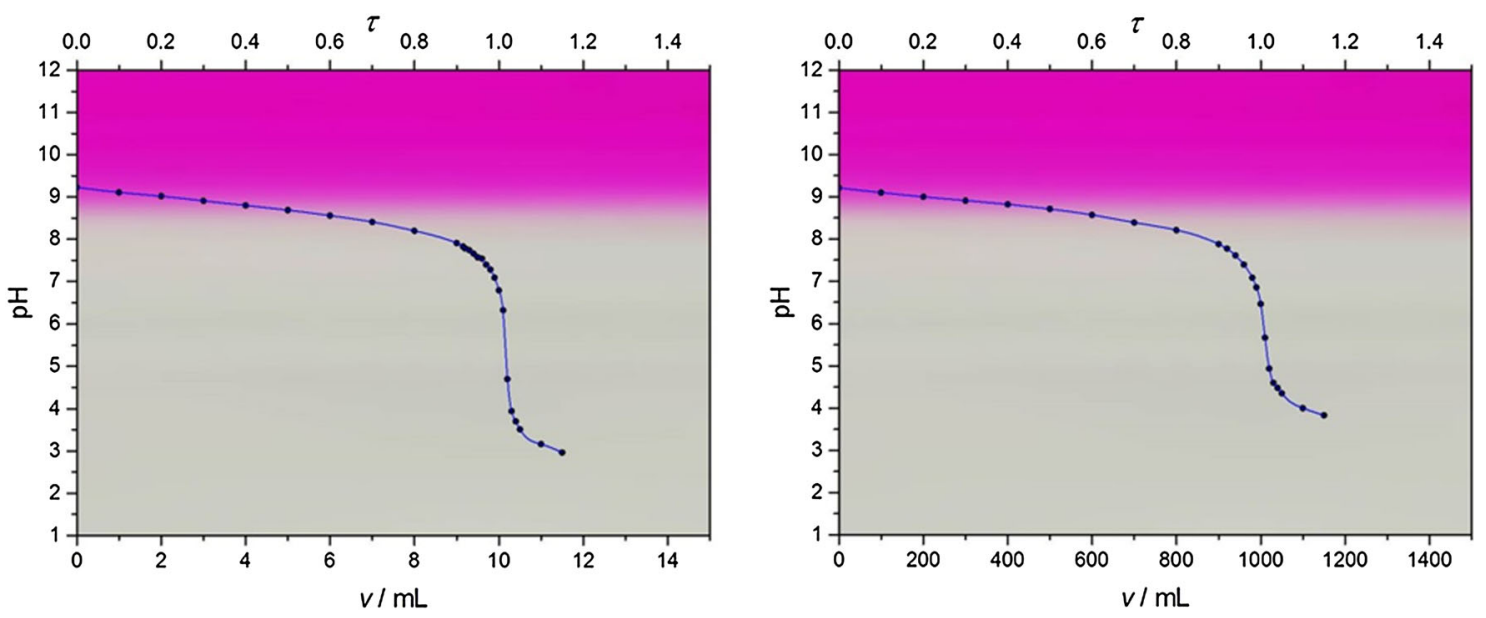

Fig. 16 Titration of of a $0.5 \mathrm{mmol}$ borax $\left(C^{\mathrm{o}} \approx 5 \times 10^{-3} \mathrm{~mol} \mathrm{~L}^{-1}\right)$, and $\mathbf{b} 0.05 \mathrm{mmol}$ borax $\left(C^{\mathrm{o}} \approx 5 \times 10^{-4} \mathrm{~mol} \mathrm{~L}^{-1}\right)$ with $0.1 \mathrm{M} \mathrm{HCl}^{\mathrm{H}} \mathrm{and}$ Phenolphthalein as indicator. Dots experimental points, straight lines fits of experimental results with CurTiPot

Scheme 11 Structure of Thymolphthalein (only one resonance structure is shown for each species)<smiles>Cc1cc(O)c(C(C)C)cc1C1(c2cc(C(C)C)c(O)cc2C)OC(=O)c2ccccc21</smiles>

indicator acid (colourless)

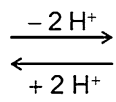<smiles>CC1=CC(=O)C(C(C)C)=CC1=C(c1cc(C(C)C)c([O-])cc1C)c1ccccc1C(=O)[O-]</smiles>

indicator base (blue)
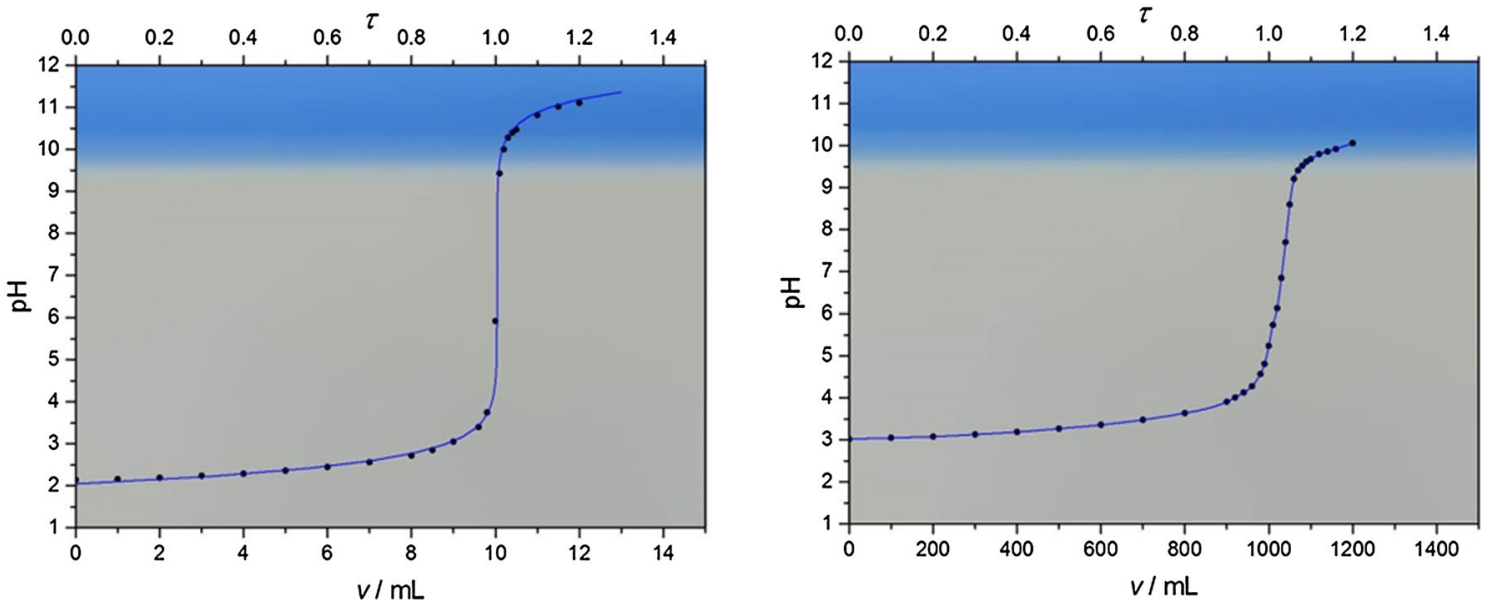

Fig. 17 Titration of a $1 \mathrm{mmol} \mathrm{HCl}\left(C^{\mathrm{o}} \approx 0.01 \mathrm{~mol} \mathrm{~L}^{-1}\right)$ and $0.1 \mathrm{mmol} \mathrm{HCl}\left(C^{\mathrm{o}} \approx 0.001 \mathrm{~mol} \mathrm{~L}^{-1}\right)$ with $0.1 \mathrm{M} \mathrm{NaOH}$ and Thymolphthalein as indicator. Similar curves are observable for $\mathrm{H}_{2} \mathrm{SO}_{4}$. Dots experimental points, straight lines fits of experimental results with CurTiPot

blue colour is obtained between $\mathrm{pH} \approx 9.7$ and 10.0 , i.e., $\tau=1.009 \pm 0.003$ (high concentration, titration error $+0.9 \%$ ), and $\tau=1.06 \pm 0.02$ (low concentration, titration error $+6 \%)$. As in case of Phenolphthalein, it is important to avoid all colour influences from outside, and the progress of titration should be controlled with a white background. 

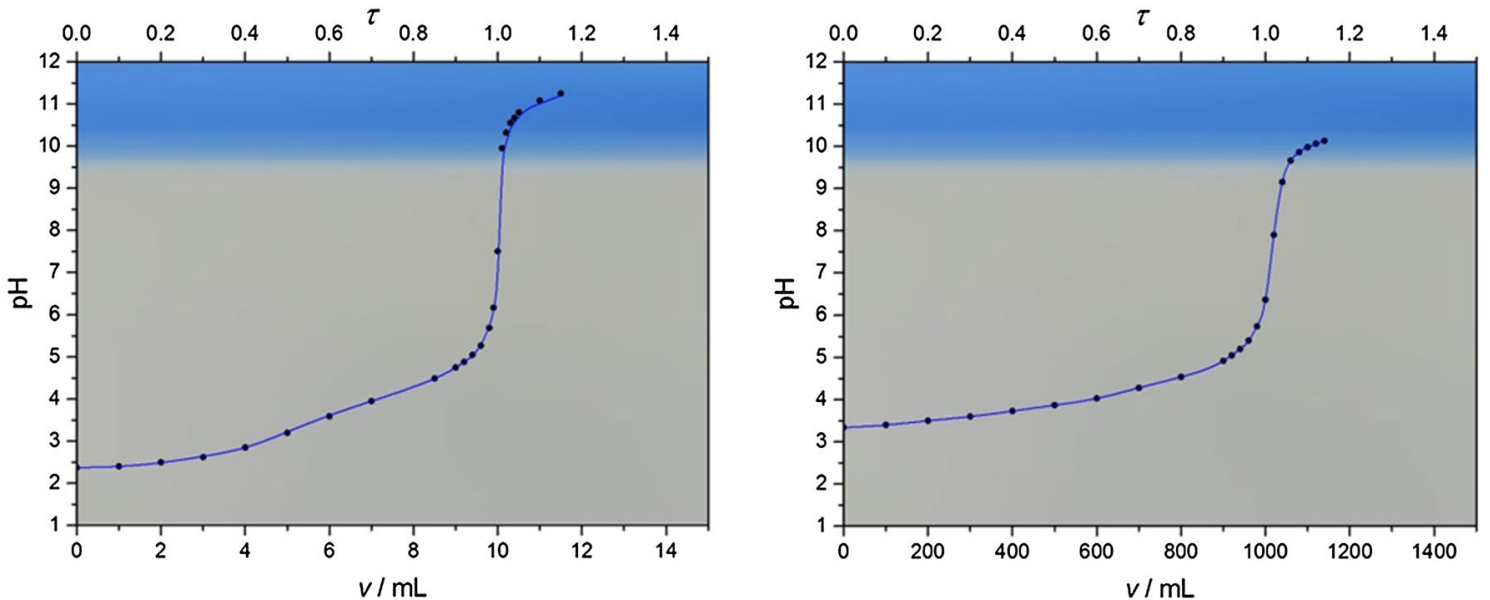

Fig. 18 Titration of a $0.5 \mathrm{mmol}$ oxalic acid $\left(C^{\mathrm{o}} \approx 5 \times 10^{-3} \mathrm{~mol} \mathrm{~L}-1\right)$, and $\mathbf{b} 0.05 \mathrm{mmol}$ oxalic acid $\left(C^{\mathrm{o}} \approx 5 \times 10^{-4} \mathrm{~mol} \mathrm{~L}{ }^{-1}\right)$ with $0.1 \mathrm{M}^{-1}$ $\mathrm{NaOH}$ and Thymolphthalein as indicator. Dots experimental points, straight lines fits of experimental results with CurTiPot
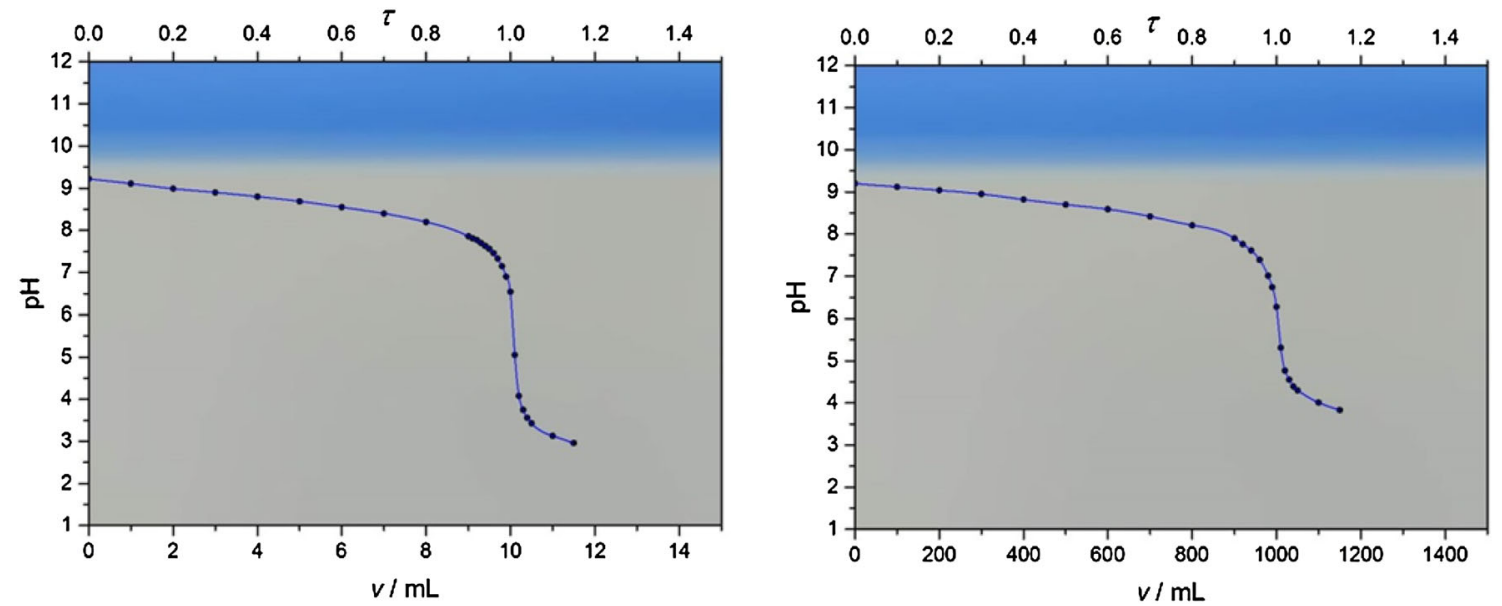

Fig. 19 Titration of a $0.5 \mathrm{mmol}$ borax $\left(C^{\mathrm{o}} \approx 5 \times 10^{-3} \mathrm{~mol} \mathrm{~L}^{-1}\right)$, and b $0.05 \mathrm{mmol}$ borax $\left(C^{\mathrm{o}} \approx 5 \times 10^{-4} \mathrm{~mol} \mathrm{~L} \mathrm{~L}^{-1}\right)$ with $0.1 \mathrm{M} \mathrm{HCl}$ and Thymolphthalein as indicator. Dots experimental points, straight lines fits of experimental results with CurTiPot

Similar results are obtainable with a weak acid like oxalic acid, as it is depicted in Fig. 18a, b. The first very faint blue colour is obtained between $\mathrm{pH} \approx 9.7$ and 10.0, i.e., $\tau=1.006 \pm 0.002$ (titration error $+0.6 \%$ ) in case of high concentration, and $\tau=1.06 \pm 0.02$ (titration error $+6 \%$ ) in case of low concentration.

Weak bases like borax are not titratable using Thymolphthalein as indicator. Here, already the sample solutions are colourless, as it is shown in Fig. 19a, b.

\section{Sulfonephthaleins}

Sulfonephthaleins (Scheme 12) are closely related to the Phthaleins and are formed by the reaction of o-sulfobenzoic acid anhydride with a phenol. They are sparingly soluble in water in the biprotonated form, whereas the monosodium salt is soluble in water. The structure contains the less stable sulfone ring which is opened already in acidic solutions. This leads to a quinoide structure, and the sulphonphthaleins are coloured in the acidic form, too. Sulfonephthaleins can be deprotonated in two steps [22]:

The $\mathrm{p} K_{\mathrm{a} 1}$ values are generally below 2 , therefore most of these molecules presents only one transition interval in aqueous solutions in the range of $\mathrm{p} K_{\mathrm{a} 2}$, i.e., between 3.5 and 8.5 (Scheme 13) [23].

\section{Bromophenol blue}

Bromophenol blue is an orange or light brown powder. Aqueous stock solution should contain $0.1 \%$ of the monosodium salt of the indicator. The transition interval is from 3.0 to 4.6 (Scheme 14).

The solutions of high and low concentrations of hydrochloric acid and sulfuric acid with Bromophenol blue 
<smiles>[R]c1cc(C2(c3cc([R])c(O)c([R])c3[Y20])OS(=O)(=O)c3ccccc32)c([R])c([R])c1O</smiles><smiles>[R]C1=CC(=C(c2ccccc2S(=O)(=O)O)c2cc([R])c(O)c([R])c2[Y])C([R])=C([R])C1=O</smiles>

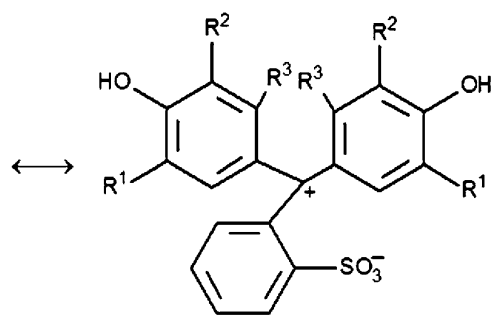

Scheme 12 Structure of the neutral biprotonated form of sulfonephthaleins (only one resonance structure is shown for each species)<smiles>[R]c1cc(C2(c3cc([Y])c(O)c([R])c3[Y7])OS(=O)(=O)c3ccccc32)c([R])c(O)c1[R]</smiles>

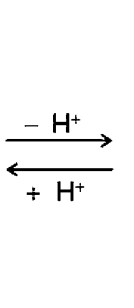

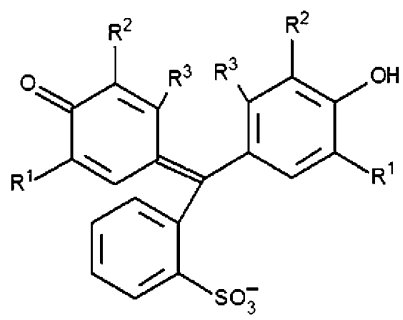

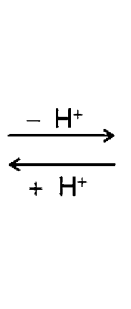

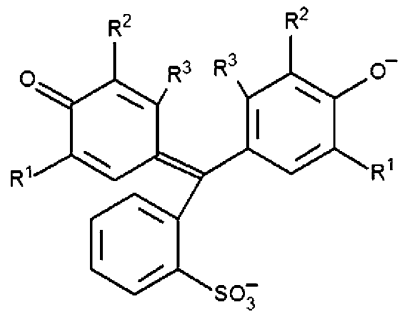

Scheme 13 Dissociation scheme of Sulfonephthaleins (only one resonance structure is shown for each species)<smiles>O=C1C(Br)=CC(=C(c2ccccc2)c2cc(Br)c(O)c(Br)c2)C=C1[Hg]</smiles>

monoanion (pale yellow)

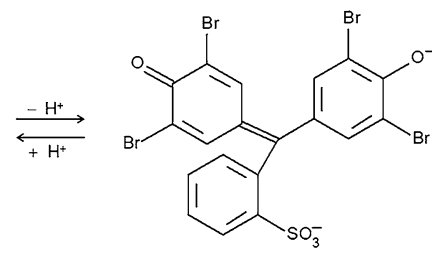

dianion (blue purple)
Scheme 14 Structures of the mono- and dianion of Bromophenol blue (only one resonance structure is shown for each ion)

are pale yellow in colour $(\mathrm{pH}=2.1$ and $\mathrm{pH}=3.0$ in case of high and low concentrations, respectively, cf. Fig. 20a, b). In case of high concentrations, around $\tau=0.97-0.98$
$(\mathrm{pH} \approx 3.5-3.7)$ the solutions start getting greenish yellow to grey and then to pale blue. The most striking colour change takes place at $\tau=0.989 \pm 0.003(\mathrm{pH} \approx 4.0)$ the colour changes to blue purple resulting in a titration error of $-1.1 \%$. During ongoing addition of the titrant, a smeared out colour change from blue purple to purple was observed. At lower concentrations, a faint greenish yellow colour is already visible at $\tau=0.7(\mathrm{pH} \approx 3.5)$, but the transition to blue purple takes place at $\tau=0.94 \pm 0.01$ $(\mathrm{pH} \approx 4.2)$, resulting in a titration error of $-6 \%$.

In case of oxalic acid, the sample solution with high concentration of the acid $(\mathrm{pH}=2.4)$ shows a pale yellow colour, too (Fig. 21a). Already at $\tau \approx 0.6$ (pH $\approx 3.6$ ), the solution gets greenish yellow, and at $\tau \approx 0.7$
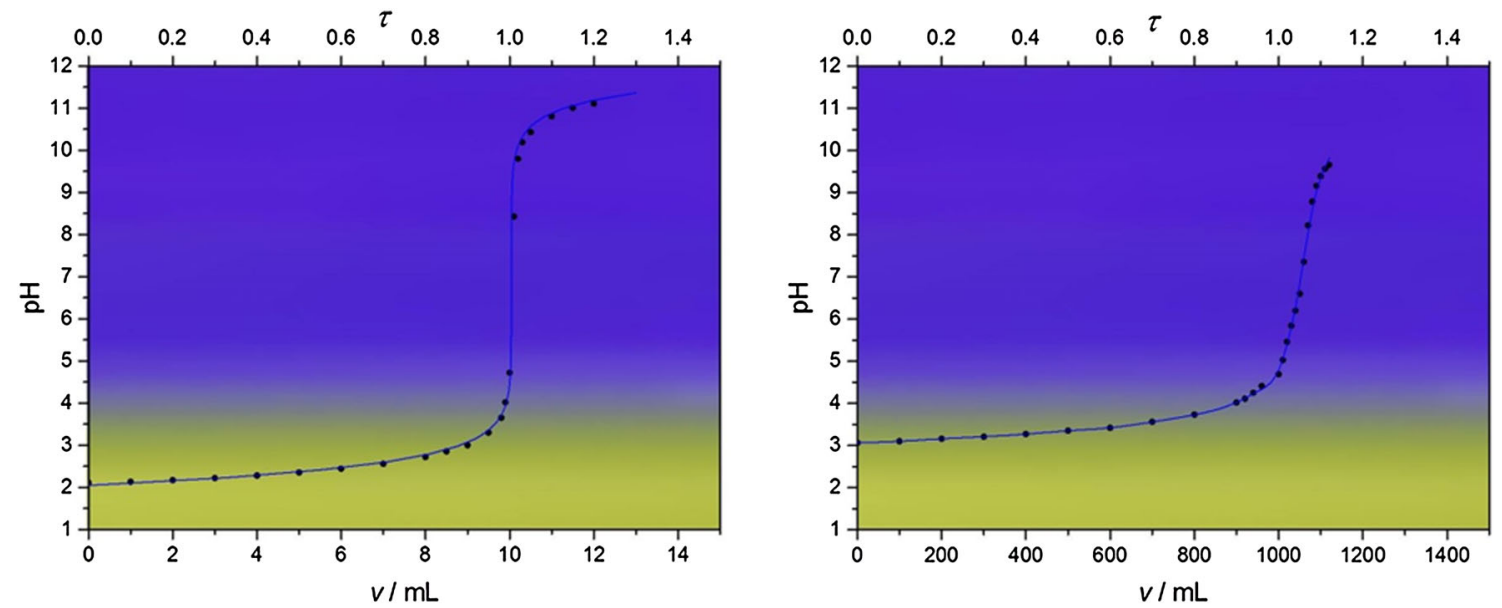

Fig. 20 Titration of a $1 \mathrm{mmol} \mathrm{HCl}\left(C^{\mathrm{o}} \approx 0.01 \mathrm{~mol} \mathrm{~L}^{-1}\right)$, and b $0.05 \mathrm{mmol} \mathrm{H}_{2} \mathrm{SO}_{4}\left(C^{\mathrm{o}} \approx 5 \times 10^{-4} \mathrm{~mol} \mathrm{~L}^{-1}\right)$ with $0.1 \mathrm{M} \mathrm{NaOH}$ and Bromophenol blue as indicator. Dots experimental points, straight lines fits of experimental results with CurTiPot 

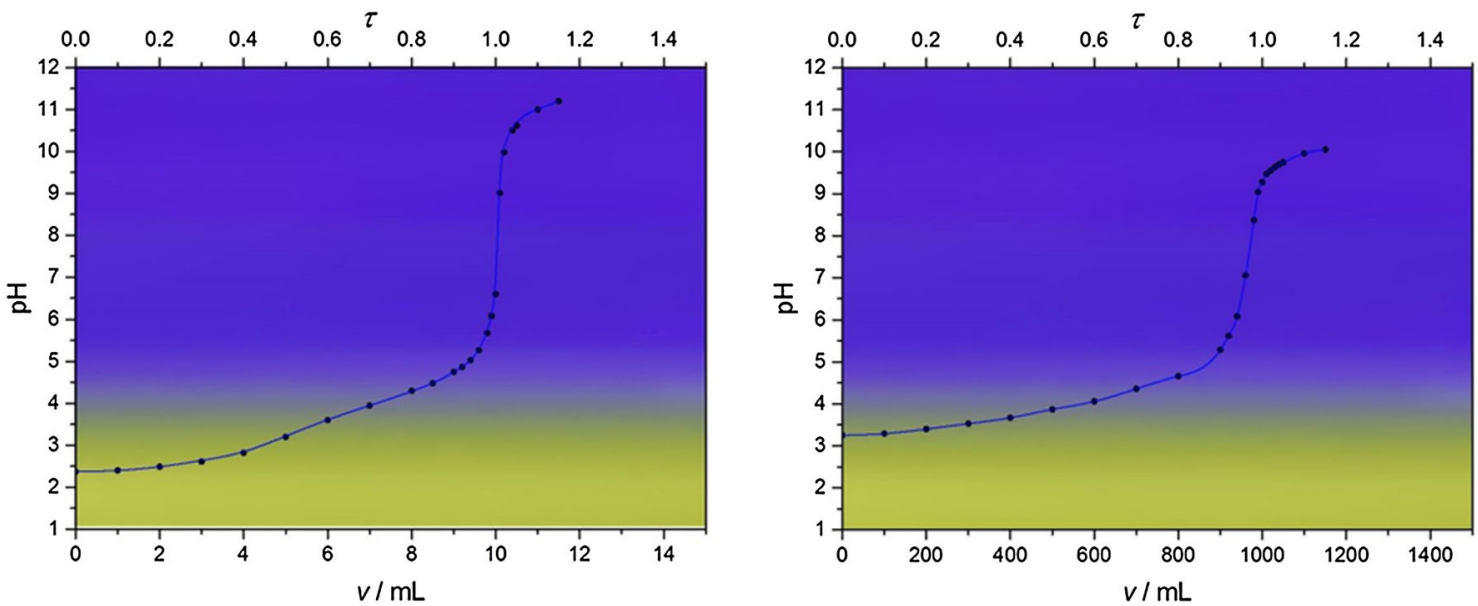

Fig. 21 Titration of a $0.5 \mathrm{mmol}$ oxalic acid $\left(C^{\mathrm{o}} \approx 5 \times 10^{-3} \mathrm{~mol} \mathrm{~L}^{-1}\right)$, and b $0.05 \mathrm{mmol}$ oxalic acid $\left(C^{\mathrm{o}} \approx 5 \times 10^{-4} \mathrm{~mol} \mathrm{~L}{ }^{-1}\right)$ with $0.1 \mathrm{M}$ $\mathrm{NaOH}$ and Bromophenol blue as indicator. Dots experimental points, straight lines fits of experimental results with CurTiPot
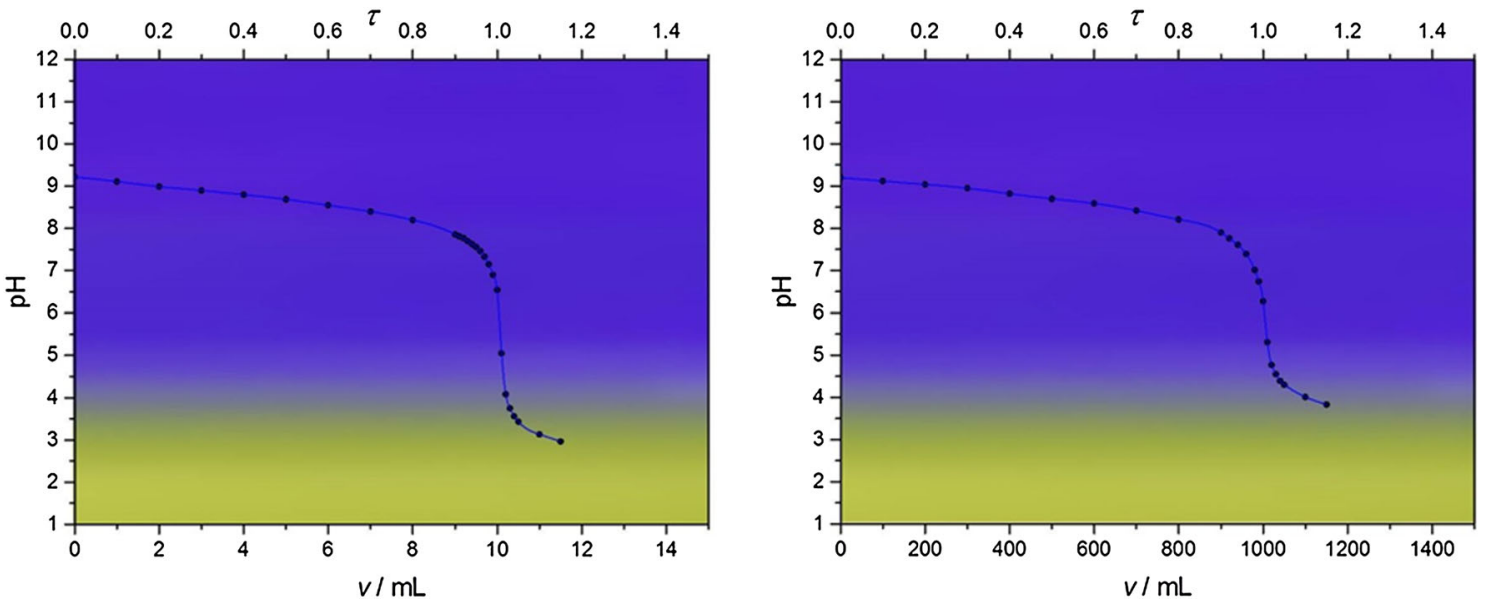

Fig. 22 Titration of a $0.5 \mathrm{mmol}$ borax $\left(C^{\mathrm{o}} \approx 5 \times 10^{-3} \mathrm{~mol} \mathrm{~L}^{-1}\right)$, and b $0.05 \mathrm{mmol}$ borax $\left(C^{\mathrm{o}} \approx 5 \times 10^{-4} \mathrm{~mol} \mathrm{~L}^{-1}\right)$ with $0.1 \mathrm{M} \mathrm{HCl}$ and Bromophenol blue as indicator. Dots experimental points, straight lines fits of experimental results with CurTiPot

$(\mathrm{pH} \approx 3.8-4.0)$ the colour changes via grey to pale blue. A clear transition to blue purple takes place at $\tau=0.87 \pm 0.02 \quad(\mathrm{pH}=4.6)$, i.e., a titration error of $-13 \%$. In case of low concentration of oxalic acid (Fig. 21b), the starting solution is greenish yellow in colour $(\mathrm{pH}=3.3)$, and the colour changes slightly right from the beginning of the titration. Between $\tau \approx 0.4$ and $\tau \approx 0.8$, the colour turns gradually from pale blue to blue. The transition to blue purple takes place at $\tau=0.86 \pm 0.05$ giving a titration error of $-14 \%$.

Solutions of high and low concentrations of borax with Bromophenol blue as indicator are purple at the beginning, changing gradually to blue purple during ongoing titration (Fig. 22a, b). The blue colour starts degrading at $\tau \approx 0.99$ (high concentration) and $\tau \approx 1.00$ (small concentration) $(\mathrm{pH} \approx 5.0-4.5)$. A transition from pale blue via grey to greenish yellow is observable between $\tau \approx 1.00$ and $\tau \approx 1.03$ for high concentrations, and between $\tau \approx 1.01$ and $\tau \approx 1.15$ for low concentrations, respectively $(\mathrm{pH} \approx 4.5-3.2)$. If grey colour $(\mathrm{pH} \approx 4.0)$ is taken for the determination of the transition point, the systematic errors are +1 and $+8 \%$ for high and low concentrations, respectively. In both cases, one will not end up with a clear pale yellow colour.

\section{Bromocresol green}

Bromocresol green in the acidic form is a green powder. The monosodium salt is a dark red amorphous hydrate which becomes colourless at about $190{ }^{\circ} \mathrm{C}$. The aqueous stock solution should contain $0.04 \%$ of the indicator. The transition interval lies between $\mathrm{pH} 3.8$ and 5.6 (Scheme 15).

Sample solutions with high concentrations of strong acids with Bromocresol green as indicator are yellow in 
<smiles>CC1=C(Br)C(=O)C(Br)=CC1=C(c1ccccc1[S+](=O)([O-])[O-])c1cc(Br)c(O)c(Br)c1C</smiles>

monoanion (yellow)

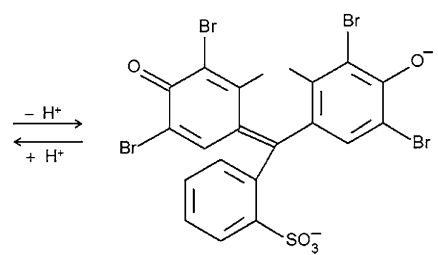

dianion (blue green)
Scheme 15 Structures of the mono- and dianion of Bromocresol green (only one resonance structure is shown for each ion)

colour $(\mathrm{pH}=2.1$, Fig. 23a). The colour changes at $\tau>0.91(\mathrm{pH}>3.1)$ to become greenish yellow, but a clear colour change from green to bright blue green is observed at $\tau=0.999 \pm 0.002(\mathrm{pH} \approx 5.0$, titration error $-0.1 \%)$, i.e., the systematic error is negligible. Also in case of small concentrations of strong acids, a sharp colour change is observed (Fig. 23b). The solutions are slightly greenish yellow right on from the beginning of the titration $(\mathrm{pH}=3.0)$. Bright blue green solutions are observed for $\tau=1.00 \pm 0.01$.

A quite different result is obtainable in case of high and low concentrations of a weak acid like oxalic acid. Starting with a yellow solution, in case of high concentration $(\mathrm{pH}=2.4)$ it becomes greenish yellow, soon; in case of low concentration we already start with a greenish yellow solution $(\mathrm{pH}=3.3)$. The colour change is smeared out from turquoise to bright blue green between $\tau \approx 0.70$ and $\tau=(0.97 \pm 0.01)(\mathrm{pH}=4.0-5.4)$ for high concentrations, and between $\tau \approx 0.75$ and $\tau=(0.91 \pm 0.03)$ $(\mathrm{pH}=4.4-5.0)$ for low concentrations (i.e., the titration errors are -3 and $-9 \%$, cf. Fig. 24a, b).

Solutions of borax in high and low concentration are bright blue green $(\mathrm{pH}=9.2$ and $\mathrm{pH}=9.0$ for high and
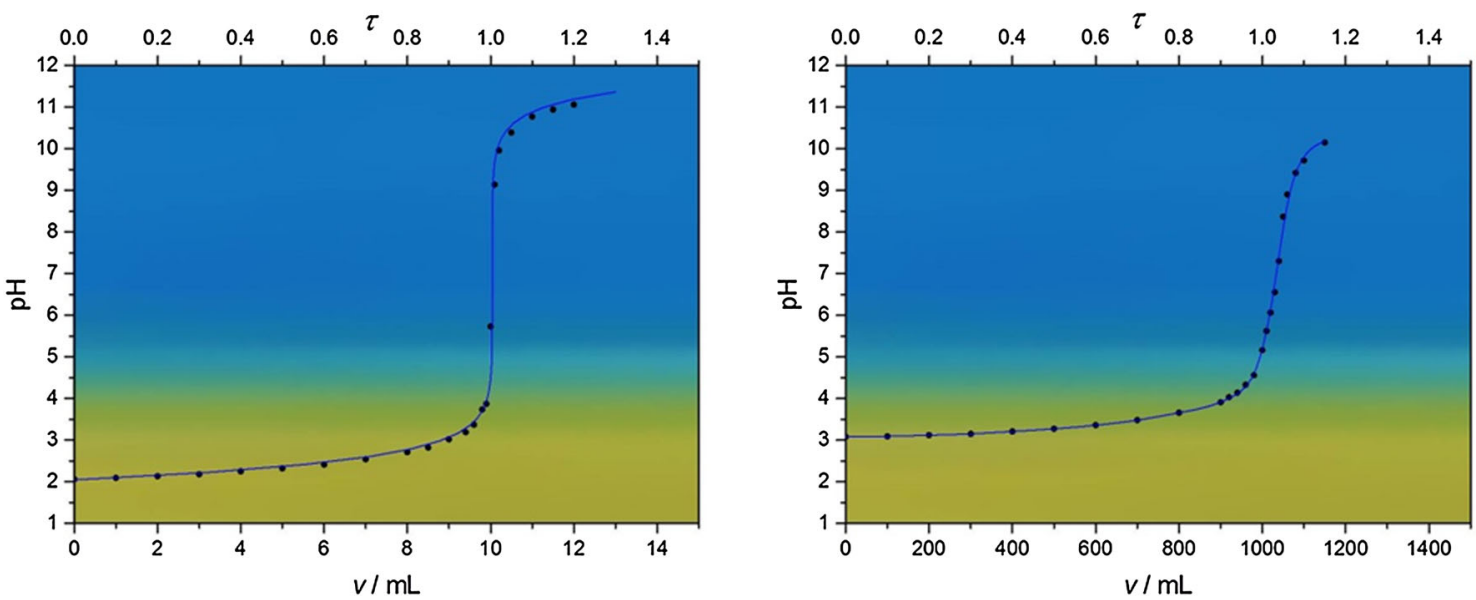

Fig. 23 Titration of a $1 \mathrm{mmol} \mathrm{HCl}\left(C^{\mathrm{o}} \approx 0.01 \mathrm{~mol} \mathrm{~L}^{-1}\right)$, and b $0.05 \mathrm{mmol} \mathrm{H}_{2} \mathrm{SO}_{4}\left(C^{\mathrm{o}} \approx 5 \times 10^{-4} \mathrm{~mol} \mathrm{~L}^{-1}\right)$ with $0.1 \mathrm{M} \mathrm{NaOH}$ and Bromocresol green as indicator. Dots experimental points, straight lines fits of experimental results with CurTiPot
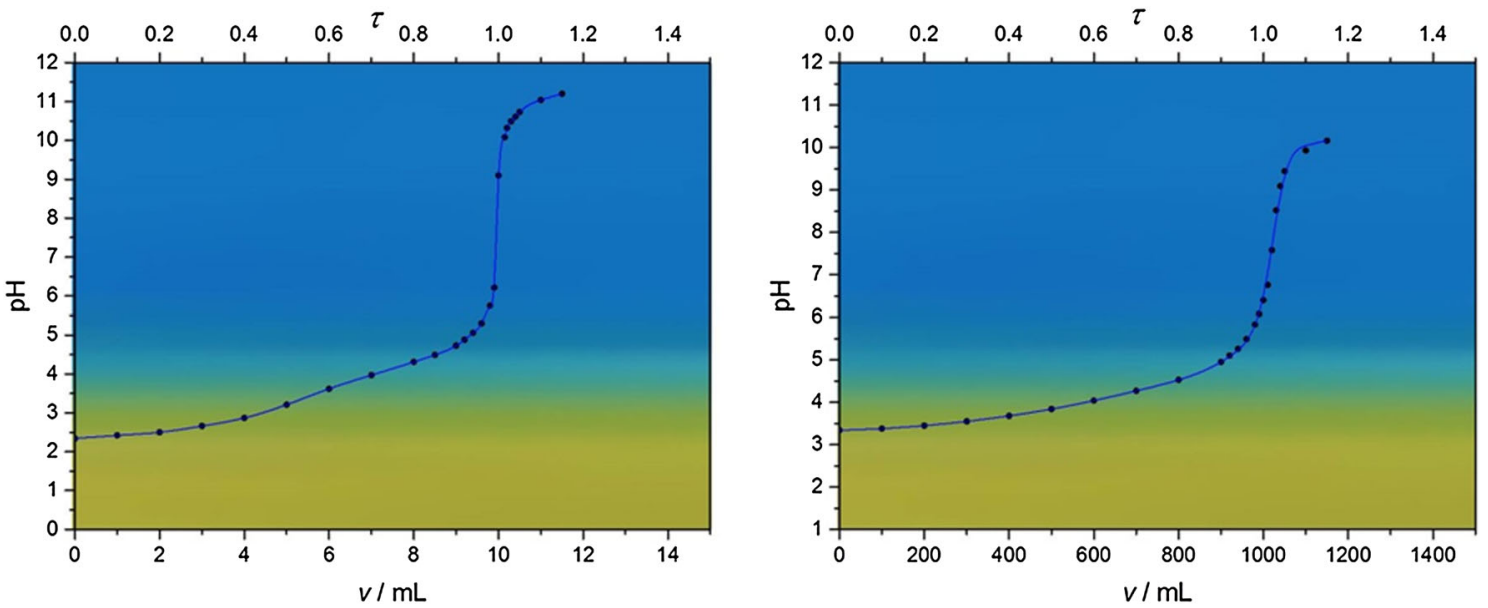

Fig. 24 Titration of a) $0.5 \mathrm{mmol}$ oxalic acid $\left(C^{\mathrm{o}} \approx 5 \times 10^{-3} \mathrm{~mol} \mathrm{~L}^{-1}\right)$, and b $0.05 \mathrm{mmol}$ oxalic acid $\left(C^{\mathrm{o}} \approx 5 \times 10^{-4} \mathrm{~mol} \mathrm{~L} \mathrm{~L}^{-1}\right)$ with $0.1 \mathrm{M}$ $\mathrm{NaOH}$ and Bromocresol green as indicator. Dots experimental points, straight lines fits of experimental results with CurTiPot 

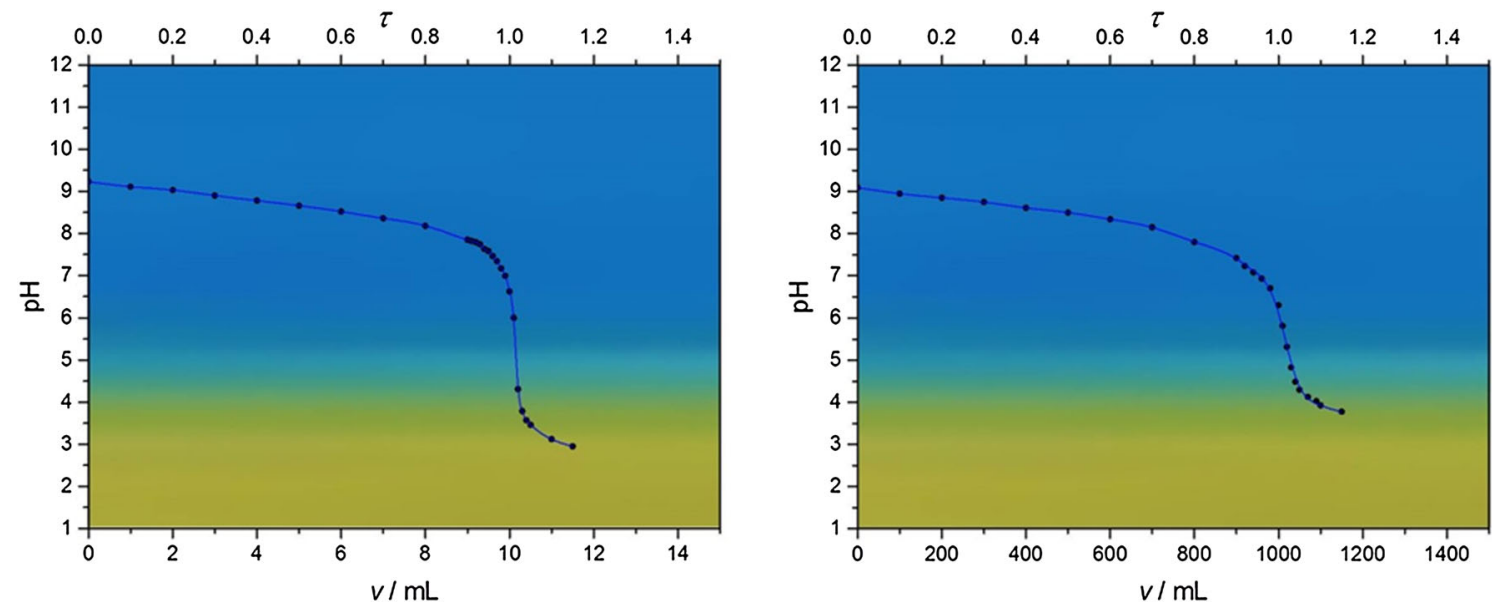

Fig. 25 Titration of a $0.5 \mathrm{mmol}$ borax $\left(C^{\mathrm{o}} \approx 5 \times 10^{-3} \mathrm{~mol} \mathrm{~L}^{-1}\right)$, and b) $0.05 \mathrm{mmol}$ borax $\left(C^{\mathrm{o}} \approx 5 \times 10^{-4} \mathrm{~mol} \mathrm{~L} \mathrm{~L}^{-1}\right)$ with $0.1 \mathrm{M} \mathrm{HCl}$ and Bromocresol green as indicator. Dots experimental points, straight lines fits of experimental results with CurTiPot

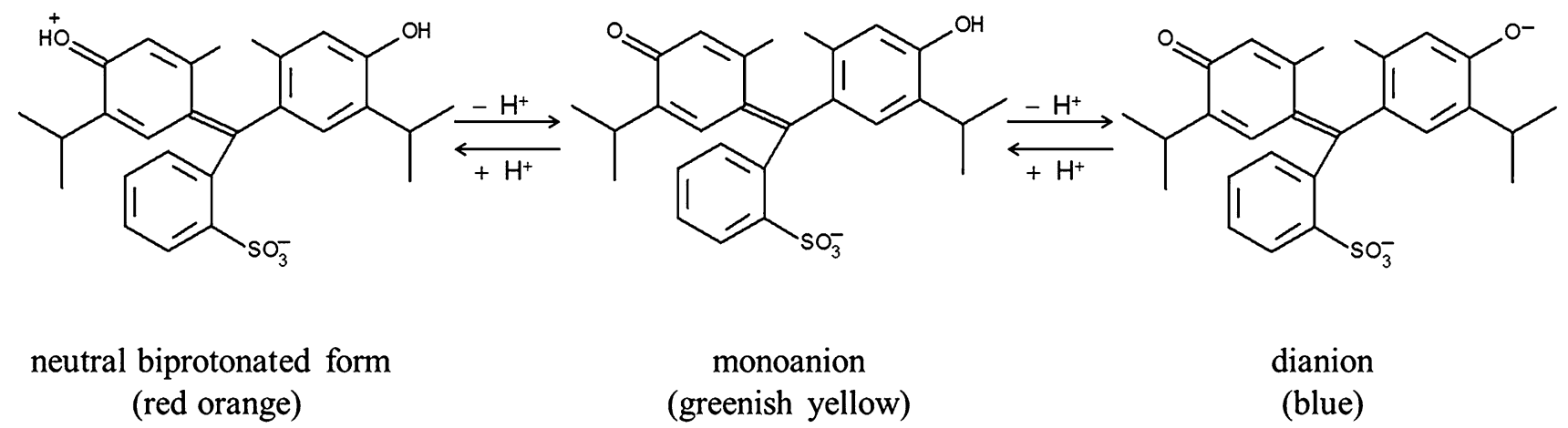

Scheme 16 Structures of the neutral form, and the mono- and dianion of Thymol blue (only one resonance structure is shown for each species)

low concentration, respectively), when Bromocresol green is added. Here, with ongoing addition of hydrochloric acid, the transition from blue green via turquoise to greenish yellow is rather sharp, and at $\tau=1.009 \pm 0.002$ (high concentrations) and $\tau=1.05 \pm 0.02$ (low concentrations) the greenish yellow colour is established $(\mathrm{pH}=4.2$, titration errors +0.9 and $+5 \%$ ). In case of high concentrations, the colour will change until a yellow solution results, but this needs a markedly excess of hydrochloric acid $(\tau \approx 1.1, \mathrm{pH} \approx 3.5)$. In case of small concentrations the solutions are still greenish yellow at $\tau \approx 1.2(\mathrm{pH} \approx 3.6)$ (cf. Fig. 25).

\section{Thymol blue}

Thymol blue forms dark green crystals. A stock solution can be prepared by dissolving $100 \mathrm{mg}$ of the indicator in a solution containing $0.001 \mathrm{~mol} \mathrm{~L}^{-1}$ sodium hydroxide. This indicator shows two transition regions: one at $\mathrm{pH} 1.2-2.8$ from red orange to greenish yellow, and one at $\mathrm{pH}$ 8.0-9.6 from greenish yellow to blue (Scheme 16).
Only in case of high concentrations of strong acids, a smeared transition from red orange to greenish yellow can be observed at the beginning of the titration (cf. Fig. 26a), because the sample solutions have a $\mathrm{pH}=2.1$. In case of low concentrations of strong acids one already starts with a greenish yellow solution $(\mathrm{pH}=3.0$, cf. Fig. $26 \mathrm{~b}$ ). The same holds true for high and low concentrations of oxalic acid ( $\mathrm{pH}=2.4$ and $\mathrm{pH}=3.3$, cf. Fig. 27a, b). In all cases, a sharp transition from greenish yellow to blue is obtained at the following degrees of titration: $\tau=1.000 \pm 0.003$ (strong acid, high concentration), $\tau=1.01 \pm 0.02$ (strong acid, low concentration), $\tau=1.002 \pm 0.003 \quad\left(\mathrm{H}_{2} \mathrm{C}_{2} \mathrm{O}_{4}\right.$, high concentration), $\tau=1.01 \pm 0.01\left(\mathrm{H}_{2} \mathrm{C}_{2} \mathrm{O}_{4}\right.$, low concentration), i.e., the titration error is negligible. But also here we can observe the influence of carbon dioxide (as it was already discussed in case of Methyl red). The blue colour turns quickly to green.

In case of borax the sample solutions are blue, but the colour turns quickly to greenish yellow $(\tau \approx 0.4)$, and a definite determination of a transition point is impossible (cf. Fig. 28a, b). 

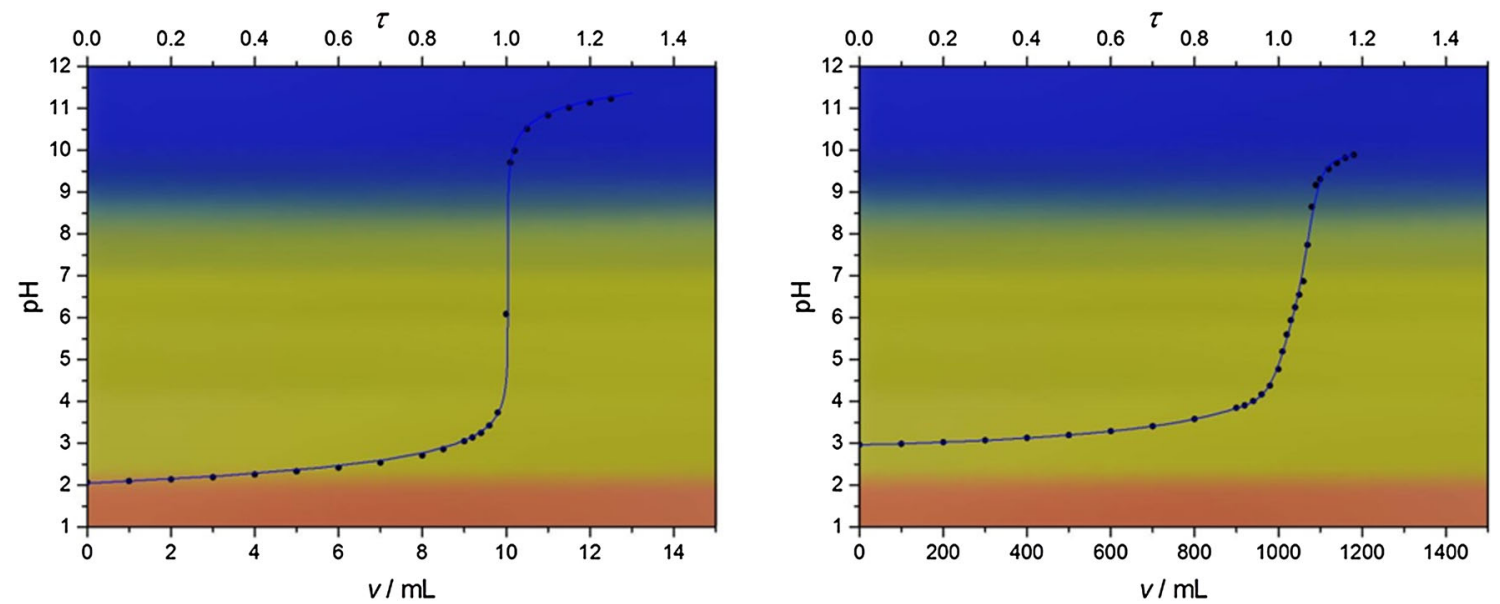

Fig. 26 Titration of a $1 \mathrm{mmol} \mathrm{HCl}\left(C^{\mathrm{o}} \approx 0.01 \mathrm{~mol} \mathrm{~L}^{-1}\right)$ and $0.1 \mathrm{mmol} \mathrm{HCl}\left(C^{\mathrm{o}} \approx 0.001 \mathrm{~mol} \mathrm{~L}^{-1}\right)$ with $0.1 \mathrm{M} \mathrm{NaOH}$ and Thymol blue as indicator. Similar curves are observable for $\mathrm{H}_{2} \mathrm{SO}_{4}$. Dots experimental points, straight lines fits of experimental results with CurTiPot
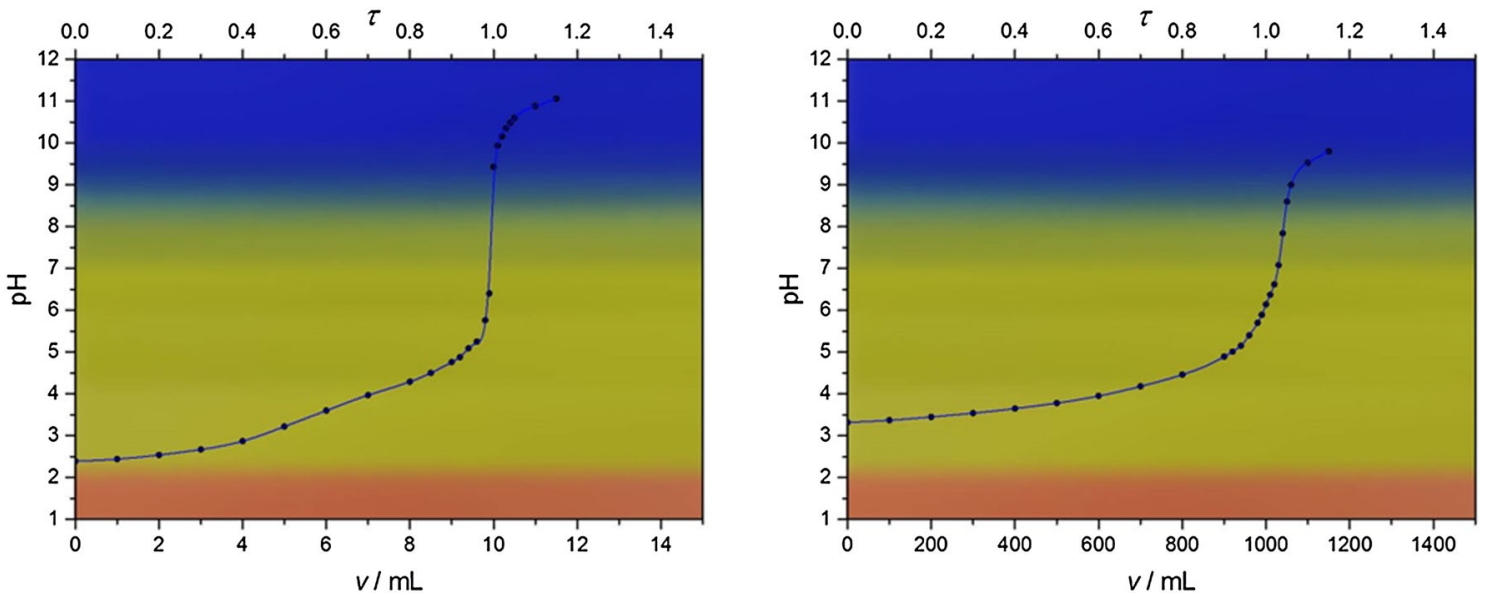

Fig. 27 Titration of a $0.5 \mathrm{mmol}$ oxalic acid $\left(C^{\mathrm{o}} \approx 5 \times 10^{-3} \mathrm{~mol} \mathrm{~L}^{-1}\right)$, and b $0.05 \mathrm{mmol}$ oxalic acid $\left(C^{\mathrm{o}} \approx 5 \times 10^{-4} \mathrm{~mol} \mathrm{~L}{ }^{-1}\right)$ with $0.1 \mathrm{M}$ $\mathrm{NaOH}$ and Thymol blue as indicator. Dots experimental points, straight lines fits of experimental results with CurTiPot
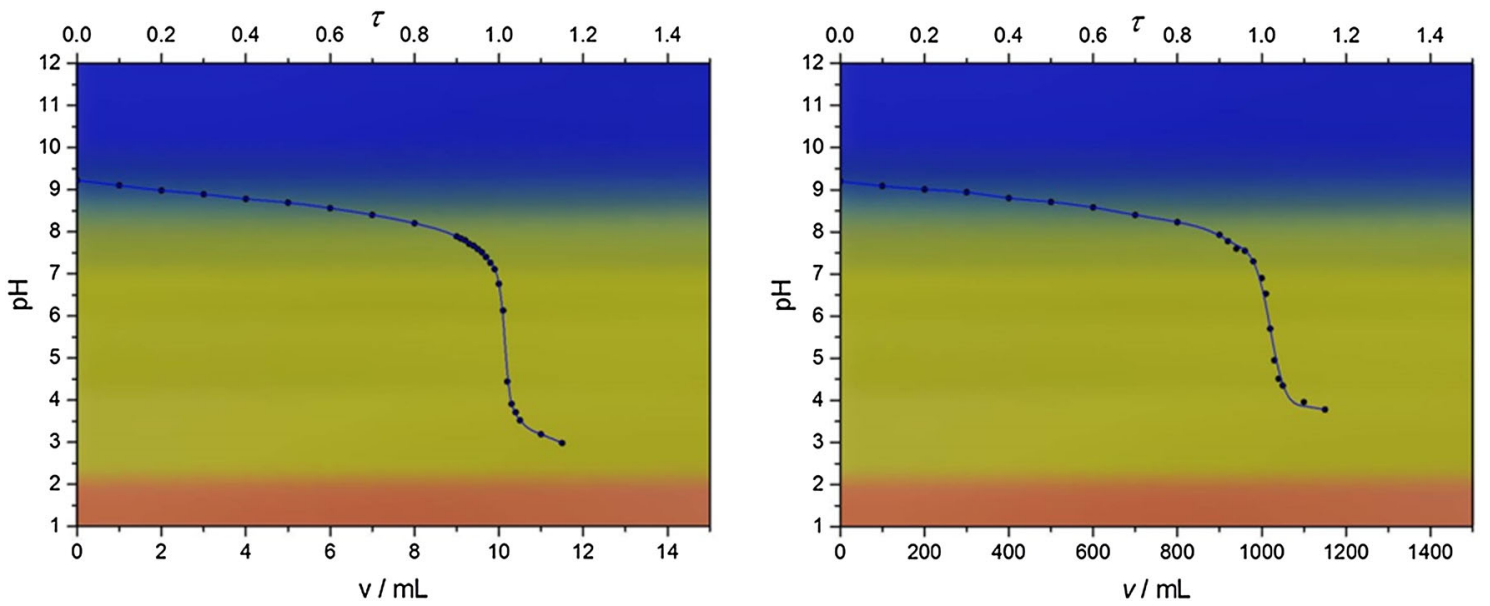

Fig. 28 Titration of a $0.5 \mathrm{mmol}$ borax $\left(C^{\mathrm{o}} \approx 5 \times 10^{-3} \mathrm{~mol} \mathrm{~L}^{-1}\right)$, and b $0.05 \mathrm{mmol}$ borax $\left(C^{\mathrm{o}} \approx 5 \times 10^{-4} \mathrm{~mol} \mathrm{~L}^{-1}\right)$ with $0.1 \mathrm{M} \mathrm{HCl}$ and Thymol blue as indicator. Dots experimental points, straight lines fits of experimental results with CurTiPot 
<smiles>CC1=CC(=C(c2ccc(O)c(C)c2)c2ccccc2[S+](=O)(=O)[O-])C=CC1=O</smiles>

monoanion (yellow)

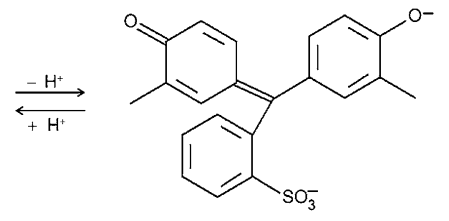

dianion (vivid violet)
Scheme 17 Structures of the mono- and dianion of Cresol red (only one resonance structure is shown for each ion)

\section{Cresol red}

Cresol red forms dark green-red crystalline powder. The stock solution should contain $0.04 \%$ of the indicator. As in case of thymol blue, in very strong acidic solutions $(\mathrm{pH}<1.8)$, the quinoide structure is protonated and the zwitter ion is red in colour. At pH values above 1.8, the deprotonated quinoide system is yellow, and the transition from yellow to vivid violet is between 7.2 and 8.8 (Scheme 17).

In all cases considered here, only the transition from yellow to vivid violet (or vice versa in case of borax) is considered. The transition is very sharp, very close to the transition point the solutions appears pale pink to nearly colourless ( $\mathrm{pH} \approx 7.3-7.8$ ), (cf. Figs. 29a, b, 30a, b, 31a, b). As it was discussed already for other indicators, the influence of carbon dioxide from ambient air is very strong, during the titration of acids with a strong base. The colour turns quickly back to yellow. For all the three acids considered here in high and low concentration the titration error is negligible. The end points are obtained at the following degrees of titration: $\tau=1.003 \pm 0.003$ (strong acid, high concentration),
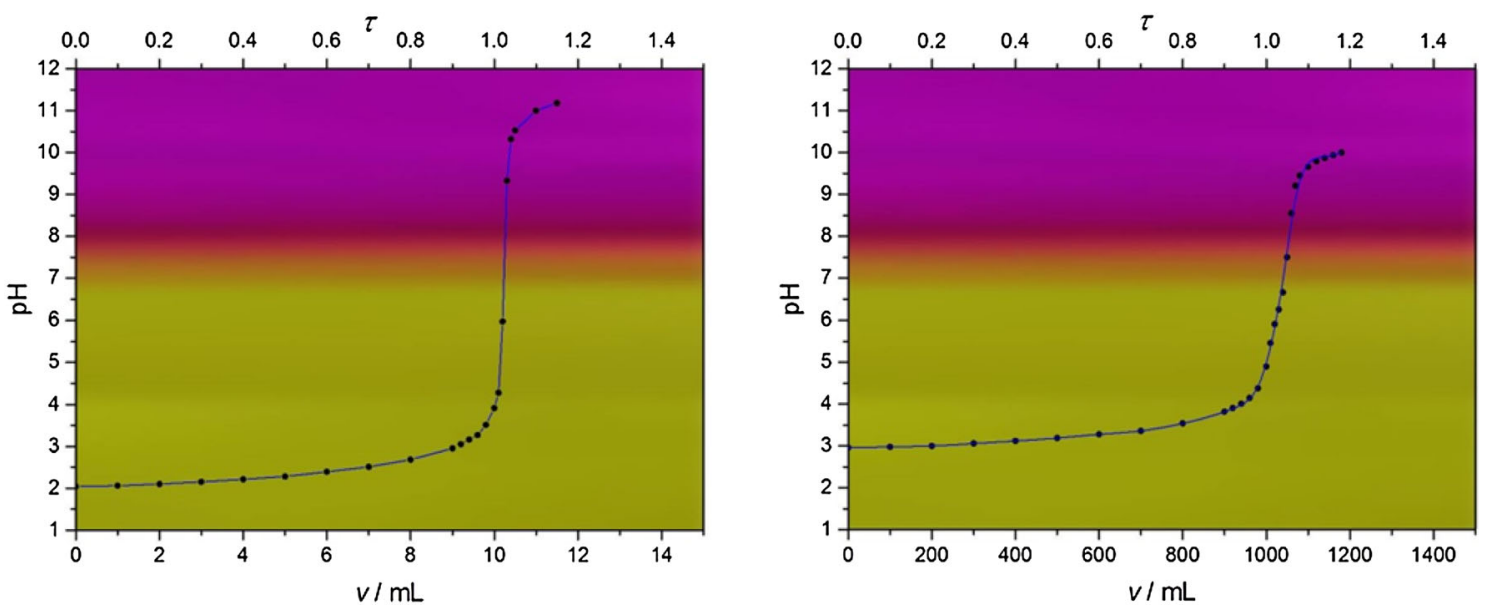

Fig. 29 Titration of a $0.5 \mathrm{mmol} \mathrm{H}_{2} \mathrm{SO}_{4}\left(C^{\mathrm{o}} \approx 5 \times 10^{-3} \mathrm{~mol} \mathrm{~L}^{-1}\right)$, and b) $0.1 \mathrm{mmol} \mathrm{HCl}\left(C^{\mathrm{o}} \approx 0.001 \mathrm{~mol} \mathrm{~L}-1\right)$ with $0.1 \mathrm{M} \mathrm{NaOH}$ and Cresol red as indicator. Dots experimental points, straight lines fits of experimental results with CurTiPot
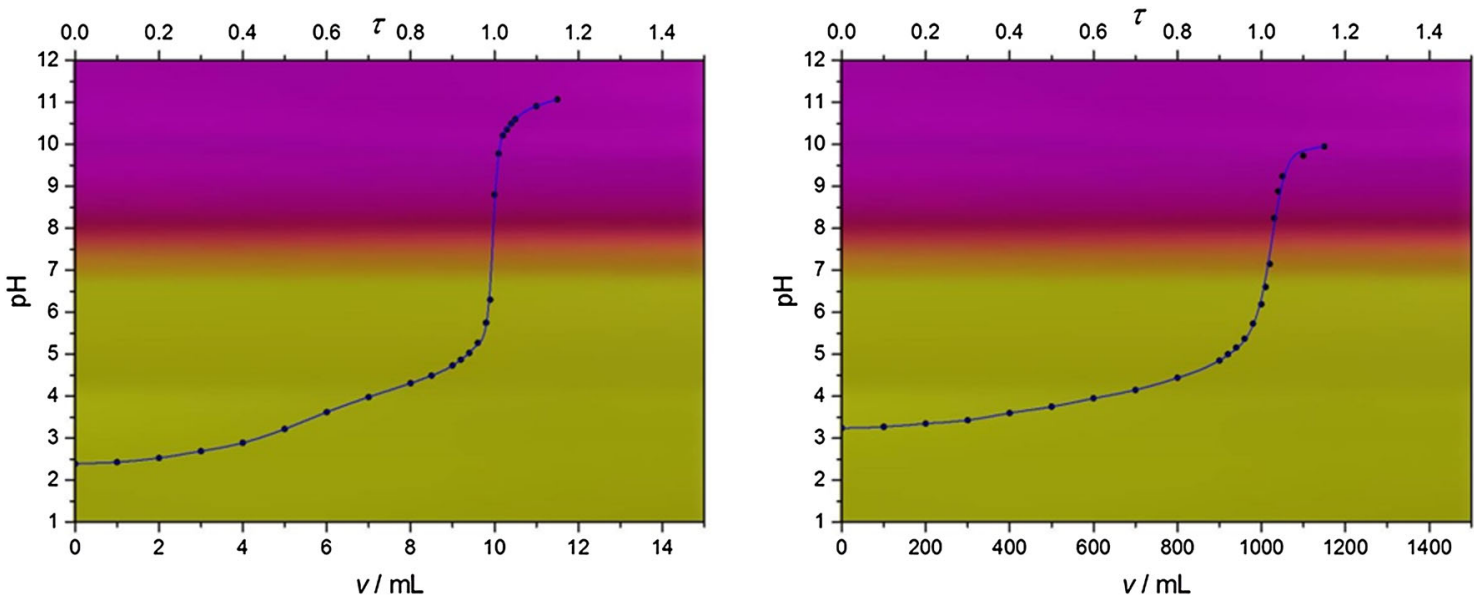

Fig. 30 Titration of a $0.5 \mathrm{mmol}$ oxalic acid $\left(C^{\mathrm{o}} \approx 5 \times 10^{-3} \mathrm{~mol} \mathrm{~L}{ }^{-1}\right)$, and b $0.05 \mathrm{mmol}$ oxalic acid $\left(C^{\mathrm{o}} \approx 5 \times 10^{-4} \mathrm{~mol} \mathrm{~L} \mathrm{~L}^{-1}\right)$ with $0.1 \mathrm{M}$ $\mathrm{NaOH}$ and Cresol red as indicator. Dots experimental points, straight lines fits of experimental results with CurTiPot 

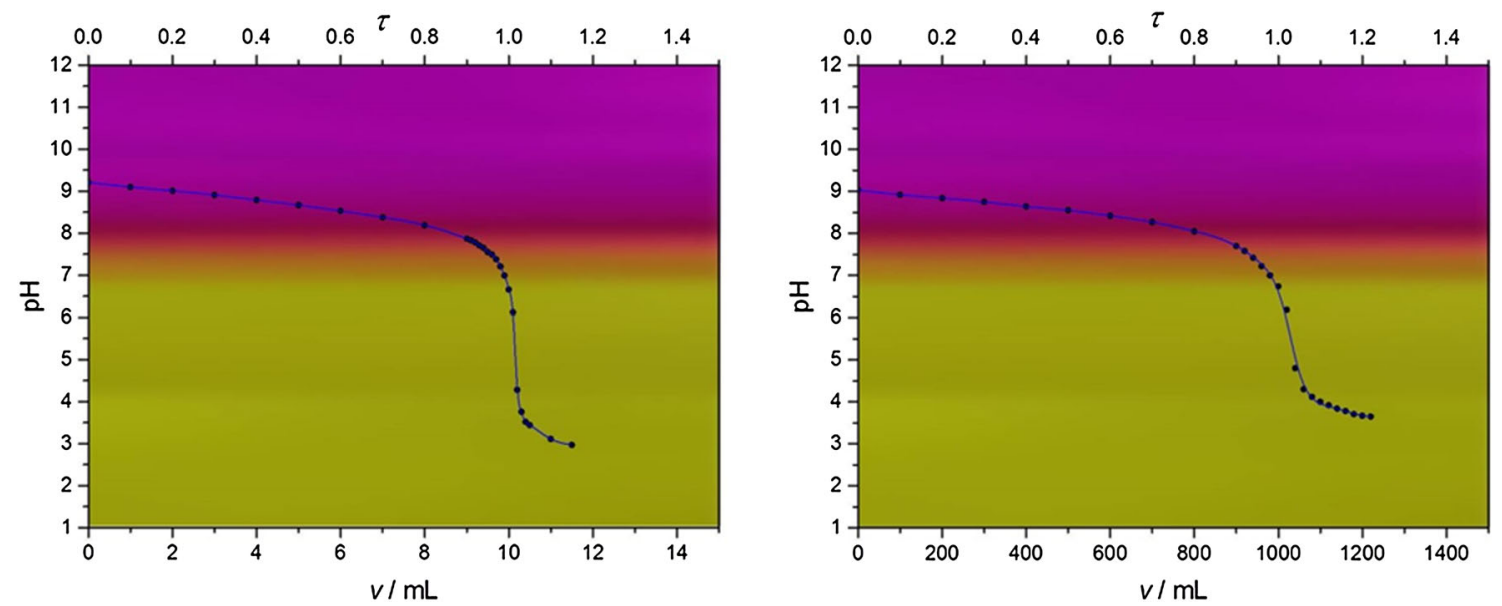

Fig. 31 Titration of a $0.5 \mathrm{mmol}$ borax $\left(C^{\mathrm{o}} \approx 5 \times 10^{-3} \mathrm{~mol} \mathrm{~L}^{-1}\right)$, and b $0.05 \mathrm{mmol}$ borax $\left(C^{\mathrm{o}} \approx 5 \times 10^{-4} \mathrm{~mol} \mathrm{~L} \mathrm{~L}^{-1}\right)$ with $0.1 \mathrm{M} \mathrm{HCl}$ and Cresol red as indicator. Dots experimental points, straight lines fits of experimental results with CurTiPot

Scheme 18 Structures of indicator acid and indicator base of Neutral red (only one resonance structure is displayed for the indicator base, two possible resonance structures are given for the indicator acid)

$$
\text { indicator base (mustard yellow) }
$$<smiles>Cc1cc2nc3ccc(N(C)C)cc3nc2cc1N</smiles><smiles>[PH3+][C@@H]1[C+]=C1</smiles><smiles>Cc1cc2nc3ccc(=[N+](C)C)cc-3[nH]c2cc1N</smiles><smiles></smiles>

\section{indicator acid (fuchsia)}

$\tau=1.00 \pm 0.01 \quad$ (strong acid, low concentration); $\tau=0.999 \pm 0.002 \quad\left(\mathrm{H}_{2} \mathrm{C}_{2} \mathrm{O}_{4}, \quad\right.$ high concentration $)$, $\tau=1.00 \pm 0.02\left(\mathrm{H}_{2} \mathrm{C}_{2} \mathrm{O}_{4}\right.$, low concentration).

In case of borax we start with the vivid violet solutions (Fig. $31 \mathrm{a}, \mathrm{b})$. At $\tau \approx 0.8(\mathrm{pH} \approx 8.2)$ the colour turns to pale pink (nearly colourless). A clear transition from colourless to yellow is obtained at $\tau=0.95 \pm 0.01$ (titration error $-5 \%$ ) in case of high concentration and $\tau=0.92 \pm 0.02$ (titration error $-8 \%$ ) in case of low concentration $(\mathrm{pH}=7.5)$.

\section{Other aromatic indicators}

\section{Neutral red}

Neutral red is one representative of other aromatic compounds suitable as acid base indicators. It is a dark green, nearly black powder moderately soluble in water and ethanol. Stock solutions contain $0.01 \%$ of the indicator in an ethanol water mixture of 50-70\% ethanol. The transition interval ranges from 6.8 to 8.0 . At $\mathrm{pH}$ values above 7.4, the uncharged molecule is the dominant species [24]. At lower $\mathrm{pH}$ values the cation is dominant (Scheme 18). The salt error of the compound is very small.

In case of strong and weak acids in both, high and low concentrations, the sample solutions are fuchsia, and a sharp transition from fuchsia via salmon to mustard yellow is observable (Figs. 32a, b, 33a, b), but solutions turn rapidly to fuchsia again under ambient conditions (see discussions above). For all the three acids considered here in high and low concentration the titration error is negligible. The end points are obtained at the following degrees of titration: $\tau=1.001 \pm 0.003$ (strong acid, high concentration), $\tau=1.00 \pm 0.02$ (strong, acid, low concentration); 

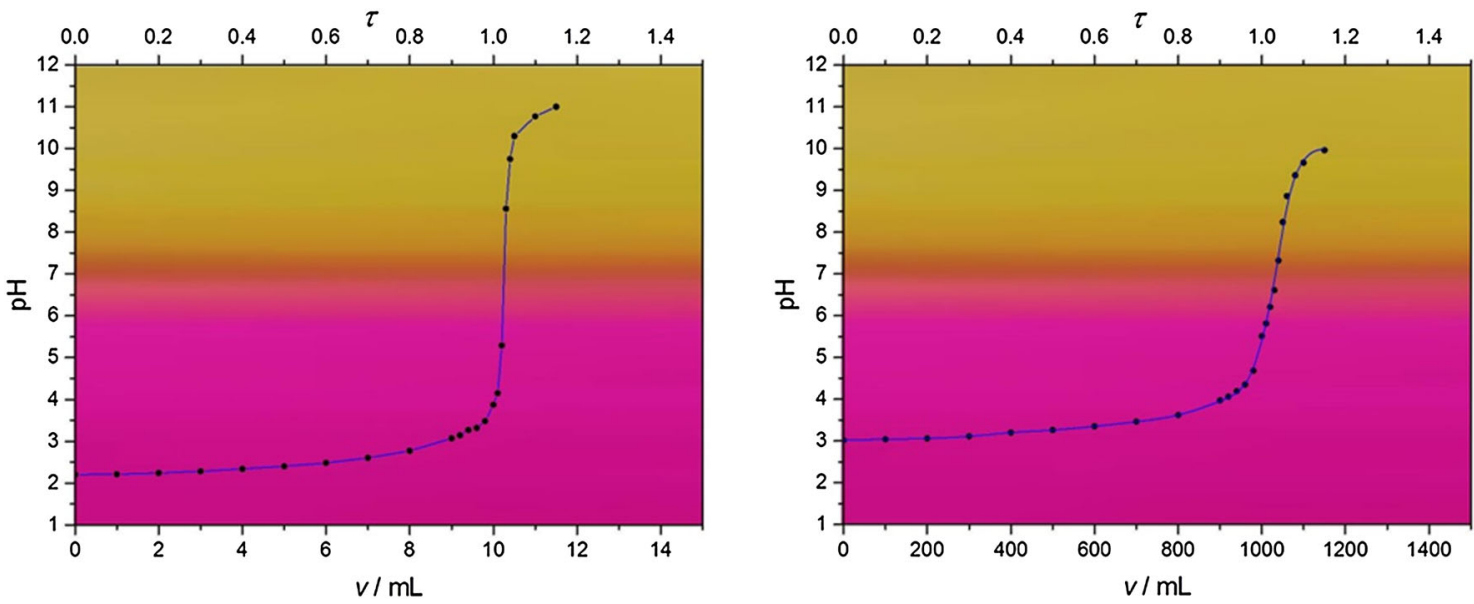

Fig. 32 Titration of a $0.5 \mathrm{~mol} \mathrm{H}_{2} \mathrm{SO}_{4}\left(C^{\mathrm{o}} \approx 5 \times 10^{-3} \mathrm{~mol} \mathrm{~L}^{-1}\right)$, and b $0.05 \mathrm{~mol} \mathrm{H}_{2} \mathrm{SO}_{4}\left(C^{\mathrm{o}} \approx 5 \times 10^{-4} \mathrm{~mol} \mathrm{~L}^{-1}\right)$ with $0.1 \mathrm{M} \mathrm{NaOH}$ and neutral red as indicator. Similar curves are observable for HCl. Dots experimental points, straight lines fits of experimental results with CurTiPot
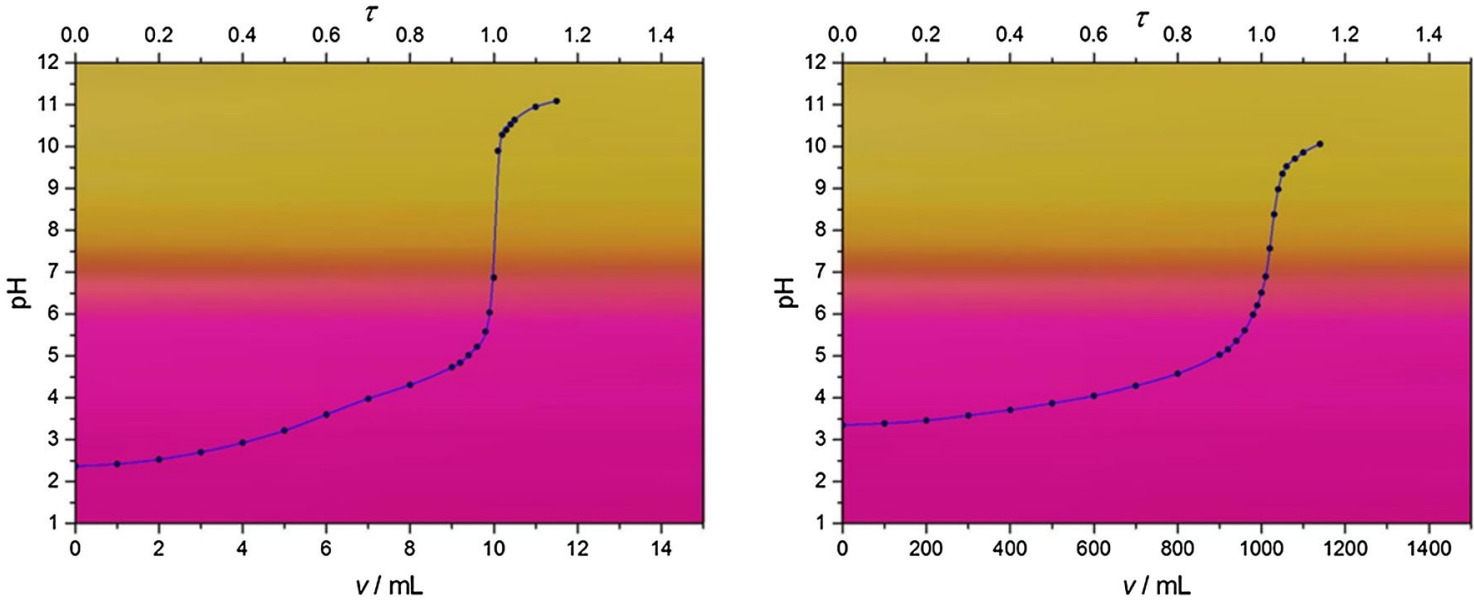

Fig. 33 Titration of a $0.5 \mathrm{mmol}$ oxalic acid $\left(C^{\mathrm{o}} \approx 5 \times 10^{-3} \mathrm{~mol} \mathrm{~L}{ }^{-1}\right)$, and b $0.05 \mathrm{mmol}$ oxalic acid $\left(C^{\mathrm{o}} \approx 5 \times 10^{-4} \mathrm{~mol} \mathrm{~L}{ }^{-1}\right)$ with $0.1 \mathrm{M}$ $\mathrm{NaOH}$ and Neutral red as indicator. Dots: experimental points, straight lines: fits of experimental results with CurTiPot

$\tau=0.999 \pm 0.002 \quad\left(\mathrm{H}_{2} \mathrm{C}_{2} \mathrm{O}_{4}, \quad\right.$ high concentration $)$, $\tau=1.01 \pm 0.02\left(\mathrm{H}_{2} \mathrm{C}_{2} \mathrm{O}_{4}\right.$, low concentration).

In case of borax titrations, it is much more difficult to determine the end point, because the transition starts already at $\tau \approx 0.95$ (high concentration) and $\tau \approx 0.90$ (low concentration) $(\mathrm{pH} \approx 7.5)$, and the colour changes from salmon via pale pink to fuchsia. A clear fuchsia is obtained at $\tau=0.993 \pm 0.004$ (high concentration) and $\tau=0.99 \pm 0.02$ (low concentration) $(\mathrm{pH}=6.8$, Fig. 34a, b).

\section{Error discussion}

To evaluate the applicability of an indicator for a given titration, the following points need to be considered: (1) the desired accuracy of the titration (tolerated systematic error, i.e., deviation of the end point from the equivalence point, i.e., the systematic titration error), and (2) the standard deviation of the indicated transition point, i.e., the random error. As mentioned in the introduction, also in case of an optimal indicator $\left(\mathrm{p} K_{\mathrm{I}}=\mathrm{pH}_{\text {eqp }}\right)$ the maximum possible accuracy depends (1) on the strength of the acid (or base) to be titrated, (2) the concentrations of the sample and the titrant, and (3) on the direction of the titration (i.e., if an acid will be titrated with a base, or vice versa). In practise, the colours and the colour intensities of the indicator acid and bases also play an important role (see Tables 2, 3, and 4). Here, the systematic errors calculated with the help of $\mathrm{pH}-\log c_{\mathrm{i}}$ diagrams and the $\mathrm{p} K_{\mathrm{I}}$ values of the indicators (transition point value - equivalence point value, $s_{\mathrm{I}}$ ), and the $\mathrm{pH}$ at which the best colour change has been detected (end point value, theoretical - equivalence point value, $s_{\mathrm{c}}$ ) are compared with the average of the titration error for 10 

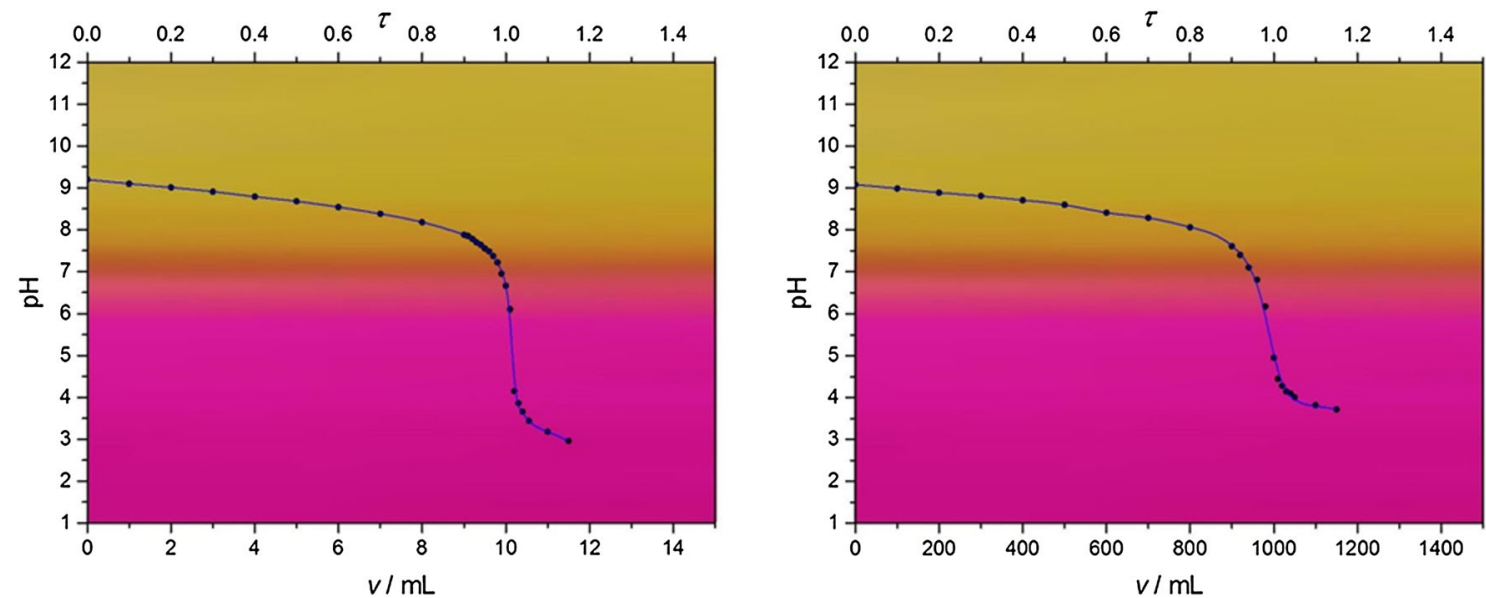

Fig. 34 Titration of a $0.5 \mathrm{mmol}$ borax $\left(C^{\mathrm{o}} \approx 5 \times 10^{-3} \mathrm{~mol} \mathrm{~L}^{-1}\right)$, and b $0.05 \mathrm{mmol}$ borax $\left(C^{\mathrm{o}} \approx 5 \times 10^{-4} \mathrm{~mol} \mathrm{~L} \mathrm{~L}^{-1}\right)$ with $0.1 \mathrm{M} \mathrm{HCl}$ and Neutral red as indicator. Dots experimental points, straight lines fits of experimental results with CurTiPot

Table 2 Comparison of the systematic errors calculated with the help of $\mathrm{pH}-\log c_{\mathrm{i}}$ diagrams and the $\mathrm{p} K_{\mathrm{I}}$ values of the indicators $\left(s_{\mathrm{I}}\right)$, and the $\mathrm{pH}$ at which the best colour change has been detected $\left(s_{\mathrm{c}}\right)$ with the average of the titration error for 10 titrations $\left(s_{\mathrm{t}}\right)$ of $\mathrm{HCl}$ $\left(C_{\mathrm{H}_{3} \mathrm{O}^{+}}^{\mathrm{o}} \approx 0.01 \mathrm{~mol} \mathrm{~L}^{-1}\right)$ with $0.1 \mathrm{M} \mathrm{NaOH}$

\begin{tabular}{|c|c|c|c|c|c|}
\hline Indicator & $\mathrm{p} K_{\mathrm{I}}$ & Transition interval & $s_{\mathrm{I}} / \%$ & $s_{\mathrm{c}} / \%$ & $s_{\mathrm{t}} / \%$ \\
\hline Bromophenol blue & 3.85 & $3.0-4.6$ & -1.4 & $-0.6(\mathrm{pH}=4.2$, blue purple $)$ & -1.1 \\
\hline Congo red & 4.0 & $3.0-5.0$ & -1.0 & $-0.1(\mathrm{pH}=5.0$, orange $)$ & -0.7 \\
\hline Methyl orange & 3.46 & $3.0-4.4$ & -3.5 & $-0.4(\mathrm{pH}=4.4$, bright yellow $)$ & -0.6 \\
\hline Bromocresol green & 4.66 & $3.8-5.4$ & -0.21 & $-0.21(\mathrm{pH}=4.6$, bright blue green $)$ & -0.1 \\
\hline Methyl red & 5.0 & $4.4-6.2$ & -0.1 & $-0.04(\mathrm{pH}=5.4$, bright yellow $)$ & -0.1 \\
\hline Tashiro & 5.0 & $4.4-6.2$ & -0.1 & $-0.03(\mathrm{pH}=5.6$, first green colour $)$ & -0.1 \\
\hline Neutral red & 7.38 & $6.8-8.0$ & 0.001 & $0.001(\mathrm{pH}=7.4$, mustard yellow $)$ & 0.1 \\
\hline Cresol red & 8.3 & $7.0-8.8$ & 0.02 & $0.02(\mathrm{pH}=8.3$, vivid violet $)$ & 0.3 \\
\hline Thymol blue 2nd transition & 8.9 & $8.0-9.6$ & 0.08 & $0.08(\mathrm{pH}=8.9$, blue $)$ & 0.0 \\
\hline Phenolphthalein & 9.4 & $8.0-10.0$ & 0.25 & $0.03(\mathrm{pH}=8.5$, faint pink $)$ & 0.3 \\
\hline Thymolphthalein & 9.7 & $9.3-10.5$ & 0.5 & $0.5(\mathrm{pH}=9.7$, faint blue $)$ & 0.9 \\
\hline
\end{tabular}

titrations (end point value - experimental equivalence point value, $s_{\mathrm{t}}$ ).

In case of the titration of a strong acid $\left(C_{\mathrm{H}_{3} \mathrm{O}^{+}} \approx 0.01 \mathrm{~mol} \mathrm{~L}^{-1}\right)$ with $0.1 \mathrm{M} \mathrm{NaOH}$, the systematic errors $s_{\mathrm{I}}$ would imply that Bromophenol blue, Congo red, and even Methyl orange are not suitable for the titration because the systematic errors exceed $-1 \%$. For Bromophenol blue the titration error $s_{\mathrm{t}}$ is slightly smaller than $s_{\mathrm{I}}$, but slightly larger than it could be expected from $s_{\mathrm{c}}$, due to the fact that it is difficult to distinguish between blue, blue purple, and violet, whereas the transition from greenish yellow to pale blue (the colour change in the lower part of the transition range) is more striking. The colour contrast in the transition range of Congo red is not as sharp as in other cases, also due to the pale colours of the acidic and alkaline form of the indicator. The observed titration error $\left(s_{\mathrm{t}}\right)$ is rather close to $s_{\mathrm{I}}$, even if the impression of the solution was of pure orange. Both indicators cannot be recommended for the titration of strong acids with strong bases even for higher analyte concentrations. In case of Methyl orange it is difficult to distinguish between red orange and yellow orange at the transition point of the indicator. If the titration is terminated at the point when the solution is bright yellow for the first time (i.e., without any orange; upper limit of the transition interval), the titration error $s_{\mathrm{t}}$ is smaller than $s_{\mathrm{I}}$ and only a little bit larger than $s_{\mathrm{c}}$. In other words, if Methyl orange is used as indicator for the titration of a strong acid with a strong base at this concentration level, the titration should be terminated when the solution exhibits the first bright yellow colour; however, if a maximum uncertainty of $\pm 0.5 \%$ is desired, other indicators should be preferred (cf. Fig. 35a). The colour change in titration solutions with Bromocresol green is very sharp and clearly visible, but it has to be mentioned, that one 
Table 3 Comparison of the systematic errors calculated with the help of $\mathrm{pH}-\log c_{\mathrm{i}}$ diagrams and the $\mathrm{p} K_{\mathrm{I}}$ values of the indicators $\left(s_{\mathrm{I}}\right)$, and the $\mathrm{pH}$ at which the best colour change has been detected $\left(s_{\mathrm{c}}\right)$ with the

\begin{tabular}{|c|c|c|c|c|c|}
\hline Indicator & $\mathrm{p} K_{\mathrm{I}}$ & Transition interval & $s_{\mathrm{I}} / \%$ & $s_{\mathrm{c}} / \%$ & $s_{\mathrm{t}} / \%$ \\
\hline Bromophenol blue & 3.85 & $3.0-4.6$ & -36 & $-27(\mathrm{pH}=4.2$, blue purple $)$ & -13 \\
\hline Congo red & 4.0 & $3.0-5.0$ & -32 & $-8(\mathrm{pH}=5.0$, orange $)$ & -13 \\
\hline Methyl orange & 3.46 & $3.0-4.4$ & -43 & $-21(\mathrm{pH}=4.4$, bright yellow $)$ & -10 \\
\hline Bromocresol green & 4.66 & $3.8-5.4$ & -15 & $-16(\mathrm{pH}=4.6$, bright blue green $)$ & -3 \\
\hline Methyl red & 5.0 & $4.4-6.2$ & -8 & $-3(\mathrm{pH}=5.4$, bright yellow $)$ & -1 \\
\hline Tashiro & 5.0 & $4.4-6.2$ & -8 & $-2(\mathrm{pH}=5.6$, first green colour $)$ & -2 \\
\hline Neutral red & 7.38 & $6.8-8.0$ & -0.03 & $-0.03(\mathrm{pH}=7.4$, mustard yellow $)$ & -0.1 \\
\hline Cresol red & 8.3 & $7.0-8.8$ & 0.02 & $0.02(\mathrm{pH}=8.3$, vivid violet $)$ & -0.1 \\
\hline Thymol blue 2 nd transition & 8.9 & $8.0-9.6$ & 0.1 & $0.1(\mathrm{pH}=8.9$, blue $)$ & 0.2 \\
\hline Phenolphthalein & 9.4 & $8.0-10.0$ & 0.2 & $0.03(\mathrm{pH}=8.5$, faint pink $)$ & 0 \\
\hline Thymolphthalein & 9.7 & $9.7-10.5$ & 0.7 & $0.7(\mathrm{pH}=9.7$, faint blue $)$ & 0.6 \\
\hline
\end{tabular}

Table 4 Comparison of the systematic errors calculated with the help of $\mathrm{pH}-\log c_{\mathrm{i}}$ diagrams and the $\mathrm{p} K_{\mathrm{I}}$ values of the indicators $\left(s_{\mathrm{I}}\right)$, and the $\mathrm{pH}$ at which the best colour change has been detected $\left(s_{\mathrm{c}}\right)$ with the average of the titration error for 10 titrations $\left(s_{\mathrm{t}}\right)$ of borax $\left(C^{\mathrm{o}} \approx 5 \times 10^{-3} \mathrm{~mol} \mathrm{~L}^{-1}\right)$ with $0.1 \mathrm{M} \mathrm{HCl}$ average of the titration error for 10 titrations $\left(s_{t}\right)$ of Oxalic acid $\left(C^{\mathrm{o}} \approx 5 \times 10^{-3} \mathrm{~mol} \mathrm{~L}^{-1}\right)$ with $0.1 \mathrm{M} \mathrm{NaOH}$

\begin{tabular}{llllll} 
Cresol red & 8.3 & $7.0-8.8$ & -12 & $-2(\mathrm{pH}=7.5$, yellow $)$ & -5 \\
Phenolphthalein & 9.4 & $8.0-10.0$ & -100 & $-20(\mathrm{pH}=8.5$, colourless $)$ \\
\hline
\end{tabular}
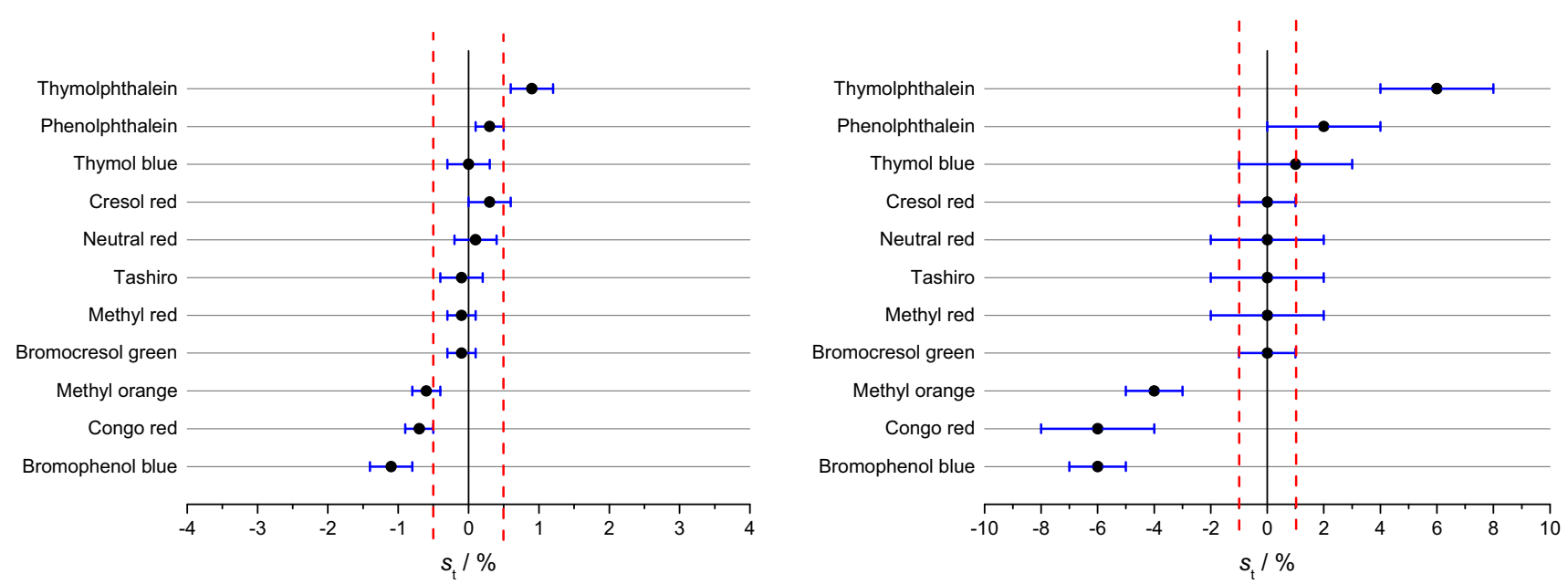

Fig. 35 Titration error $s_{\mathrm{t}}$ (circle) for the titration of a $1 \mathrm{mmol} \mathrm{HCl}\left(C_{\mathrm{H}_{3} \mathrm{O}^{+}}^{\mathrm{o}} \approx 0.01 \mathrm{~mol} \mathrm{~L}^{-1}\right)$, and b) $0.1 \mathrm{mmol} \mathrm{HCl}\left(C_{\mathrm{H}_{3} \mathrm{O}^{+}}^{\mathrm{o}} \approx 0.001 \mathrm{~mol} \mathrm{~L} \mathrm{~L}^{-1}\right)$ with $0.1 \mathrm{M} \mathrm{NaOH}$ and indicators used in this study (standard deviation for $n=10$ is given by the whiskers)

should really titrate until the appearance of a bright blue green colour. If the end point volume is read when the solution is still greenish yellow, a rather large titration error results. Methyl red, Tashiro, Neutral red, Cresol red, and Thymol blue are the most suitable indicators for the titration of strong acids at higher concentrations, because of the 

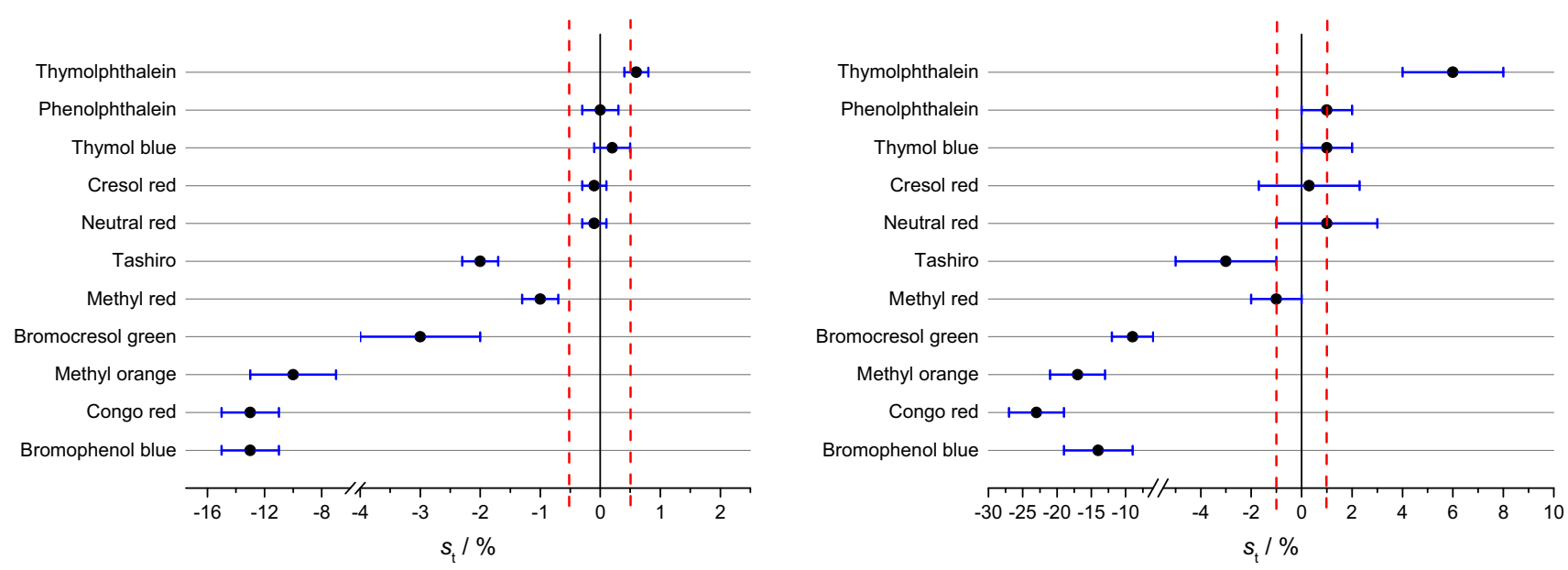

Fig. 36 Titration error $s_{\mathrm{t}}$ (circle) for the titration of a) $0.5 \mathrm{mmol}$ oxalic acid $\left(C^{\mathrm{o}} \approx 5 \times 10^{-3} \mathrm{~mol} \mathrm{~L}^{-1}\right)$, and b $0.05 \mathrm{mmol}$ oxalic acid $\left(C^{\mathrm{o}} \approx 5 \times 10^{-4} \mathrm{~mol} \mathrm{~L}^{-1}\right)$ and indicators used in this study (standard deviation for $n=10$ is given by the whiskers)

very small values of $s_{\mathrm{I}}$, and because $s_{\mathrm{c}}$ and $s_{\mathrm{t}}$ are comparable with these values. The transitions and also the colour contrasts are very sharp, i.e., the standard deviations of $s_{\mathrm{t}}$ are small (error bars in Fig. 35a). With Methyl red, the colour of the acidic form of the indicator is seen after a certain time span due to the already discussed influence of carbon dioxide from ambient air. Phenolphthalein is frequently recommended as a suitable indicator for the titration of strong acids with a strong base. In principle, in case of high concentrations of the acid this holds true, however, it is important to mention that (1) the end point must be read when the solution is faint pink, (2) the background must be covered with white paper, and (3) the effect of carbon dioxide has to be taken into consideration. The colour transition in case of Thymolphthalein is even more difficult to observe, and because of the high value of $s_{\mathrm{I}}$, Thymolphthalein is not recommendable even in the case of high concentrations of a strong acid.

If a strong acid in low concentration $\left(C_{\mathrm{H}_{3} \mathrm{O}^{+}} \approx 0.001 \mathrm{~mol} \mathrm{~L}^{-1}\right)$ is titrated with $0.1 \mathrm{M} \mathrm{NaOH}$, the values of $s_{\mathrm{I}}$ and $s_{\mathrm{c}}$ are ten times larger than the values given in Table 2 for high concentration, i.e., indicators like Bromophenol blue, Congo red, Methyl orange, Thymolphthalein and even Phenolphthalein cannot be recommended, if a titration error of $\pm 1 \%$ is accepted. The experimental values $s_{\mathrm{t}}$ are in good agreement with that statement as it is shown in Fig. 35b. Methyl orange is often recommended as a possible indicator for titrations of strong acids with strong bases, but as it can be seen here, even if we titrate until the solution is bright yellow (upper end of the transition interval), the titration error is about $-4 \%$. Interestingly, Bromocresol green seems to be suitable as an indicator, may be due to the sharp contrast between greenish yellow and bright blue green.
In Table 3, the systematic errors calculated with the help of $\mathrm{pH}-\log c_{\mathrm{i}}$ diagrams and the $\mathrm{p} K_{\mathrm{I}}$ values of the indicators $\left(s_{\mathrm{I}}\right)$, and the $\mathrm{pH}$ at which the best colour change has been detected $\left(s_{\mathrm{c}}\right)$ are compared with the average of the titration error for 10 titrations $\left(s_{t}\right)$ of oxalic acid in high concentration $\left(C^{\mathrm{o}} \approx 5 \times 10^{-3} \mathrm{~mol} \mathrm{~L}^{-1}\right)$. Of course, indicators with $\mathrm{p} K_{\mathrm{I}} \leq \mathrm{p} K_{\mathrm{a} 2 \text {,oxalicacid }}=4.23$ (Bromothymol blue, Congo red, Methyl orange) are totally inappropriate to indicate the end point of the titration at both concentration levels (see also Fig. 36a, b). Interestingly, the experimental titration error $s_{\mathrm{t}}$ for Bromocresol green is smaller than expected, although it has to be mentioned here, that it is difficult to determine the end point due to the early transition to turquoise, resulting in a rather high standard deviation of $s_{\mathrm{t}}$. Additionally, the titration error of $-3 \%$ is inacceptable for an acid-base titration at the high concentration level. In case of Methyl red and Tashiro, the colour transition can be detected with a rather small standard deviation; however, the titration error exceeds $-1 \%$. Neutral red, Cresol red, Thymol blue, and Phenolphthalein show very sharp transitions (small standard deviation of $s_{\mathrm{t}}$ ) and small titration errors in the high concentration range of oxalic acid. Thymolphthalein is not recommendable, if a maximum uncertainty of $0.5 \%$ is desired.

In case of the titration of low concentration of oxalic acid $\left(C^{\mathrm{o}} \approx 5 \times 10^{-4} \mathrm{~mol} \mathrm{~L}^{-1}\right)$ with $0.1 \mathrm{M} \mathrm{NaOH}$ the same conclusions are valid (see Fig. 36b). Indicators like Bromophenol blue, Congo red, Methyl orange, Bromocresol green, and Thymolphthalein are not applicable due to high titration errors and standard deviations of these errors. Indicators like Neutral red, Cresol red, Thymol blue, and Phenolphthalein are most suitable.

During the titration of borax with a strong acid, the weak boric acid $\left(\mathrm{p} K_{\mathrm{a} 1 \text {, boricacid }}=9.24\right)$ is formed: 

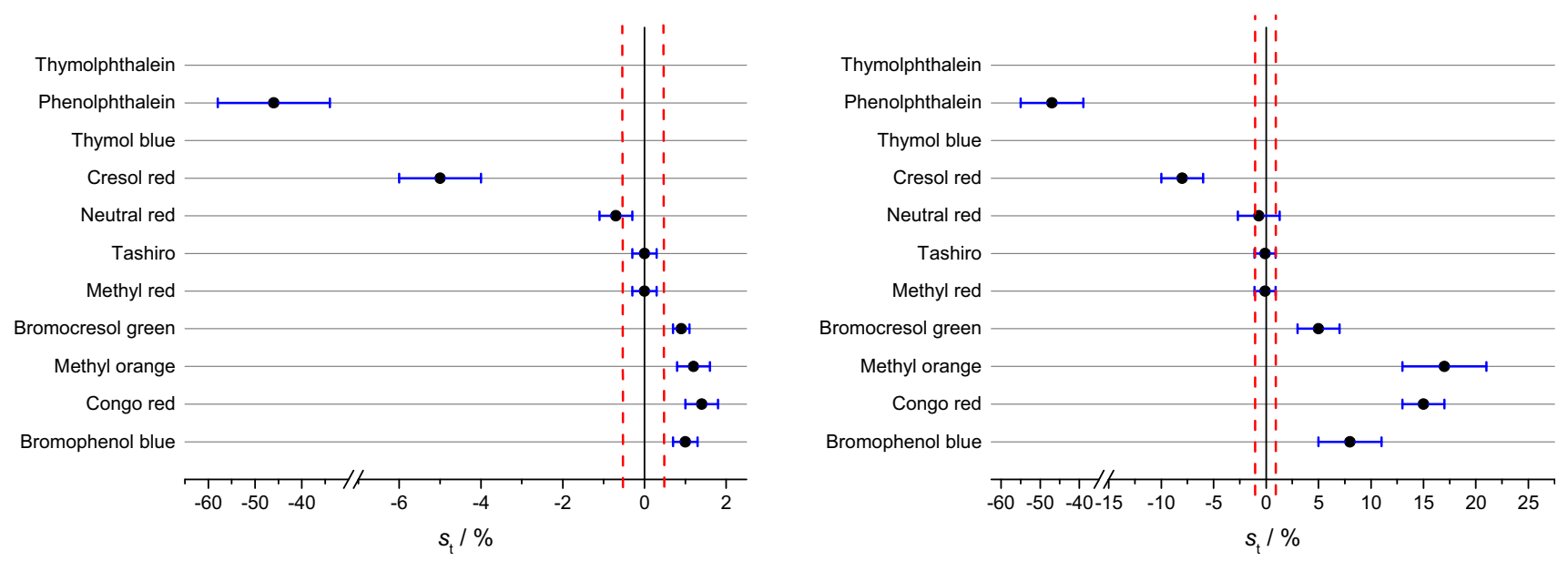

Fig. 37 Titration error $s_{\mathrm{t}}$ (circle)for the titration of a) $0.5 \mathrm{mmol}$ borax $\left(C^{\mathrm{o}} \approx 5 \times 10^{-3} \mathrm{~mol} \mathrm{~L}^{-1}\right)$, and b $0.05 \mathrm{mmol}$ borax $\left(C^{\mathrm{o}} \approx 5 \times 10^{-4}\right.$ mol L ${ }^{-1}$ ) with $0.1 \mathrm{M} \mathrm{HCl}$ and indicators used in this study (standard deviation for $n=10$ is given by the whiskers)

$\mathrm{B}_{4} \mathrm{O}_{5}(\mathrm{OH})_{4}^{2-}+2 \mathrm{H}_{3} \mathrm{O}^{+}+\mathrm{H}_{2} \mathrm{O} \rightleftarrows 4 \mathrm{H}_{3} \mathrm{BO}_{3}$

The $\mathrm{pH}$ values of the resulting solutions at the equivalence point are 5.6 and 6.1 for high and low concentrations, respectively, i.e., indicators with $\mathrm{p} K_{\mathrm{I}}$ values in the alkaline range are not suitable for the determination of the end point with a small titration error. The comparison of the systematic errors calculated with the help of $\mathrm{pH}-\log c_{\mathrm{i}}$ diagrams and the $\mathrm{p} K_{\mathrm{I}}$ values of the indicators $\left(s_{\mathrm{I}}\right)$, and the $\mathrm{pH}$ at which the best colour change has been detected $\left(s_{\mathrm{c}}\right)$ with the average of the titration error for 10 titrations $\left(s_{\mathrm{t}}\right)$ of borax $\left(C^{\mathrm{o}} \approx 5 \times 10^{-3} \mathrm{~mol} \mathrm{~L}^{-1}\right)$ with $0.1 \mathrm{M} \mathrm{HCl}$ is shown in Table 4, and in Fig. 37a and b the titration errors are depicted with the standard deviation for 10 repeated titrations at both concentration levels. Although, in some cases the colour change is clearly detectable and the standard deviation of $s_{\mathrm{t}}$ are rather small (cf. Bromocresol green), only Methyl red or Tashiro are recommendable as indicators for the titration of borax with a strong acid.

\section{References}

1. Sandel FB, West TS (1969) Pure Appl Chem 18:427-436

2. Harris DC (2010) Quantitative chemical analysis, 7th edn. WH Freeman, New York

3. Harris DC (2002) Lehrbuch der quantitativen Analyse. Springer, Berlin

4. Christian GD (2004) Analytical Chemistry, 6th edn, Wiley, London
5. Mendham J, Denney RC, Barnes JD, Thomas MJK (2000) Vogel's textbook of quantitative inorganic analysis, 6th edn, Prentice Hall, Englewood Cliffs

6. Kahlert H, Scholz F (2013) Acid-base diagrams. Springer, Heidelberg

7. Baker AA Jr (1964) Chymia 9:147-167

8. Johansson A (1988) Anal Chim Acta 206:97

9. Szabardváry F (1966) History of analytical chemistry, Elsevier, New York

10. Szabardváry F (1966) Geschichte der analytischen Chemie. Akadémiai Kiadó, Budapest

11. Szabardváry F, Chalmers RA (1979) Talanta 26:609-617

12. Kolthoff IM (1937) Acid-base indicators. The Macmillan Company, New York

13. Sabnis RW (2007) Handbook of acid-base indicators. CRC Press, Boca Raton

14. Salvatore F, Salvatore MM (2014) World J Chem Educ 2:8-20

15. Fluck E, Becke-Goehring M (1977) Einführung in die Theorie der quantitativen Analyse. Theodor Steinkopff, Dresden

16. de Levie R (2006) Aqueous acid-base equilibria and titrations. Oxford University, Oxford

17. Schulze G, Simon J, Martens-Menzel R (2012) Jander/Jahr Massanalyse, 18th edn. De Gruyter, Berlin

18. Schweda E (2012) Jander/Blasius Anorganische Chemie II, 16th edn. Hirzel Verlag, Stuttgart

19. Gutz IGR (2014) CurTiPot-pH and acid-base titration curves: analysis and simulation freeware, version 4.2. http://www.iq.usp. br/gutz/Curtipot_.html

20. Bishop E (1972) Indicators. Pergamon Press, Oxford

21. Ruland A (1985) Küster/Thiel Rechentafeln für die Chemische Analytik, 103rd edn. De Gruyter, Berlin

22. Aragoni MC, Arca M, Crisponi G, Nurchi VM, Silvagni R (1995) Talanta 42:1157-1163

23. Casula R, Crisponi G, Cristiani F, Nurchi VM, Casu M, Lai A (1993) Talanta 40:1781-1788

24. Köbel H (1957) Z Hyg Infektionskr 143:387-396 